University of Zurich

Department of Economics

Working Paper Series

ISSN 1664-7041 (print)

ISSN 1664-705X (online)

Working Paper No. 339

\title{
Other-regarding Preferences and Redistributive Politics
}

Ernst Fehr, Thomas Epper and Julien Senn

Revised version, December 2021 


\title{
Other-Regarding Preferences and Redistributive Politics*
}

\author{
Ernst Fehr $(\mathrm{r}$ Thomas Epper $(\mathbb{P}$ Julien Senn
}

December 23, 2021

\begin{abstract}
Increasing inequality and associated egalitarian sentiments have again put redistribution on the political agenda. Other-regarding preferences may also affect support for redistribution, but knowledge about their distribution in the broader population and how they are associated with political support for redistributive policies is still scarce. In this paper, we take advantage of Swiss direct democracy, where people voted several times on strongly redistributive policies in national plebiscites, to study the link between other-regarding preferences and support for redistribution in a broad sample of the Swiss population. We document that inequality aversion and altruistic concerns play a quantitatively large positive role in the support for redistribution, in particular for more affluent individuals. In addition, previously identified key motives underlying opposition to redistribution - such as the belief that effort is an important driver of individual success - play no role for selfish individuals but are highly relevant for altruistic and egalitarian individuals. Finally, while inequality averse individuals display strong support for policies that primarily aim at reducing the incomes of the rich, altruistic individuals are considerably less supportive of such policies. Thus, knowledge about the fundamental properties and the distribution of individuals' other-regarding preferences also provides a deeper understanding about who is likely to support specific redistributive policies.
\end{abstract}

Key Words: Social Preferences, Altruism, Inequality Aversion, Preference Heterogeneity, Demand for Redistribution

JEL Codes: D31, D72, H23, H24

${ }^{*}$ The "(r)" symbol indicates that the authors' names are in certified random order. We would like to thank Stefano DellaVigna, Ruben Durante, Benjamin Enke, Ray Fisman, Patricia Funk, Ulrike Malmendier, Michel Marechal, Salvatore Nunnari, Pietro Ortoleva, Ricardo Perez-Truglia, Chris Roth, Stefanie Stantcheva, Bertil Tungodden and seminar audiences at Berkeley, Bonn, CESifo, Copenhagen, Nice, NBER, NYU, and Stanford for useful comments on the paper. Fehr: Department of Economics, Zurich University. Blümlisalpstrasse 10, 8006 Zurich, Switzerland (ernst.fehr@econ.uzh.ch). Epper: IESEG School of Management, Univ. Lille, CNRS, UMR 9221- LEM - Lille Economie Management F-59000 Lille, France (thomas.epper@cnrs.fr). Senn: Department of Economics, Zurich University. Blümlisalpstrasse 10, 8006 Zurich, Switzerland (julien.senn@econ.uzh.ch) 


\section{Introduction}

Rising income inequality and the extremely high and salient incomes of top executives have again put income redistribution on the political agenda. In the US, for example, almost all the candidates in the democratic presidential primary for the 2020 elections proposed reforms that would have involved substantial changes in the distribution of income. ${ }^{1}$ Likewise, left-leaning parties in Germany and the UK support various redistributive measures, and Switzerland held four radically redistributive national plebiscites ${ }^{2}$ during the last 10 years. For example, one of these plebiscites would have implemented - if supported by a majority - a law that constrains the maximal ratio between the lowest and the highest incomes in a company to 1:12, i.e., a CEO could not have earned more than 12 times the wage of the lowest paid employee.

What motivates citizens to support redistributive policy proposals? Clearly, households with low current and expected future incomes that benefit economically from redistributive policies have a self-interested reason to support redistribution. However, affluent households who would be the net payers of redistributive measures often also support redistributive policies. This suggests that other-regarding ("social") preferences may play a role, i.e., that people care about other individuals' incomes when considering redistributive policies. In this paper, we examine the extent and the ways in which social preferences are associated with redistributive policies. We are also interested in how fundamental differences in people's social preferences help us to better understand the support for specific types of redistributive policies. For example, voters whose social preferences are characterized by an altruistic concern for the worse off may show less support for proposals with the primary goal to reduce the income of the rich, while individuals with egalitarian preferences may well support such proposals.

Our study is motivated by evidence suggesting that a non-negligible share of subjects displays an altruistic concern for the worse off (see e.g., Andreoni and Miller, 2002; Charness and Rabin, 2002; Engelmann and Strobel, 2004; Fisman, Kariv and Markovits, 2007; Fisman, Jakiela, Kariv and Markovits, 2015; DellaVigna, List and Malmendier, 2012; Alger and Weibull, 2013) or a concern for equality (see e.g. Fehr and Schmidt, 1999; Bolton and Ockenfels, 2000; Dawes, Fowler, Johnson, McElreath and Smirnov, 2007; Bellemare, Kröger and Van Soest, 2008; Almås, Cappelen and Tungodden, 2019; Kerschbamer and Müller, 2020). However, knowledge about the overall distribution of social preferences like inequality aver-

\footnotetext{
${ }^{1}$ Almost all democratic candidates supported a doubling of the federal minimum wage, a substantial increase in health care provision, and universal nationally paid family and medical leave programs. And a substantial number of them supported considerably higher taxation of rich households.

${ }^{2}$ Plebiscites are also called "popular initiatives". We use the two terms interchangeably.
} 
sion and altruistic concerns in the broader adult population and the extent to which they are related to actual political support for redistributive proposals is still relatively rare (though see Fisman, Jakiela and Kariv, 2017).

Using an online experiment, we measure social preferences in a sample of the Swiss population that is broadly representative in terms of age, gender, geographical area, income, and education. Social preferences are elicited with the help of a large set of incentivized choice situations where respondents have to decide how to allocate money between themselves and another participant of the study. Based on individuals' overall behavior, we identify a small number of distinct preference clusters using a novel nonparametric Bayesian clustering method (Kulis and Jordan, 2012). This algorithm infers the prevailing social preference types in the population using the subjects' overall behavior in the money allocation task, and endogenously assigns each individual to types. Importantly, this procedure neither requires ex-ante assumptions on the existence of different (social preferences) types nor assumptions about the preference and noise structure. ${ }^{3}$ We then link individuals' assignments to social preference types to their political support for four redistributive proposals - a 1:20 proposal that constrains the maximal ratio between the lowest and the highest incomes in a company to 1:20, the fair taxes initiative that aimed at substantially increasing taxes for the rich, a minimum wage proposal and the proposal for an unconditional basic income.

We focus on these redistributive policies because they are either identical or very similar to policies that were up for vote in a previous recent national plebiscite in Switzerland. This has the advantage that our respondents have already been exposed to the pros and cons of the proposals because they have been broadly discussed in national TV and the newspapers. ${ }^{4}$ Two of the redistributive policies for which we elicit individuals' support are exactly identical to previous referenda, which gives us the chance to validate our measure of political support for these policies with the observed voting results across Swiss cantons. A third advantage of the Swiss set-up is that citizens frequently experience direct democratic referenda which provides a general feeling of empowerment. ${ }^{5}$ This strongly mitigates citizens distrust of politics and the government because people know that if a referendum proposal receives a majority it will be turned into law. This aspect is important in light of recent work showing that mistrust in politicians and the government confounds general support for redistributive policies (Kuziemko et al., 2015). In the presence of such mistrust, people with social preferences (e.g.,

\footnotetext{
${ }^{3}$ While the advantages of being able to infer preference clusters and individuals' assignment to clusters without any constraints on the structure of utility functions are transparent, the advantage of avoiding assumptions about the structure of the error term (i.e., utility noise) may seem less obvious. However, it has been shown in the domain of risk preferences that assumptions about the utility noise in random utility models are not innocuous. For instance, Buschena and Zilberman (2000) showed that the assumptions on the error term are decisive for whether expected utility theory or non-expected utility models capture the data best.

${ }^{4}$ Most TV viewers in Switzerland watch the national (public) TV, i.e., private TV has a rather low market share. National TV is obliged to be nonpartisan such that all viewpoints are represented.

${ }^{5}$ For a detailed description and analysis of Swiss direct democracy see Funk (2010) and Funk and Gathmann (2011).
} 
a concern for the poor) may not support politically enforced redistribution.

We use respondents' support for the above-mentioned four policies to construct an individual-level measure of support for redistribution. We validate this measure (i) with actual geographic voting patterns in the former referenda that are identical to proposed policies in the online survey and (ii) with a donation task in which subjects could donate money to civic groups that either support or oppose redistribution. Then, we regress the validated measure of political support for redistribution on our social preference measures while controlling for a large number of socio-demographic characteristics and other determinants of policy preferences previously discussed in the literature (see e.g., Meltzer and Richard, 1981; Piketty, 1995; Benabou and Ok, 2001; Fong, 2001; Alesina and Angeletos, 2005; Alesina and La Ferrara, 2005; Kuziemko, Norton, Saez and Stantcheva, 2015; Giuliano and Spilimbergo, 2013; Cruces, Perez-Truglia and Tetaz, 2013; Karadja, Mollerstrom and Seim, 2017; Alesina, Stantcheva and Teso, 2018).

The application of the nonparametric Bayesian clustering approach to people's choices in the money allocation task indicates the existence of three fundamentally different clusters of other-regarding preferences in our population ${ }^{6}$ :

(1) A large share of individuals $(\approx 50 \%)$ makes predominantly egalitarian choices, i.e., their behavior indicates that they generally care about equality in addition to their self-interest. These individuals can be characterized as inequality averse in the sense of Fehr and Schmidt (1999) or Bolton and Ockenfels (2000) because they display a willingness to pay to increase poorer individuals' incomes and a willingness to pay to reduce richer individuals' incomes for the sake of equality.

(2) Another large group, comprising roughly 35\% of our sample, displays a strikingly different behavioral pattern. These individuals are basically never willing to reduce the other individual's payoff even in situations where the other individual is much better off. However, like the individuals in the first group, they are willing to sacrifice money to increase the payoff of individuals that are worse off, i.e. they show aversion to advantageous inequality. Their behavior is therefore consistent with an altruistic concern for the worse off as defined by Charness and Rabin (2002) as well as with other-regarding CES-preferences that incorporate an equity-efficiency trade-off as modelled by Fisman et al. $(2007,2015){ }^{7}$

\footnotetext{
${ }^{6}$ Two of the authors of this paper (Epper and Fehr) have also been involved in examining the distribution of social preferences in a large sample of the Danish population $(n \approx 4000)$ with this nonparametric Bayesian procedure. The same three preference types as identified in the Swiss population also show up in the Danish population.

${ }^{7}$ In the model of Charness and Rabin (2002), individuals care for their own payoff, the sum of payoffs, and the payoff of the worse-off individual (in the two-person case). The CES approach to other-regarding preferences (Fisman et al., 2007, 2015) is sufficiently general to incorporate Charness-Rabin preferences because it allows for (i) the extreme case where the individual cares only for his/her own payoff and the sum of payoffs, (ii) the extreme case where he/she only cares for equality (the "Rawlsian" case) in the sense that the individual is willing to give up resources to increase the payoff of the worse off individual until equality is achieved, and (iii) the cases in which the individual cares for both the sum of payoffs as well as equality. Note, however, that other-regarding CES preferences do not capture inequality aversion because they rule out individuals that are willing to pay to
} 
(3) Finally, the third type is characterized by predominantly self-interested individuals who generally do not care much about the others' payoffs. These individuals comprise roughly $15 \%$ of the sample.

To better understand the potential role of inequality aversion and altruistic concerns for the worse off in the support for redistribution, we incorporate them into a simple Meltzer and Richard (1981) model with proportional taxes and lump-sum redistribution of the tax revenue. This analysis shows that both inequality aversion and altruistic concerns increase the demand for redistribution in an income-dependent way. At low incomes the influence of social preferences is limited because selfish individuals are already highly supportive of redistribution and the existence of social preferences among low income earners cannot add much. However, at high incomes sufficiently strong social preferences tend to play a large role because selfish individuals are strongly opposed to redistribution such that affluent individuals with social preferences can make a difference. While the model cannot be directly applied to the Swiss referenda (because they differ from the distributional policy assumed in the model), the income-dependent effect of social preferences is likely to be generally operative for redistributive policies.

Our results show that both inequality aversion and altruistic concerns play a quantitatively large role in individuals' support for redistribution that is consistent with the general message of a "social preference augmented" Meltzer-Richards model. For above median income earners, in particular, inequality aversion is associated with an increase in political support for redistribution of 57 percent of a standard deviation compared to selfish individuals. For individuals with an altruistic concern, the corresponding number is 43 percent of a standard deviation. Our results also corroborate the traditional Meltzer-Richards model that assumes purely selfish preferences because we show that selfish individuals display indeed a huge decline in support for redistribution in response to rising incomes: the support of selfish individuals in the highest income category is $92 \%$ of a standard deviation weaker than the support of selfish individuals in the lowest income category. Thus, while for selfish individuals the support for redistribution steeply declines as their incomes rise, this incomedependence almost vanishes for inequality averse individuals and it is considerably (roughly $50 \%)$ mitigated for altruistic individuals. These findings suggest that omitting controls for social preferences may bias the link between income and support for redistribution downwards (because selfish individuals are lumped together with individuals that have social preferences).

The above-mentioned results are based on regression models that control for a host of other motives that have been discussed in the literature. Two of these motives have been shown to be strongly and robustly associated with political support for redistribution (e.g. Fong, 2001; Alesina and La Ferrara, 2005; Alesina and Giuliano, 2011). People who believe reduce another's income for the sake of achieving equality. 
that effort is an important driver of success are less supportive of redistribution, presumably because they think that effort deserves to be rewarded. Likewise, people who strongly believe that success is primarily due to luck and inheritance are more supportive of redistribution because they think luck and inheritance do not merit a distributional advantage (Cappelen, Hole, Sørensen and Tungodden, 2007). It is fair to say that these two motives are probably among the most important predictors of support for redistribution. But since these motives essentially rest on fairness arguments, they may only be relevant for individuals who indeed care about other people's payoffs, but may be irrelevant for selfish individuals. After all, why should an entirely selfish individual care about fairness? We indeed find that these beliefs are essentially irrelevant for the support for redistribution of selfish individuals, but are highly relevant for individuals with either social preference type. Thus, social preferences that incorporate notions of fairness appear to be the basis on which these beliefs become politically relevant.

Finally, our results also indicate how insights into the fundamental properties of social preferences can help us better understand the nature of the support for specific redistributive policies. In particular, inequality concerns and altruistic concerns diverge with regard to policies that are primarily perceived as being about reducing the incomes of the rich for the sake of lower inequality. We would thus expect that inequality averse individuals will support referenda that primarily aim at reducing the incomes of the rich - such as the 1:20 proposal or the fair taxes initiative - while those with an altruistic concern might be less enthusiastic. Our data indeed indicate that inequality aversion is a quantitatively important and significant predictor of support for these initiatives. In contrast, altruistic individuals' support is only about half as strong, and altruism is no longer a significant predictor of support for these initiatives.

Our paper contributes and is related to different bodies of research. It is, first, related to a growing body of research that examines the empirical determinants of the demand for redistribution (for a review, see Alesina and Giuliano, 2011). This literature has proposed and identified a list of important factors in the demand for redistribution: individuals' current income as well as future income prospects (Alesina and La Ferrara, 2005), beliefs and biases regarding income mobility (Piketty, 1995; Benabou and Ok, 2001; Benabou and Tirole, 2006; Alesina et al., 2018), beliefs about whether luck or effort are primarily responsible for individual success (see e.g. Fong, 2001; Alesina and Angeletos, 2005), the actual role of luck versus effort for individuals redistributive actions (Almås et al., 2019), a history of personal misfortune (Giuliano and Spilimbergo, 2013), mistrust in politicians and the government (Kuziemko et al., 2015), individuals' risk aversion (Gärtner et al., 2017), beliefs and biases about the prevailing income distribution and individuals' relative income standing (Cruces et al., 2013; Karadja et al., 2017), or belonging to demographic groups (such as the elderly and AfricanAmericans in the US) that have become more averse to redistribution over time (Ashok et al., 
2015).

However, none of these studies has measured and examined the role of inequality aversion and altruistic concerns in the demand for redistribution. This measurement allowed us to show (i) that social preferences play a quantitatively important role in the demand for redistribution, (ii) that the prevalence of two fundamentally different types of social preferences- inequality aversion versus altruistic concerns - in the broader population helps us to better understand the motivational basis for egalitarian redistributive policies and (iii) to uncover social preferences as a plausible motivational basis for two other powerful factors in the demand for redistribution - the extent to which people believe that effort and luck (inheritance) matter for an individuals' success in life. Taken together, we thus believe that our study contributes to this literature by providing an improved understanding of citizens' political demand for redistribution.

Second, our study is also related to the literature on social preferences mentioned above and, in particular, the literature on the structural estimation of the overall distribution of social preferences in broad population samples (see e.g. Bellemare et al., 2008, 2011; Fisman et al., 2015), and the literature that relates social preferences to issues of political economy (see e.g. Tyran and Sausgruber, 2006; Dhami and al Nowaihi, 2010; Dawes et al., 2012; Durante et al., 2014; Dimick et al., 2016; Fisman et al., 2017; Kerschbamer and Müller, 2020; Almås et al., 2019). However, none of these studies examined the support for redistributive policies that were actually up for vote in popular referenda (or are similar to such proposals). ${ }^{8}$ Our approach has the advantage of allowing us to validate our measures of support for redistribution, and to unambiguously yield measures of supports for actual policy proposals. This contrasts with the literature which tends to rely on questions that measures a "general willingness to redistribute" or to proxy demand for redistribution with political affiliation or support for a politician, which confounds redistribution with other policy goals.

We also differ from this literature by providing a parsimonious clustering of individuals to endogenously determined behavioral types. This enables a characterization of the distribution of social preferences in terms of individuals' assignment to a small number of distinct preference groups that display differential support for redistribution. While the pre-

\footnotetext{
${ }^{8}$ Tyran and Sausgruber (2006) and Durante et al. (2014) examine the role of social preferences on the demand for redistribution in laboratory voting games. Dhami and al Nowaihi (2010) incorporate social preferences into a theoretical political economy model. Dawes et al. (2012) relate subjects' decisions in a single dictator game to their preferences for political parties. Dimick et al. (2016) do not measure individual's social preferences; instead they test the predictions of their model of "utilitarian altruism" by relating individuals' endorsement of redistribution based on a question in the General Social Survey - to (i) their individual incomes, (ii) the difference between their incomes and the US national average income, and the interaction between (i) and (ii). Fisman et al. (2017) estimate individuals' social preferences under the assumption that other-regarding preferences are CES and relate these preferences to subjects' self-reported voting for Obama in the 2012 presidential election. Kerschbamer and Müller (2020) measure preferences with a method that generates 9 different social preference types. Then, they relate these preferences to subjects' answers to relatively general hypothetical questions such as "should the government mitigate income differences?". Almås et al. (2019) show that there are substantial differences in social preferences between Norwegians and US-Americans in a third-party redistribution game and conjecture that this may explain differences in overall redistributive policies across the two countries.
} 
vious structural estimation literature made assumptions on pre-existing preferences such as inequity aversion (Bellemare et al., 2008), intention-based reciprocity (Bellemare et al., 2011), or other-regarding CES preferences (Fisman et al., 2015, 2017), the application of a nonparametric clustering method makes it possible to identify the fundamental behavioral patterns of distinct preference groups, as well as the assignment of each individual to one such group, without structural assumptions on preferences and noise.

\section{Research design}

\subsection{Institutional setting}

Switzerland is a confederation of 26 member-states that are called cantons. A key element of the Swiss political system is direct democracy: adult Swiss citizens regularly vote on a variety of topics. Votes take place at the national, cantonal, and municipal levels and typically occur four times a year. For our purposes, one advantage of this political system is that it separates redistributive proposals from other policies. In contrast, people in a representative democracy do not vote on specific topics such as redistributive policy proposals. Instead, they can only vote for parties or candidates. However, parties and candidates always represent a bundle of different policy goals (e.g., on foreign policy, on religion, on abortion, etc.). It is, therefore, not clear whether voters support a particular politician or political party because of their position on redistribution or because of other aspects in their program.

Another advantage of direct democracy for our study is that the specific plebiscites are extensively covered in the media, and debates about politics are very common between friends, family, and colleagues. Over a period of 3-4 months before a national plebiscite the benefits and costs of a proposed law change are widely discussed on national TV, the newspapers, the social media, and the general population. Each voter also receives a booklet with his or her ballot about one month before the vote. This booklet provides detailed information on the plebiscite, including the positions of the Swiss Federal Council, the parliament, and the group that initiated the plebiscite. Therefore, voters are relatively well informed about the various pros and cons of a proposal before casting their vote, and the discussions provide frequent opportunities to deliberate on how to weigh them. ${ }^{9}$

\footnotetext{
${ }^{9}$ The public deliberations that happen in the period before the vote also tends to affect the voters' support for the policy proposals. Very often, the voters' support for an initiative declines considerably during this period, in particular for "populist" proposals with high emotional appeal. This downward trend is often observed in national polls conducted with representative samples of swiss voters up to 2 months before the vote. For example, the average support for the four proposals that we included in our study (for details, see below) decreased from $41.5 \%$ in the first representative survey of likely voters to $31 \%$ in the actual vote. In contrast, the average opposition increased from $47.8 \%$ in the first survey to $69 \%$ in the actual vote. This pattern suggests that the (perceived) cost of a redistributive policy may end up looming larger than its perceived benefits after the public deliberations.
} 


\subsection{Measuring political support for redistributive policy proposals}

We used an online survey to elicit swiss citizens' political support for four different redistributive proposals. These proposals, which we describe below, were identical (or very similar) to proposals that were up for vote in recent national plebiscites. We measured support for these proposals by asking our respondents to indicate whether they would support or oppose the initiatives, should they be put to vote "this weekend". We described the content of each of these initiatives using a wording that is very similar to the one that was used in the official voting booklets distributed to every Swiss citizen before each vote. ${ }^{10}$ The respondents could provide one of five possible answers: "Support", "Rather Support", "Don't Know", "Rather Reject", "Reject".

The initiative for a fair tax code. The primary aim of this initiative was to increase the marginal tax rates for the rich in Switzerland's "tax havens". In Switzerland, taxation occurs at three levels: federal, cantonal, and municipal. Some cantons and some municipalities try to attract rich residents by proposing very low marginal tax rates (both on income and on wealth) even for relatively rich people. The initiative proposed to put an end to this form of tax competition at the cantonal and municipal level by imposing a minimal marginal tax rate of $22 \%$ on all cantons and municipalities for taxable annual incomes exceeding CHF 250,000. In addition, the initiative demanded a minimal marginal tax rate of $0.5 \%$ on taxable wealth exceeding CHF 2 million. Thus, this popular initiative - if accepted - would have substantially increased taxation of the richest $1-2 \%$ of Switzerland's taxpayers who are residents of regional or local "tax havens." 11

The 1 to 12 initiative. The aim of this initiative was to make sure that the highest salary a company pays does not exceed 12 times its lowest salary. ${ }^{12}$ Throughout the campaign, this initiative was largely described by its proponents as an effective way of reducing the ("unfair") salaries the top earners receive. The public debate largely revolved around the salaries earned by the top managers, which are often perceived as abusive, in particular when companies pay them in difficult financial situations. In the official voting booklet edited by the government, the initiative committee motivated the need for the proposed change with the example of an investment banker who received CHF 26 million upon arrival at a large

\footnotetext{
${ }^{10}$ The precise description of the redistributive proposals that was given to the subjects is given in Appendix A.3.

${ }^{11}$ At the time, all the municipalities of 8 cantons and some municipalities of 7 cantons had a marginal tax rate on incomes exceeding CHF 250,000 lower than 22\%. The Swiss fiscal authorities, based on numbers from 2007 , estimated that 32,000 taxpayers (i.e. $1 \%$ of the taxpayers) had a taxable income in excess of CHF 250,000 . Similarly, in 2007 about 86,000 taxpayers had a wealth exceeding CHF 2 million. In some or all the municipalities of 16 cantons, marginal tax on wealth exceeding CHF 2 million is lower than $0.5 \%$.

${ }^{12}$ The initiative defined income as being both the salary as well as any other payment (in cash, in goods, or in services) that are related to the work an employee does.
} 
Swiss bank that reported a loss of CHF 2.5 billion at the time. ${ }^{13}$ In our study, we elicited support for a 1 to 20 initiative which stipulates that the maximum income in a company cannot be more than 20 times higher than the minimum income in that company.

The initiative for a national minimum wage. The aim of this initiative was to introduce a minimum wage of CHF 22 per hour worked, i.e. approximately CHF 4,000 per month (CHF $1 \approx$ USD 1$)$. This rather high minimum wage would have applied to all workers in Switzerland, and would have been adjusted to the price index over time. ${ }^{14}$ If accepted, this initiative would have implied a major change in Swiss labor law that is rather liberal compared to other European countries. The public debate largely focused on the working poor. In the media, the initiative committee regularly depicted the situation of workers who finished school and completed an apprenticeship but who nevertheless earn very little. The proponents described the initiative as an effective way to increase the salary of the poorest workers. In the official voting booklet, the initiative committee argues "that 330,000 humans work hard to earn so little is disgraceful; a real shame in a rich country." (official voting booklet, p. 33). In our study, we elicited support for a national minimum wage of CHF 3000 per month.

The initiative for an unconditional basic income. The initiative proposed the introduction of a universal basic income to be received by any Swiss citizen. The proponents of the initiative considered an unconditional basic monthly income of CHF 2'500 per adult and CHF 625 per child as an appropriate first step.

Note that the four popular initiatives differ in terms of their primary goals. The 1:12 and the fair taxes initiative were primarily framed and publicly discussed in terms of reducing income inequality by either imposing higher taxes on the rich (fair taxes initiative) or by constraining the top incomes in companies (1:12 initiative). Hence, a distaste for inequality might explain support for these initiatives. Even individuals who must bear economic costs from redistribution might be willing to support these proposals, provided their distaste for inequality is large enough. This focus on taking away money from the rich was basically absent in the minimum wage initiative. The public discourse on the initiative for the unconditional basic income was, however, also strongly focused on the implications for the public budget and the necessary tax increases. The reason why we slightly deviated from the original 1:12 initiative and the CHF 4000 minimum wage proposal was that the overall support for these initiatives

\footnotetext{
13 “Last year, UBS lost CHF 2.5 billion. At the same time, bonuses exceeded CHF 2.5 billion. Investment banker Andrea Orcel alone received CHF 25 million upon arrival at the bank. The average Swiss worker would need to work 385 years to reach this amount." (p. 11, official voting booklet). The proponents and the opponents of popular initiatives can present their cases in the official voting booklet.

${ }^{14}$ At the time, it was estimated that approximately 330,000 individuals (close to 1 worker out of 10) earned less than CHF 4,000 per month. (official voting booklet, p.28)
} 
was not very high because they were perceived as very radical. ${ }^{15}$ We therefore made the proposals somewhat less radical to increase the overall political support for redistribution.

\subsection{Measuring other-regarding preferences}

We measured respondents' other-regarding preferences using a considerable number of incentivized money allocation tasks ("dictator games") that systematically varied the cost of redistribution. In each task, the participant had to decide how to allocate experimental currency units (ECUs) between herself and an anonymous other participant of the study. ${ }^{16}$ Figure 1a provides an example of how we presented a choice situation to the subjects. There were always seven interpersonal allocations (labeled by 1 to 7) available per choice situation, and all of them were located on a budget line. Each available allocation consisted of a specific distribution of ECUs between the participant (bars labeled by "You receive") and the other person (bars labeled by "other person receives"). To make the trade-offs involved salient, we represented the available choices numerically and graphically. This presentation format makes the distributional consequences and the total payoff implications of the available choice options very transparent to the subjects. Figure $1 \mathrm{~b}$ plots the budget line corresponding to the example depicted in Figure 1a in the "self-payoff $\left(w_{\text {own }}\right)$ - other's payoff $\left(w_{\text {other }}\right)$ " space. In this example, the slope of the budget line is -2 , indicating that for every ECU the dictator gives up, the other individual receives 2 ECUs. Perfect equality in payoffs can be achieved by choosing allocation $4 .{ }^{17}$

\section{Figure 1: Example choice situation}

(a) Decision screen

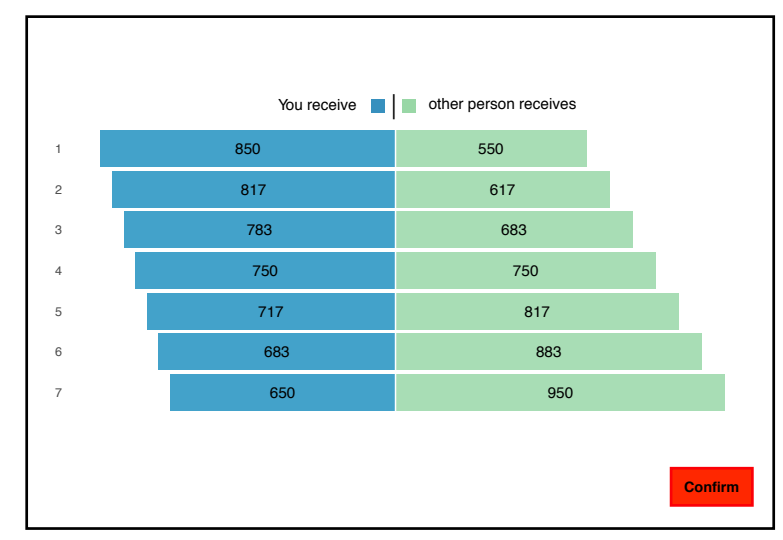

(b) Budget line

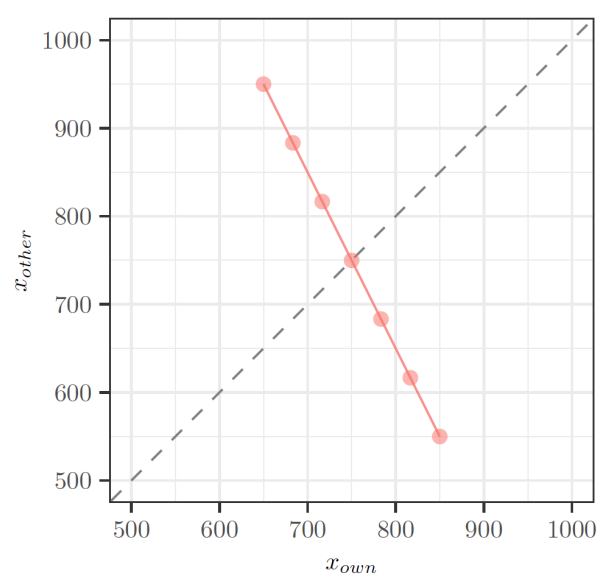

\footnotetext{
${ }^{15}$ The $1: 12$ initiative was accepted by $34.7 \%$ of the voters, and the minimum wage initiative was accepted by $23.7 \%$ of the voters.

${ }^{16}$ All subjects also knew that any form of reciprocity was ruled out, i.e., it was transparent that the decisionmaker could not receive any money from any recipient in the money allocation task.

${ }^{17}$ Since the average amount of ECU's at stake across all choice situations was roughly 750, the graphical representation scaled all ECU amounts relative to 750 (i.e. 750 represented 100\%). For example, a payoff of 950 was represented by a $(950 / 750)=1.267$ times larger bar than a payoff of 750 .
} 
A key feature of the set of budget lines we used is that they have both positive and negative slopes. Negatively sloped budget lines with different slopes enable us to measure individuals' willingness to pay to increase the other's income, while positively sloped budget lines make it possible to measure subjects' willingness to pay to decrease others' income for the sake of, e.g., achieving a higher level of equality. The different choice situations (i.e., budget lines) appeared in individualized random order on subjects' screens. One choice situation was randomly chosen for payment at the end of the online survey (with 100 ECUs $=$ CHF 2.5).

We provide the information about all choice situations presented to subjects in Appendix A.1. We use a total of 14 money allocation tasks (budget lines) to identify social preference types and the distribution of individuals across types. Each budget line crosses the 45-degree line, which is why we label them as being part of the "center bundle" (see Figure A.1b in Appendix A.1). We use two additional sets of tasks to assess the robustness and predictive validity of the types identified on the basis of the center bundle. In the "north bundle" the feasible money allocations are always (weakly) above the 45-degree line, i.e., the decisionmaker is always (weakly) worse off than the other participant. In the "south bundle" the feasible allocations are (weakly) below the 45-degree line such that the decision-maker is always (weakly) better off. In the validation exercise presented in Appendices B.2 and B.3 we show that the types identified on the basis of the center bundle provide good out-of-sample predictions for the north and the south bundle.

\subsection{Measuring other determinants of political support for redistribution}

Throughout the online survey, we also collected a large set of additional covariates. Many of them have been mentioned in the previous literature on the political demand for redistribution. As the purpose of our study is to isolate the role played by social preferences, we use these measures as controls in our empirical analyses. However, they also provide further insights about the role of these factors in a political setting that provides ideal conditions for studying the demand for redistribution. ${ }^{18}$

Socio-demographics. We collected data on respondents' age, gender, income, marital status, education, occupation, history of unemployment, and municipality of residence.

Beliefs about the determinants of success. A considerable literature suggests that these beliefs are among the most important predictors for individuals' support for redistribution (e.g. Fong, 2001; Alesina and La Ferrara, 2005; Alesina and Giuliano, 2011). Following Fong

\footnotetext{
${ }^{18}$ The questions used to measure these covariates were distributed throughout the survey, and we also used them to separate the money allocation task from the different questions that measured individuals' political support for the national plebiscites. Details on the measurement of the different covariates can be found in Appendix A.3.
} 
(2001), we asked respondents the extent to which they believe that a) the willingness to take risks, b) inheritance, c) hard work and initiative, d) luck, and e) having the right education are important reasons why some people get ahead and succeed in life while others do not. For each item, individuals had to indicate on a five-point scale whether they believe the respective factor is not at all important (1) or extremely important (5). Note that the willingness to take risks as well as hard work, initiative, and educational effort can be viewed as factors that are at least partially under the individual's control, while inheritance and luck are not. Based on this consideration, we create two indices. One index - labelled "effort matters" - measures the extent to which subjects believe that factors under an individual's control are important determinants of success (consisting of answers to item a, c and e). The other index - labelled "luck and inheritance matters" - measures the extent to which respondents believe that factors outside individuals' control are important determinants of success (consisting of answers to item $b$ and $d)$.

Economic preferences and trust in people. We gathered data on four other economic preferences - risk aversion, impatience, and positive and negative reciprocity - as well as a measure of general trust in other people, using the experimentally validated survey questions by Falk et al. (2016). We control for these preferences because some of them may be correlated with distributional preferences (e.g., negative reciprocity with inequality aversion or positive reciprocity with altruism), while others may have an independent role in the demand for redistribution. The results of Gärtner et al. (2017) suggest, for example, that individuals' risk aversion may be relevant for the demand for redistribution.

Beliefs about past and expected future mobility. Beliefs about expected future income and the future life situation may also play a role, as those individuals who expect improvements may have a self-interested reason to oppose redistribution (Benabou and Ok, 2001). Therefore, we used a proxy - taken from (Fong, 2001) - for perceived past improvements as well as beliefs about future improvements by asking respondents to picture a ladder whose top step (step 10) represents the best possible life outcome and 0 represents the worst possible life outcome for the respondent. Respondents were then asked on which step they feel they currently stand, where they stood five years ago, and where they think they will stand in 5 years from now. It is well known that income within a society is substantially correlated with subjective well-being (see e.g. Stevenson and Wolfers, 2013), suggesting that the question above also provides a reasonable proxy for future expected income. ${ }^{19}$ We construct a dummy for future

\footnotetext{
${ }^{19}$ Fong (2006) - using the National Survey of Midlife Development in the U.S. - also shows that her measure of expected future well-being correlates quite strongly with individuals' expected future financial situation (controlling for current financial situation). In addition, we validated the "income-proxy interpretation" of Fong's measure in a follow-up survey with the following question: "Compared to today, I expect my annual income in 5 years to have decreased a lot $(-2)$, decreased a little bit $(-1)$, stayed roughly the same $(0)$, increased a little bit $(+1)$, increased a lot $(+2)$. The Spearman rank correlation of this measure with Fong's measure is 0.4, suggesting that
} 
upwards mobility, which equals one if the individual believes he will be upwardly mobile in the next five years. We also construct a dummy for perceived past upward mobility, which equals one if the individual reports having been upwardly mobile in the past five years. Our results do not change if, instead of dummies, we use continuous measures for expected future and past upward mobility.

Perceived inequality. In order to assess respondents' beliefs about inequality, we asked them to indicate a) what they think is the share of the total income that the $10 \%$ of the households with the highest income receive in Switzerland, and b) what they think is the share of the total income that the $10 \%$ of the households with the lowest income receive in Switzerland. We then define perceived inequality as "perceived income share of the top 10\%" divided by the "perceived income share of the bottom $10 \%$.

Mistrust in politicians. We elicit mistrust in politicians by asking respondents how much (on a four-point scale) they believe that Swiss politicians work to enrich themselves and the lobbies they support instead of working for the benefit of the majority of the citizens. This measure may be viewed as a proxy for people's mistrust in political institutions (e.g. the parliamentary institutions) including the government because politicians are the visible "face" of these institutions.

General political attitude. Subjects were also asked to locate themselves on the left-right political spectrum where one indicated "being far left" and ten indicated "being far right".

Attention checks. In order to check for data quality, we added 2 attention checks to the survey (one in the first half and one at the later part of the survey). Attention checks are questions that measure whether participants read survey items carefully before answering them (Berinsky et al., 2014). In our sample, data quality is remarkably high: $76 \%$ of the subjects correctly answered both attention checks, and only $11 \%$ failed to pass both checks. ${ }^{20}$ The attention checks enable us to examine whether our results regarding the role of otherregarding preferences for redistributive politics are robust to the exclusion of those who do not pass the screeners.

the latter captures changes in expected income reasonably well. For additional details on the follow-up survey, see below and Appendix A.5.

${ }^{20}$ The proportion of respondents who do not correctly answer attention checks in short studies can be extremely high in some online samples. For example, Berinsky et al. (2014) show that between a third and a half of their sample fails to properly answer their attention checks. Thus, our pass rates can be considered very high, in particular when considering the fact that our study took more than an hour on average. 


\subsection{Data collection and sample implementation}

We conducted the online survey in collaboration with the LINK Institute, a leading company for high-quality market research in Switzerland, in March and April 2017. Because we are primarily interested in studying the link between social preferences and political support for redistribution, we restricted our attention to individuals who are eligible to vote, i.e. citizens who hold a Swiss passport and are older than 18. While Switzerland has four official languages (French, German, Italian and Romansh), we focus only on Swiss citizens from the French and German language area, who make up more than $90 \%$ of the Swiss population. The LINK Institute reached out to participants per email by sending them an invitation (in their corresponding languages) which contained an URL to our online survey. All the instructions were displayed on participants' screens. In order to mitigate spillovers between the money allocation task and the measures of policy preferences, policy preferences with regard to some randomly determined initiatives were elicited before the money allocation task, while others were measured after it. In addition, we always had several other survey questions that were used as filler questions between these measures. For their participation in the study, respondents were paid a show-up fee of CHF $15 .{ }^{21}$ In addition, we incentivized respondents' choices in the money allocation task by implementing one of their decisions. The exchange rate between points in the money allocation task and Swiss Francs was 100 points = CHF 2.5. Median time to complete the survey was 62 minutes, for which respondents were paid CHF 26 (incl. the show-up fee) on average, provided they completed the survey fully.

\section{Sample characteristics}

Our sample comprises data on 815 participants spanning 24 of the 26 cantons. Descriptive statistics on participants' socio-demographic characteristics can be found in Table A.2 in Appendix A.2. Overall, our sample is broadly representative of the Swiss voting population in the German and the French language areas with respect to age, gender, geographical area, income, and education (see Table A.3 in Appendix A.2).

\section{Follow-up study}

Two years after the main survey, we conducted an obfuscated follow-up study (again with the LINK institute) with the same respondents to collect additional information. We could survey $70 \%$ of the original subjects, which is remarkably high given that 2 years passed between the two waves. In Appendix A.2, we show that the respondents of the follow-up are not significantly different (in terms of their observable characteristics) from our original sample. Importantly, we also show that attrition is orthogonal to social preferences (see Appendix

\footnotetext{
${ }^{21}$ At the time the survey took place, the exchange rate between Swiss Francs and USD was approximately equal to CHF 1 = USD 1.
} 
A.4). In Appendix A.5 we provide further details on the tasks implemented in the follow-up study.

\subsection{Validating the measure of political support for redistribution}

Based on a respondents' support for the four initiatives described in Section 2.2, we define individual $i$ 's support for policy proposal $j$ as follows:

$$
S_{i j}= \begin{cases}1 & \text { if response } \in\{\text { Support, Rather support }\} \\ 0 & \text { if response } \in\{\text { Don't know }\} \\ -1 & \text { if response } \in\{\text { Rather reject, Reject }\}\end{cases}
$$

We then construct an individual-level measure of average political support for redistribution $\left(A S_{i}\right.$ for average support of individual $\left.i\right)$ by averaging an individual's support for the four initiatives:

$$
A S_{i}=\frac{1}{4} \sum_{j=1}^{4} S_{i j}
$$

We depict the distribution of average support in Figure A.2 in Appendix A.6. The distribution is slightly skewed to the left, with an average support of 0.28 and a standard deviation of 0.57 .

As in other countries, there are sizeable differences across regions (i.e., cantons) in the support for redistribution in Switzerland. The percentage of people supporting redistribution is rather low in some cantons, while it is relatively high in others. One of the advantages of eliciting people's support for redistribution for actually conducted referenda from the past is that we can check the validity of our measure of political support by comparing the geographic distribution of support in the actual referendum with the support for the same political measures in our online survey. In other words, if our measure of political support for redistribution contains relevant information about participants' real preferences for politically enforced redistribution, we should observe a positive correlation between the actual vote share in favor of the redistributive proposals and the average support for these redistributive proposals in our sample. The positive Spearman correlation of $\rho=0.61$ displayed in Figure 2 below shows that this is indeed the case.

We further validate our measure of support for redistribution in the follow-up study using donation tasks with real monetary stakes. In these tasks, subjects received an endowment of CHF 20 and had to decide how much of the CHF 20 to keep for themselves and how much to donate to civic groups. Subjects could donate money to groups that support redistribution as well as to groups that oppose redistribution (for further details, see Appendix A.5). These tasks provide us with behavioral measures of support for redistribution that enables us to check whether those who voted for (opposed) redistributive policies in the main sur- 
Figure 2: Correlation between the average support for redistribution in the online survey and the actual vote share for the same policy measures in the referenda

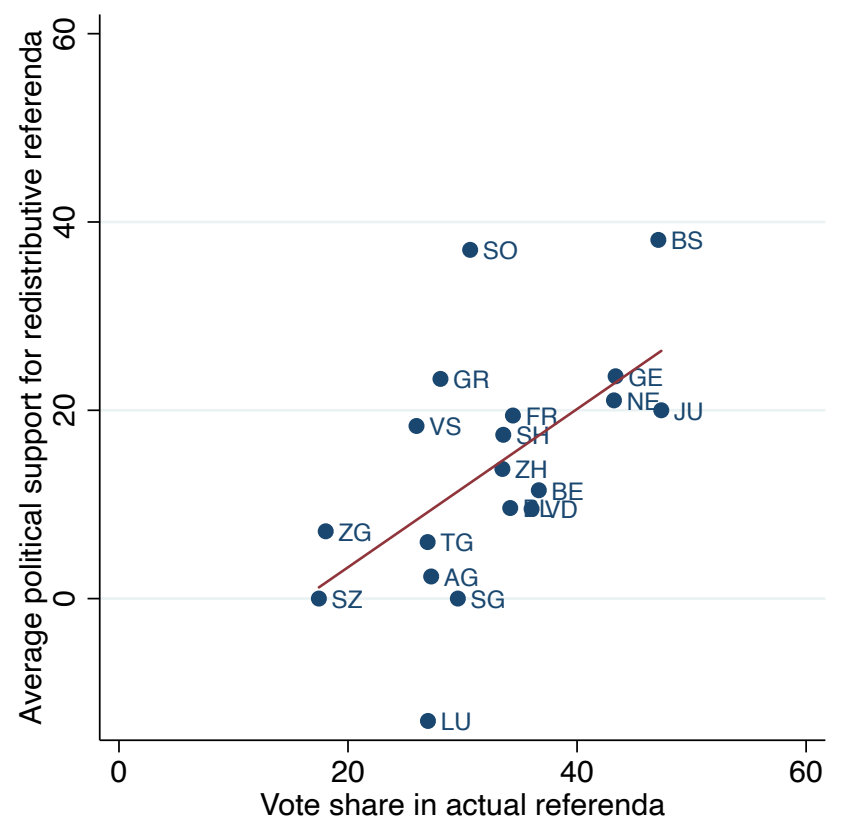

vey are also more likely to donate real money to civic groups that politically favor (oppose) redistribution.

Note that the follow-up study took place two years after the initial study. Therefore, a significant positive (negative) correlation between subjects' average support for redistribution in our online survey and their donations to civic organizations that support (oppose) redistribution would not only validate our measure of average support for redistribution but also indicate that individuals' political support for redistribution is rather stable over time. The validation results are shown in Table 1 below.

In columns 1-3 of the table the dependent variable is the standardized average donation to civic organizations that support redistribution. In column 4-6 the dependent variable is the standardized donation to organizations that oppose redistribution. Columns 1 to 3 indicate that respondents who display a stronger political support for redistribution donate significantly more to organizations that support redistribution $(p<0.01)$; an increase in AS by one unit (e.g., from "don't know" to "support") is associated with an increase in donations to civic groups that support redistribution by roughly $45 \%$ of a standard deviation. The large coefficient of $A S$ on donations thus provides strong evidence for the behavioral relevance of our measure of political support for redistribution. Columns 4-6 also shows that individuals with a stronger average support for redistribution donate considerably less to organizations that oppose redistribution. ${ }^{22}$ Thus, taken together, our measure of political support for redis-

\footnotetext{
${ }^{22}$ The smaller coefficient for $A S_{i}$ in regressions 4-6 (relative to regression 1-3) is due to the fact that donations to
} 
tributions appears to be well-validated.

Table 1: Predicting donations to civic organizations with diverging views on redistributive policies

\begin{tabular}{|c|c|c|c|c|c|c|}
\hline & \multicolumn{3}{|c|}{$\begin{array}{l}\text { Standardized donation to groups } \\
\text { supporting redistribution }\end{array}$} & \multicolumn{3}{|c|}{$\begin{array}{c}\text { Standardized donation to groups } \\
\text { opposing redistribution }\end{array}$} \\
\hline & (1) & (2) & (3) & (4) & (5) & (6) \\
\hline Average support for redistribution $\left(\mathrm{AS}_{i}\right)$ & $\begin{array}{l}0.481^{* * *} \\
(0.068)\end{array}$ & $\begin{array}{l}0.438^{* * *} \\
(0.068)\end{array}$ & $\begin{array}{l}0.452^{* * *} \\
(0.069)\end{array}$ & $\begin{array}{l}-0.192^{* *} \\
(0.079)\end{array}$ & $\begin{array}{l}-0.194^{* *} \\
(0.080)\end{array}$ & $\begin{array}{l}-0.181^{* *} \\
(0.082)\end{array}$ \\
\hline Male & & $\begin{array}{l}-0.314^{* * *} \\
(0.079)\end{array}$ & $\begin{array}{l}-0.395^{* * *} \\
(0.090)\end{array}$ & & $\begin{array}{r}0.003 \\
(0.086)\end{array}$ & $\begin{array}{r}-0.018 \\
(0.103)\end{array}$ \\
\hline Age & & $\begin{array}{r}-0.001 \\
(0.015)\end{array}$ & $\begin{array}{r}-0.017 \\
(0.020)\end{array}$ & & $\begin{array}{r}-0.004 \\
(0.017)\end{array}$ & $\begin{array}{r}-0.019 \\
(0.020)\end{array}$ \\
\hline Income: above-median & & & $\begin{array}{r}0.024 \\
(0.104)\end{array}$ & & & $\begin{array}{r}0.001 \\
(0.101)\end{array}$ \\
\hline Income: Undisclosed & & & $\begin{array}{r}-0.038 \\
(0.144)\end{array}$ & & & $\begin{array}{r}0.023 \\
(0.179)\end{array}$ \\
\hline Constant & $\begin{array}{l}-0.145^{* * *} \\
(0.045)\end{array}$ & $\begin{array}{r}-0.216 \\
(0.335)\end{array}$ & $\begin{array}{r}0.258 \\
(0.405)\end{array}$ & $\begin{array}{r}0.058 \\
(0.049)\end{array}$ & $\begin{array}{r}0.133 \\
(0.382)\end{array}$ & $\begin{array}{r}0.432 \\
(0.449)\end{array}$ \\
\hline Other socio-demographics & No & Yes & Yes & No & Yes & Yes \\
\hline Education & No & No & Yes & No & No & Yes \\
\hline Occupation & No & No & Yes & No & No & Yes \\
\hline$R^{2}$ & 0.078 & 0.152 & 0.162 & 0.013 & 0.029 & 0.034 \\
\hline Observations & 573 & 573 & 573 & 573 & 573 & 573 \\
\hline
\end{tabular}

Notes: OLS regression. The dependent variable is subjects' standardized (mean = zero, standard deviation $=1$ ) donation to organizations that support (column 1-3) or oppose (column 4-6) redistribution. Other socio-demographics include age squared, a dummy variable indicating whether the respondent's native language is french, and a dummy indicating whether the respondent is married. Education includes dummies indicating a respondent's highest educational achievement (compulsory school, vocational training, high school, university or other), and occupation includes dummies indicating whether the individual currently has a full-time job, a part-time job, is unemployed or is not in the labor force. Levels of significance: ${ }^{*} p<0.1,{ }^{* *} p<0.05,{ }^{* * *} p<0.01$

\section{The empirical distribution of social preferences}

The main goal of this section is to identify the distribution of the various types of social preferences on the basis of subjects' behavior in the money allocation task. Previous evidence (e.g. Andreoni and Miller, 2002; Bellemare et al., 2008; Fisman et al., 2015, 2017; Kerschbamer and Müller, 2020; Bruhin et al., 2018; Cappelen et al., 2007) suggests that there is strong heterogeneity in social preferences. We are interested in the question whether the distribution of preferences can be captured parsimoniously with a small number of types that exhibit fundamentally different behavioral characteristics. Previous work by Bruhin, Fehr and Schunk

civic groups that tend to oppose redistribution are generally rather small and heavily censored from below, while donations to groups that support redistribution are mostly in the interior of the donations space. 
(2018), which is based on a student sample, shows that the distribution of social preferences can be characterized by three behavioral types and that this parsimonious type distribution predicts out-of-sample behavior as well as individual level preference estimates. Thus, it may well be possible to achieve a similar level of parsimony with our broad population sample. We also believe that parsimony is important beyond our concrete project because tractability constraints in applied contexts typically impose serious limits on the degree of complexity that theories can afford at the individual level. In addition, parsimony has the advantage of simplicity and ease of interpretability.

We approach our task in two steps. First, we examine the choice behavior of subjects in the money allocation task descriptively to see whether we can find indications for the existence of fundamentally different social preference types already at this analysis level. Second, we apply a formally rigorous nonparametric approach to characterize the preference heterogeneity in the population. More specifically, we adopt a nonparametric Bayesian approach - the Dirichlet Process (DP) means clustering algorithm - introduced by Kulis and Jordan (2012).

An important aspect of the DP-means approach is that it enables identification of preference types without committing to a pre-specified number of different preference types. Moreover, this approach does neither require an ex-ante specification or parameterization of types, nor does it presume a specific error structure. This means that it remains ex-ante agnostic about key distributional assumptions, and it does not constrain heterogeneity to lie within a predetermined set of models or parameter space. In this regard, our approach differs from previous work (e.g. Bellemare et al., 2008; Fisman et al., 2015, 2017; Bruhin et al., 2018) that characterized preference heterogeneity on the basis of structural assumptions on preferences and error terms. The DP-means algorithm allows for all possible type partitions of the data spanning from a representative agent (i.e. a single data-generating process) up to as many types as there are individuals in the population (i.e. $\mathrm{n}$ data-generating processes), i.e., it determines the number of preferences types endogenously. Thus, (i) the actual number of types, (ii) the assignment of each individual to one of the types and (iii) the behavioral (preference) properties of the types emerge endogenously. ${ }^{23}$

\subsection{Are there fundamentally different behavioral types? Descriptive analysis}

Behavioral changes across budget lines within the class of negatively sloped budget lines inform us about how much money individuals are willing to sacrifice to increase another individual's payoff. In contrast, behavioral changes across budget lines within the class of positively sloped budget lines inform us about how much money individuals are willing to

\footnotetext{
${ }^{23}$ The fact that the number of types adapts to the data has important benefits (see Kulis and Jordan, 2012). Most notably, as previous work has shown (see Comiter et al., 2016), this feature of the algorithm yields higher quality type-separation than methods that specify the number of types prior to clustering (such as $k$-means).
} 
sacrifice to decrease another individuals' payoff. Thus, the distinction between negatively and positively sloped budget lines is important because it enables us to capture the fundamental difference between the willingness to pay to increase and the willingness to pay to reduce other people's income.

Therefore, to search for the potential existence of fundamentally different behavioral types, we look at each individual's median choice across the negatively sloped and across the positively sloped budget lines of the center bundle. We focus on the median because it is less susceptible to random, outlier generating, influences. For each budget line, we label the own-payoff maximizing allocation by $z=1$, the own-payoff-minimizing allocation by $z=0$, and the payoff-equalizing allocation by $z=0.5$. The other four available allocations on each budget line are equidistantly placed between $0-0.5$ and $0.5-1$, respectively.

Figure 3 below illustrates a striking fact. Among the negatively sloped budget lines, the median choice of the vast majority of individuals $(\approx 72 \%)$ is located exactly at two points $z=0.5$ and $z=1$. Likewise, among the positively sloped budget lines, the median choice of roughly $72 \%$ of the subjects is again located at $z=0.5$ and $z=1$. The subjects that are not exactly allocated at one of these points display median allocations that are at more intermediate z-values, either between 0 and 0.5 or between 0.5 and 1 .

Figure 3: Subjects' median choices on negatively sloped and on positively sloped budget lines

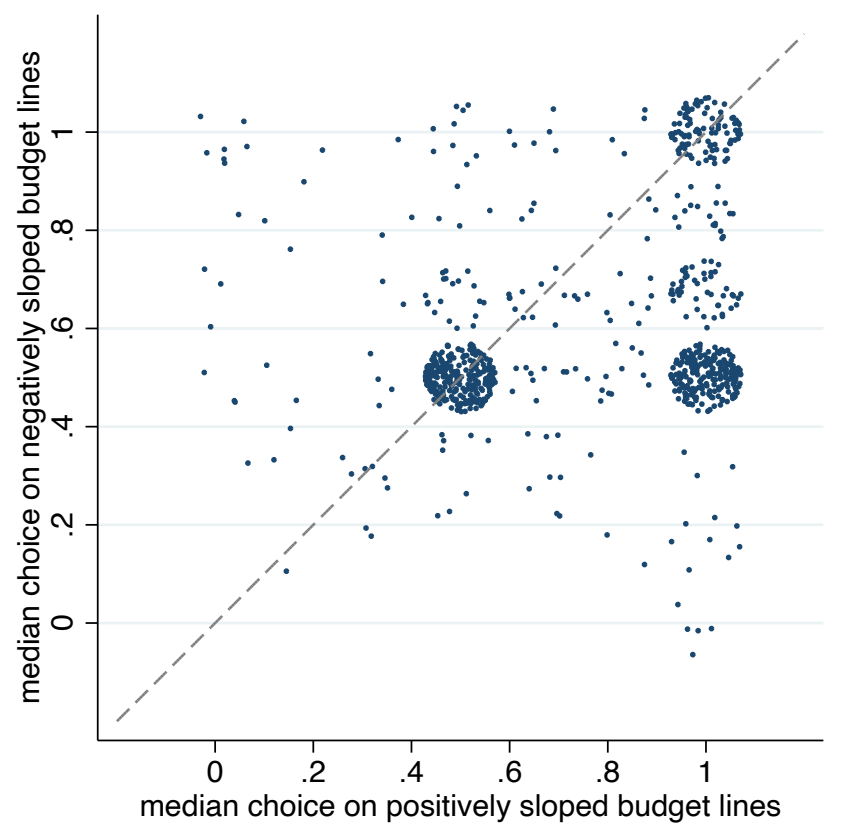

Note: The figure shows subjects' median choices among negatively sloped budget lines and among positively sloped budget lines. Each dot represents one individual. To make identical choices of individuals visible dots are jittered. For each budget line, $z=1$ indicates an own-payoff maximizing choice, $z=0$ indicates an own-payoff minimizing choice, and $z=0.5$ indicates a payoff-equalizing choice. Note that if we replace individuals' median choices by their modal choices a very similar distribution with three large behavioral agglomeration at $(0.5,0.5),(1,0.5)$ and $(1,1)$ emerges. 
Note that this bunching of subjects' median choices at, for example, $z=0.5$ does not just reflect a situation where they are roughly half of the time to the right and half of the time to the left of the median. It rather reflects the fact that they most of the time chose $z=0.5$. For example, among the subjects whose median choice is $z=0.5$ on negatively (positively) sloped budget lines, the overall percentage of all choices at $z=0.5$ is 77 percent (65 percent). Likewise, among the subjects whose median choice is $z=1$ on negatively (positively) sloped budget lines, the overall percentage of all choices at $z=1$ is 82 percent ( 87 percent). Thus, for these subjects the median choice is clearly the actually preferred choice in the overwhelming number of cases.

Together, this pattern gives rise to three behavioral agglomerations:

(i) A large agglomeration of roughly $33 \%$ of individuals whose median choice is located exactly at $z=0.5$ for both positively and negatively sloped budget lines. These individuals choose most of the time the equal-payoff allocation. Note that the choice of $z=0.5$ means that the individuals give up own payoff to increase the payoff of the other subject for negatively sloped budget lines but it also means to sacrifice own money to decrease the payoff of the other subject for positively sloped budget lines. Thus, individuals in this cluster seem to be motivated by equality.

(ii) Another relatively large agglomeration of roughly $27 \%$ of subjects whose median choice is located exactly at $z=1$ for positively sloped budget lines and $z=0.5$ for negatively sloped budget lines. These individuals choose most of the time the equal payoff allocation for negatively sloped budget lines but the own-payoff maximizing allocation for positively sloped budget lines. Thus, these individuals are unwilling to reduce the other subject's payoff for the sake of equality but they show altruistic behavior for negatively sloped budget lines.

(iii) A significant minority of roughly $12 \%$ whose median choice is the own-payoff maximizing allocation for both types of budget lines, i.e., these individuals appear to be primarily self-interested.

Figure 3 provides a first indication that there may indeed be a small number of types with fundamentally distinct social preferences. However, a descriptive analysis can only go so far, i.e., it is suggestive but not fully conclusive. Therefore, to derive a more rigorous characterization of the type distribution of social preferences - one that assigns, in particular, also the roughly $28 \%$ of "dispersed" individuals (i.e., those that are not choosing either $z=0.5$ or $z=1$ ) to endogenously determined behavioral types - we apply the above-mentioned nonparametric Bayesian approach. 


\subsection{Rigorous identification of preference types and assignment of individuals to types}

DP-means groups individuals into clusters according to behavioral similarities between them. In our application, an individual is characterized by its payoff allocation in all 14 choice situations of the center bundle. Therefore, our application of DP means is not based on subjects' median choices but exploits the full information provided by all their choices in the center bundle. In this context, similarity then refers to how "close" individuals are with respect to their allocation behavior in a 14-dimensional budget allocation space.

We describe the formalism and the intuition underlying the DP-means algorithm in some detail in Appendix B.1. Here, we report only the results of the clustering mechanism. We illustrate the results of the clustering algorithm again with the help of individuals median behavior among the negatively and the positively sloped budget lines because this simplifies the presentation considerably. However, as mentioned above, our approach considers all individual choices in the center bundle. In a previous version of this paper, we have presented and discussed the clustering results in terms of individuals' choices in all 14 choice situations of the center bundle (see Epper et al., 2020, Section 3.3).

The application of the DP-means algorithm to the center bundle of the money allocation task indeed suggests the existence of three behavioral types. Roughly half of the subjects (50.8\%) are assigned to Type 1, around one-third (34.36\%) to Type 2, and the remainder $(14.85 \%)$ to Type 3 . The three types differ substantially in terms of their behavior. A careful examination of the decisions of these types permits us to assign them a label with a clear behavioral interpretation.

Figure 4 shows the distribution of individuals' median choices among negatively and positively sloped budget lines, separately for each type. The figure thus also enables a judgment regarding how individuals that are assigned to a particular type differ from each other and how large these deviations are. The figure shows that the vast majority of individuals in type 1 make median choices that are payoff-equalizing - and they do so for both the negatively sloped budget lines (Figure 4a) and the positively sloped budget lines (Figure 4b). They thus exhibit a willingness to pay (i) for reducing inequality when this involves increasing the other individual's payoff (i.e., for negative slopes) and (ii) when it involves decreasing the other individual's payoff (i.e., for positive slopes). For this reason, we assign the label inequality averse to type 1 - which comprises $50.8 \%$ of our sample.

This pattern contrasts sharply with the individuals assigned to type 2 and type 3 . Individuals assigned to type 3 (see Figure $4 \mathrm{e}$ and $4 \mathrm{f}$ ), in particular, deviate sharply from the inequality averse type: in the vast majority of the cases their median choice is the own-payoff maximizing allocation regardless of whether budget lines have a positive or a negative slope. These $14.8 \%$ of individuals can therefore be characterized as predominantly selfish. Finally, 
Figure 4: Distribution of individuals' median choices for each preference type.

Type 1 : Inequality averse (50.8\%)

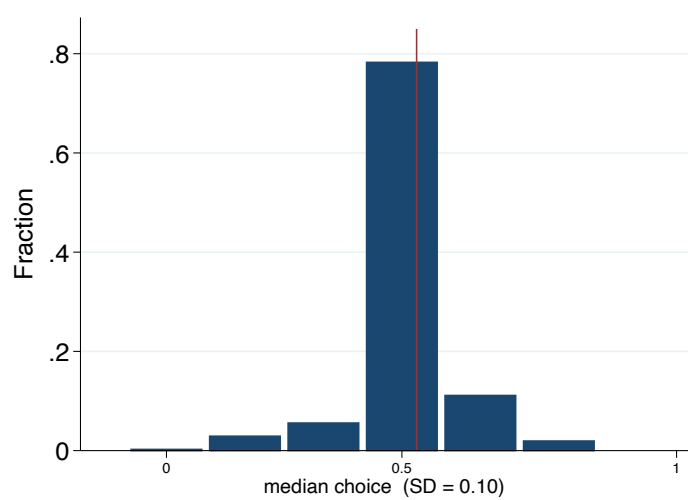

(a) Negatively sloped budget lines

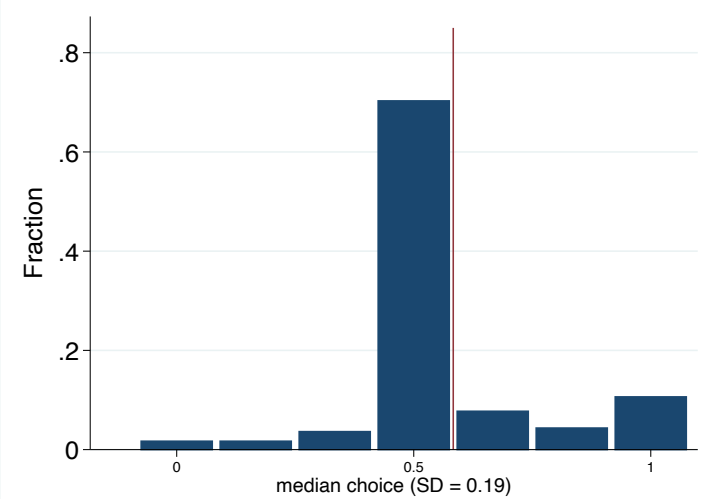

(b) Positively sloped budget lines

Type 2 : Altruistic (34.4\%)

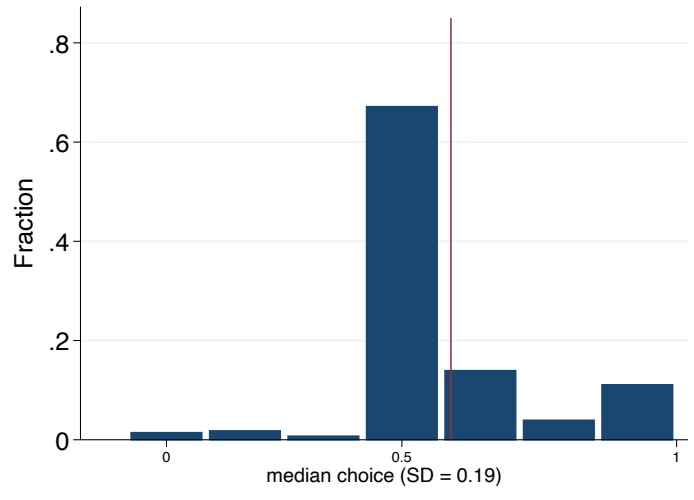

(c) Negatively sloped budget lines

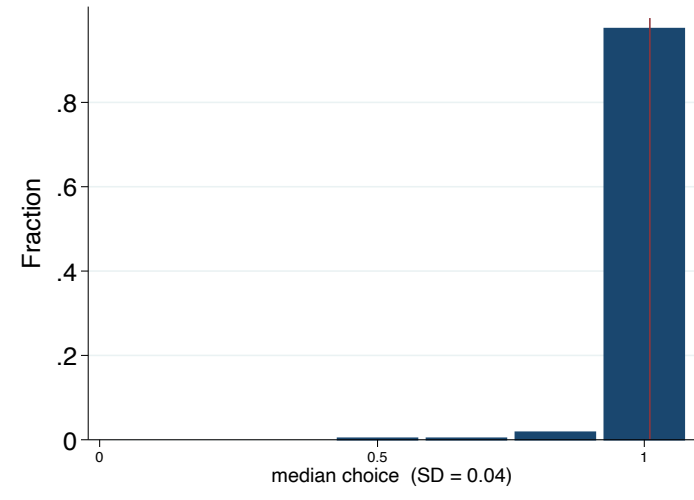

(d) Positively sloped budget lines

Type 3 : Predominantly selfish (14.8\%)

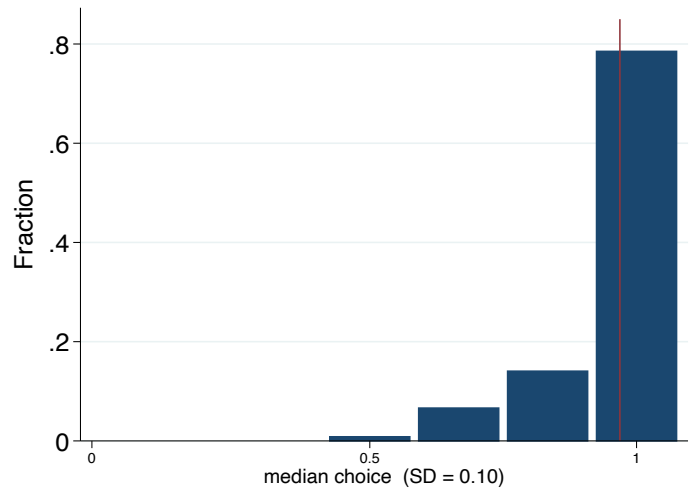

(e) Negatively sloped budget lines

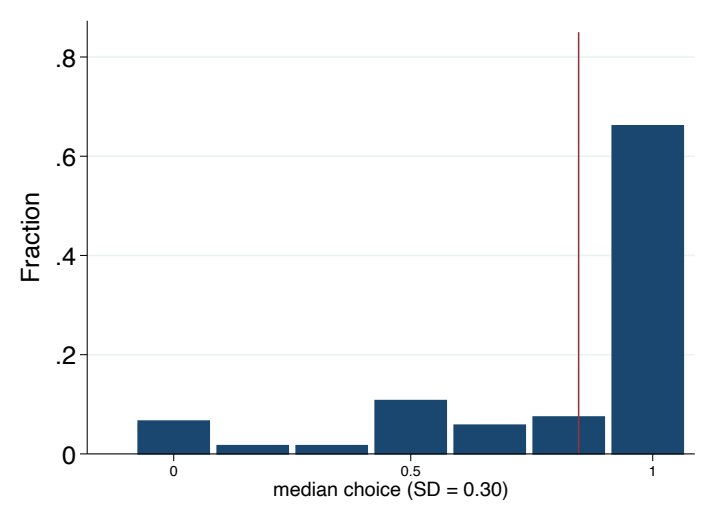

(f) Positively sloped budget lines

Note: The figure shows the distribution of individuals' median choices among negatively sloped and among positively sloped budget lines for each of the three behavioral types identified by the clustering algorithm. For each budget line, $z=1$ indicates an own-payoff maximizing choice, $z=0$ indicates an own-payoff minimizing choice, $z=0.5$ indicates a payoff-equalizing choice. The red vertical line indicates always the average over all median choices. SD indicates the standard deviation of median choices. 
individuals assigned to the type 2 cluster differ sharply from the inequality averse type for positively sloped budget lines where the own-payoff (and simultaneously other-payoff) maximizing allocation is basically their median choice in $100 \%$ of the cases (see Figure $4 \mathrm{~d}$ ). However, the behavior of type 2 individuals for the negatively sloped budget lines resembles that of the inequality averse individuals because the egalitarian allocation is their median choice in roughly $70 \%$ of the cases (Figure 4c). Thus, these individuals are willing to increase other individuals' payoff in the domain of advantageous inequality, i.e., when they are better off than others, but they are never willing to reduce other individual's payoff on positively sloped budget lines to avoid disadvantageous inequality. We therefore label individuals belonging to this type, $34.4 \%$ of our population, as subjects with an altruistic concern. The label "altruistic" is due to their willingness to sacrifice money to mitigate advantageous inequality and help those worse off.

Another remarkable aspect of Figure 4 is that there is generally very little within-type variation, as indicated by the low standard deviation associated with each of the graphs shown in the figure. This low within-type variation provides a further justification for speaking of different types of preferences; and the fact that the typical choices of the three types sharply differ justifies the notion that the preference differences across types are of a fundamental nature.

If our preference interpretation of the behavioral types is correct and stable across budget bundles, the different types should display characteristic behavioral patterns in the north and the south bundles. In other words, the inequality averse type should also display a preference for equality in these bundles even if that implies strong deviations from the allocations that lie in the middle of the budget line. Likewise, the altruistic type should also display a strong tendency to choose joint payoff maximizing allocations for positively sloped budget lines in the north and the south bundle.

We find that the behavioral types identified on the basis of individuals' behavior in the center bundle predicts the types' behavior in the south and the north bundle very well. We show this in more detail in Appendices B.2 and B.3; they indicate that the preference types generally behave very consistently across budget bundles.

\section{The role of social preferences in political support for redistribu- tion}

In this section we examine the empirical role of social preferences for the support of the different redistributive policies. Since all four referenda have strong redistributive implications, we first examine the role of social preferences on an individual's average support for these four referenda $\left(A S_{i}\right.$, defined in section 2.6). Subsequently we divide up the referenda in those that primarily aim at reducing the income of the rich - the 1:20 and the fair taxes initiative - and 
the referenda that primarily want to improve the income of those with relatively low incomes - the minimum wage and the unconditional basic income initiative. The reason for this is that the two different types of referenda might be appealing to individuals with different types of social preferences (see Section 4.4 below).

\subsection{Theoretical considerations}

Before we enter the empirical analysis, it is, however, useful to guide our intuitions about the role of social preferences in redistributive politics by a few theoretical considerations. For this purpose, we integrate social preferences into a stylized model of the demand for redistribution to better understand how inequality aversion and altruistic concerns may affect this demand.

To keep the model simple, we assume - like in the classic paper by Meltzer and Richard (1981) - a proportional tax $\tau(0 \leq \tau \leq 1)$ on individuals' gross income $y_{i}$ that is redistributed lump-sum via a transfer $T$ to everybody. Tax collection and redistribution involves a quadratic redistribution cost of $\frac{1}{2} \tau^{2}$ per unit of gross income. Consumption $c_{i}$ of individual $i$ is given by

$$
c_{i}=(1-\tau) y_{i}+T
$$

and the government's budget is balanced if the lump-sum transfer is given by

$$
T=\left(\tau-\frac{1}{2} \tau^{2}\right) \bar{y}
$$

where $\bar{y}=\frac{1}{n} \sum_{i=1}^{n} y_{i}$ denotes the average gross income in the population. To examine the role of social preferences we assume that individuals' preferences are given by a utility function inspired by Fehr and Schmidt (1999):

$$
V_{i}=c_{i}-\alpha_{i} \frac{1}{n-1} \sum_{j \neq i} \max \left(c_{j}-c_{i}, 0\right)-\beta_{i} \frac{1}{n-1} \sum_{j \neq i} \max \left(c_{i}-c_{j}, 0\right) .
$$

$V_{i}$ denotes individual $i$ 's utility, $\alpha_{i}$ is a measure of aversion against disadvantageous inequality $\left(c_{j}-c_{i}>0\right)$ and $\beta_{i}$ measures the aversion against advantageous inequality or a willingness to help those who are worse off $\left(c_{i}-c_{j}>0\right)$, respectively. For simplicity, we assume that individuals compare themselves to all other members of the population, i.e., $n$ comprises the population of the polity.

The three distinct types of individuals identified in the previous section can be nicely captured with the help of (3). The selfish type is characterized by $\alpha_{i}=\beta_{i}=0$. The inequality averse type is captured by $\alpha_{i}>0$ and $\beta_{i}>0$. This follows from the fact that the inequality averse individuals generally chose the egalitarian allocation for negative and positively sloped budget lines: $\alpha_{i}>0$ follows from choosing the egalitarian allocation for positively sloped 
budget lines (Figure $4 \mathrm{~b}$ ) and $\beta_{i}>0$ is implied by the choice of the egalitarian allocation on negatively sloped budget lines (Figure $4 \mathrm{a}$ ). In contrast, the altruistic type is characterized by $\alpha_{i}=0$ and $\beta_{i}>0$. These individuals were willing to sacrifice money to improve the situation of worse off individuals on negatively sloped budget lines (Figure 4c), implying that $\beta_{i}>0$. However, they were not willing to sacrifice money to reduce the other individuals' payoff for the sake of equality on positively sloped budget lines (Figure $4 \mathrm{~d}$ ), i.e., they are not averse against disadvantageous inequality $\left(\alpha_{i}=0\right)$.

On the basis of the above assumptions - linear tax, lump-sum transfers to everybody, quadratic redistribution costs, no other taxes and public expenditures, balanced budget, etc. - it becomes immediately clear that the model does not apply directly to any of our four referenda. Note also that the model restricts the motivational forces for the demand for redistribution just to two factors - self-interest and social preferences. However, we believe that the model nevertheless can provide valuable intuitions about the potential role of social preferences in the demand for redistribution

We derive the first-order condition for an individual's demand for redistribution in terms of the preferred redistributive $\operatorname{tax} \tau_{i}^{*}$ in Appendix C.1. This condition implies that $\tau_{i}^{*}$ is given by equation 4 below.

$$
\tau_{i}^{*}=1-\frac{1}{\bar{y}}\left(y_{i}-\alpha_{i} \frac{1}{n-1} \sum_{j \neq i} \max \left(y_{j}-y_{i}, 0\right)-\beta_{i} \frac{1}{n-1} \sum_{j \neq i} \max \left(y_{i}-y_{j}, 0\right)\right)
$$

Expression 4 implies that selfish individuals' $\left(\alpha_{i}=\beta_{i}=0\right)$ demand for redistribution falls with their gross income $y_{i}$. At very low incomes $\left(y_{i} \approx 0\right)$ selfish individuals demand a tax rate of almost $100 \%$ while at incomes above $\bar{y}$ their demand is zero. ${ }^{24}$ Except at very low incomes $\left(y_{i} \approx 0\right)$, individuals with social preferences have a higher demand for redistribution because of $\alpha_{i}>0$ and/or $\beta_{i}>0$. Figure 5 below illustrates the role of social preferences in the demand for redistribution by depicting the demand for each preference type separately.

For individuals with low incomes it is mainly the distaste against disadvantageous inequality $\left(\alpha_{i}>0\right)$ that increases their demand for redistribution because for most income comparisons they face disadvantageous inequality. In contrast, for individuals with high incomes it is mainly their willingness to mitigate advantageous inequality (i.e., their $\beta_{i}$-parameter) that increases their demand for redistribution because in most income comparisons they face advantageous inequality. Taken together, social preferences thus mitigate the decline in $\tau_{i}^{*}$ that is predicted for selfish individuals.

Note also that because selfish individuals with low incomes demand already very high levels of redistribution the model suggests that the potential impact of social preferences at low incomes levels is limited while at high income levels the scope for a role of social pref-

\footnotetext{
${ }^{24}$ Recall that $0 \leq \tau \leq 1$.
} 
erences is higher. Finally, because $\alpha_{i}>0$ for inequality averse individuals while $\alpha_{i}=0$ for the altruistic type, inequality averse individuals have, ceteris paribus, a stronger preference for redistribution in this simple model. However, since aversion against disadvantageous inequality $\left(\alpha_{i}>0\right)$ is particularly relevant at lower income levels, where even selfish individuals have a high demand for redistribution, it may be difficult to detect the differential impact of different types of social preferences on the demand for redistribution empirically.

Figure 5: Illustrating the theoretical role of social preferences

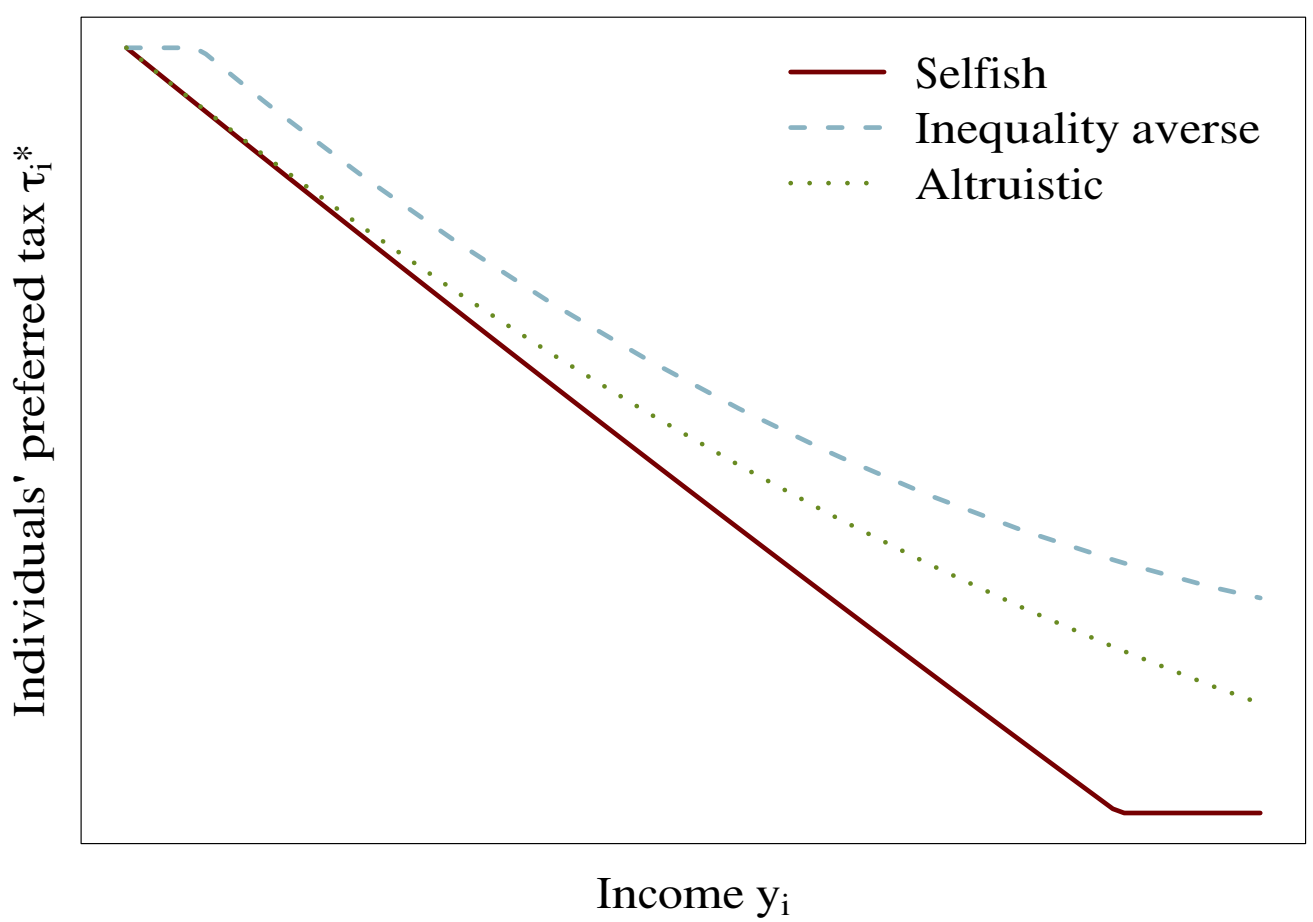

Note: The figure shows the preferred redistributive tax $\tau_{i}^{*}$ as a function of gross income for (i) selfish individuals $\left(\alpha_{i}=\beta_{i}=0\right)$, (ii) inequality averse individuals $\left(\alpha_{i}>0, \beta_{i}>0\right)$, and (iii) altruistic individuals $\left(\alpha_{i}=0, \beta_{i}>0\right)$. The figure is based on the current distribution of income in Switzerland.

\subsection{The direct empirical role of social preferences}

In this section, we link subjects' social preferences to their political support for redistribution. We illustrate the role of social preferences in Figure 6 below which depicts the average support for redistribution as a function of individuals' income for each of the three preference types. The figure displays four salient facts.

(i) At low incomes, differences in the support for redistribution across preference types are very small. Selfish individuals' support for redistribution is roughly similar to the support of individuals with social preferences.

(ii) The support for redistribution steeply declines with income for selfish individuals. 
(iii) The decline in support for redistribution with income is strongly mitigated by social preferences.

(iv) At higher incomes, individuals with social preferences show a much larger support for redistribution than selfish individuals.

Note that, qualitatively, the patterns described in (i) - (iii) are suggested by the theoretical model presented in the previous section.

Figure 6: Support for redistribution as a function of income and preference type

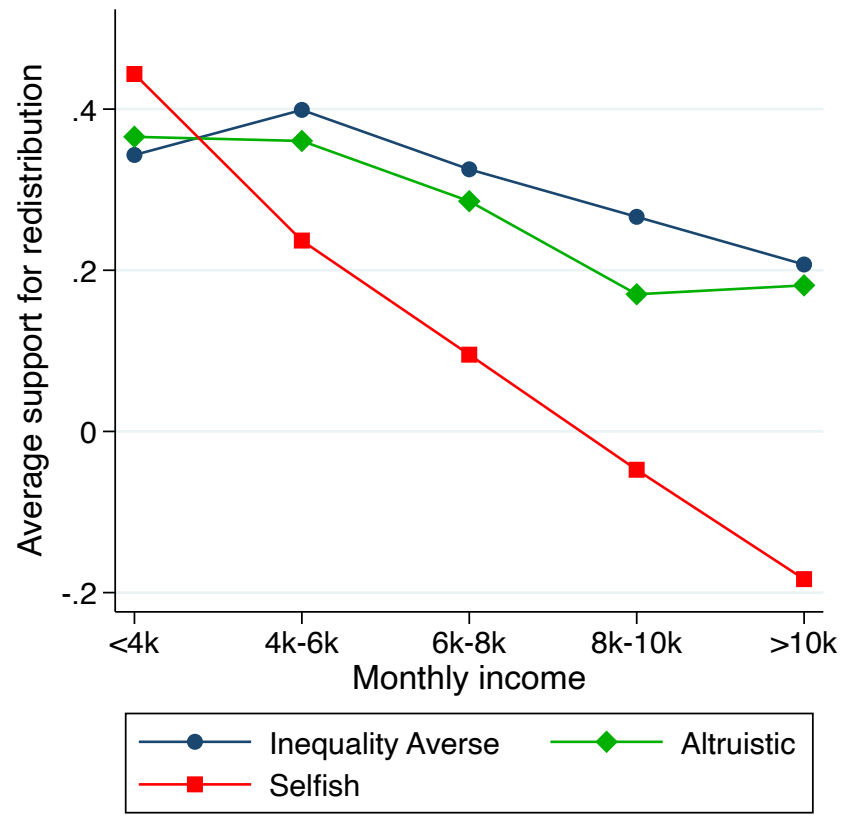

Note: The figure shows the average support for redistribution as a function of income and preference type.

To provide insights into the quantitative role of social preferences we also show their "effect size" in Table 2. This table displays the difference in the average political support for redistribution between each of the two social preference types and selfish individuals as a percentage of the standard deviation of average political support. The table reinforces the impression conveyed by Figure 6 that at higher incomes individuals with social preferences support redistribution much more than selfish individuals. For example, inequality averse individuals with monthly incomes of CHF 8'000 - 10'000 and > CHF 10'000 are between 50 and 70 percent of a standard deviation more supportive of redistribution than selfish individuals. 
Table 2: The increased demand for redistribution in individuals with social preferences relative to individuals with selfish preferences

\begin{tabular}{|c|c|c|c|c|c|}
\hline & \multicolumn{5}{|c|}{ Monthly income } \\
\cline { 2 - 6 } & $<4 k$ & $4 k-6 k$ & $6 k-8 k$ & $8 k-10 k$ & $>10 k$ \\
\hline $\begin{array}{c}\text { Inequality } \\
\text { aversion }\end{array}$ & -0.17 & 0.28 & 0.41 & 0.54 & 0.69 \\
\hline $\begin{array}{c}\text { Altruistic } \\
\text { concern }\end{array}$ & -0.14 & 0.21 & 0.33 & 0.37 & 0.63 \\
\hline
\end{tabular}

Note: The table shows how much the average political support for redistribution is higher in individuals with social preferences relative to selfish individuals as a percentage of the standard deviation of average political support for redistribution.

Figure 6 and Table 2 describe the role of social preferences without controlling for other redistributive motives discussed in the literature. To examine whether the descriptive results presented above survive these controls we regress individuals' average support for redistribution $(A S)$ on a dummy variable for being a member of the inequality averse group and another dummy for belonging to the group with altruistic concerns, and a large set of control variables. The omitted category in these regressions are individuals who are assigned to the predominantly selfish type.

We use dummy variables for the two social preference types in view of the fundamental behavioral differences between the different types and because of the relatively low individual-level variation within types (see Figure 4 above). However, we also check for potential influences of within-type heterogeneity in preferences in Appendix C.4; the results in this appendix indicate that our basic conclusions remain intact when we allow not only for between but also for within-type heterogeneity in preferences.

In all regressions, the individual-specific controls comprise age, age squared, gender, dummy variables indicating whether the respondent is married, whether French is the mother tongue, and whether a respondent did not reveal her income. We also include education dummies that indicate whether a respondent's highest educational achievement is a) compulsory school (omitted category), b) vocational training, c) high school, d) university, or e) other. The regressions also comprise occupation dummies that indicate whether the individual currently a) has a full-time job (omitted category), b) has a part-time job, c) is unemployed or d) is not in the labor force. Finally, all regressions control for canton fixed-effects. We report the results of our estimates in Table 3. The full regression results with the coefficients of all covariates is shown in Table C.1 in Appendix C.2.

In the first 4 columns of Table 3 we study the average effect of social preferences while in columns $5-7$ we examine the role of social preferences at different income levels. In column 1 , we control for canton fixed effects and the individual-level variables mentioned above. In columns $2-4$, we sequentially introduce previously identified predictors of political support for redistribution to examine whether the role of social preferences and income remains 
robust.

Column 1 shows that the two dummies for social preferences play on average a significant and quite large role in the support for redistribution. The coefficient of 0.186 for inequality aversion implies, for example, that the members of this group support redistribution more strongly than selfish types by 32 percent of a standard deviation. ${ }^{25}$ Column 1 also indicates that individuals' income is on average negatively associated with support for redistribution. The negative coefficient of -0.071 on income implies that an individual in the highest income category is, on average, 48 percent of a standard deviation less supportive of redistribution compared to an individual in the lowest income category. ${ }^{26}$

These effects also survive the inclusion of a host of controls that the literature has identified as potentially important determinants of support for redistribution. In column 2, we control for time, risk and reciprocity preferences and for two of the variables that have been identified by the previous literature as major factors in the demand for redistribution: the strength of the belief that effort matters for an individual's success in life and the strength of the belief that luck and inheritance matter for an individual's success. A comparison between columns 1 and 2 shows that these additional controls have little influence on the association between average support for redistribution and social preferences. Likewise, the income coefficient remains basically the same.

In column 3 we introduce further important controls discussed in the literature: beliefs about future upwards mobility and perceived past upwards mobility and whether individuals have been unemployed in the past. These additional controls also have basically no impact on the role played by social preferences. Finally, in column 4 we add mistrust in politicians, general trust in strangers and individuals' beliefs about the extent of inequality as covariates but again this does not change the association between social preferences and average support. ${ }^{27}$ The influence of the regressors introduced in columns 2-4 on the average support for redistribution will be discussed in more detail in a subsequent section of the paper.

Columns $1-4$ estimate the average role of social preferences across all income classes. However, the theoretical model in the previous section as well as Figure 6 and Table 2 suggest that social preferences have less scope for influencing the demand for redistribution at lower incomes because self-interested individuals at low incomes will already have a high demand

\footnotetext{
${ }^{25}$ The overall SD of average support for redistribution, indicated at the bottom of Table 3 , is 0.58 . Thus, $0.186 / 0.58=0.32$.

${ }^{26}$ Moving up one income category decreases support for redistribution by 0.071 and the highest income category is by 4 categories higher than the lowest income category such that the former's support for redistribution is $4 \mathrm{x}$ $0.071=0.284$ lower. Dividing by one standard deviation of political support (0.58) yields 48 percent.

${ }^{27}$ The regressions in Table 3 includes all the subjects, including those who did not pass one or both of the attention checks. We show in Appendix C.3 that if we exclude individuals who do not pass one or both of the attention checks the influence of social preferences and income becomes even larger. For example, if we consider only those subjects who pass both attention checks (Table C.2), inequality aversion is associated with a 40 percent of a standard deviation larger support for redistribution than the selfish individuals (while in Table 3 it is 32 percent of a SD larger). To remain on the conservative side, however, we decided to keep all subjects in our standard analyses.
} 
for redistribution. Thus, estimating the average association between social preferences and support for redistribution across incomes levels (as in columns 1-4) hides the fact that the role of social preferences is income-dependent. For this reason, we run separate regressions in columns 5 and 6 for individuals with income levels below CHF 6'000 and those with income levels equal to and above CHF 6'000, respectively. Since 49.95 percent of our sample population has incomes smaller than CHF 6'000 we refer to the two groups as below and above-median income earners. In both regressions we apply the full set of controls like in column 4.

As suggested by Figure 6, column 5 shows that the role of social preferences is much smaller and even insignificant for individuals below the median income. Column 6 shows, in contrast, that social preferences play a much larger role for above median income earners. For example, the coefficient 0.330 for inequality aversion in column 6 implies that inequality averse above-median income earners' support for redistribution is $57 \%$ of a standard deviation of political support stronger than those of selfish individuals.

Finally, in column 7 of Table 3 we consider again all individuals in the sample but interact the social preference dummies with income. This means that the coefficient on income captures only the selfish individuals' income-dependence of political support for redistribution. The coefficient of -0.133 in column 7 implies that selfish individuals display a sharp decline in support for redistribution at higher incomes: the support of those in the highest income category is $92 \%$ of a standard deviation weaker than the support of those in the lowest income category. This contrasts sharply with the much lower income dependence of political support for individuals with social preferences. For example, for inequality averse individuals the income dependence of political support is given by the sum of the coefficients for "income + income $x$ inequality aversion" which is only $-0.133+0.91=-0.42$, a coefficient which is no longer significantly different from zero $(p=0.11)$. Likewise, the income dependence of political support is roughly $50 \%$ weaker for altruistic compared to selfish individuals. ${ }^{28}$

Taken together, the results in this section indicate a significant and rather large direct role of social preferences in the support for redistribution - a conclusion that is robust when controlling for a large number of covariates and determinants of redistribution discussed by the previous literature. However, as we show in the next section, this does not yet fully exhaust the role of social preferences in the demand for redistribution.

\footnotetext{
${ }^{28}$ Note also that throughout columns $1-4$ in Table 3, the five different income classes were assigned integers from -2 to +2 such that 0 captures individuals in the income class CHF $66^{\prime} 000-8^{\prime} 000$. This labeling of income classes is inconsequential for the coefficients in regressions $1-4$ but in column 7 it implies that the coefficients of the social preference dummies capture the role of social preferences at the income class CHF $6^{\prime} 000-8^{\prime} 000$.
} 
Table 3: Social preferences and average political support for redistribution

\begin{tabular}{|c|c|c|c|c|c|c|c|}
\hline & \multicolumn{4}{|c|}{$\begin{array}{c}\text { Full } \\
\text { sample }\end{array}$} & \multirow{2}{*}{$\begin{array}{l}\begin{array}{c}\text { Below median } \\
\text { income }\end{array} \\
(5)\end{array}$} & \multirow{2}{*}{$\begin{array}{l}\begin{array}{c}\text { Above median } \\
\text { income }\end{array} \\
(6)\end{array}$} & \multirow{2}{*}{$\begin{array}{l}\begin{array}{c}\text { Full sample } \\
\text { (interactions) }\end{array} \\
(7)\end{array}$} \\
\hline & (1) & $(2)$ & (3) & (4) & & & \\
\hline Inequality averse & $\begin{array}{l}0.186^{* * *} \\
(0.063)\end{array}$ & $\begin{array}{l}0.197^{* * *} \\
(0.063)\end{array}$ & $\begin{array}{l}0.199^{* * *} \\
(0.063)\end{array}$ & $\begin{array}{l}0.186^{* * *} \\
(0.063)\end{array}$ & $\begin{array}{r}0.035 \\
(0.091)\end{array}$ & $\begin{array}{l}0.330^{* * *} \\
(0.107)\end{array}$ & $\begin{array}{l}0.210^{* * *} \\
(0.067)\end{array}$ \\
\hline Altruistic & $\begin{array}{l}0.159^{* *} \\
(0.069)\end{array}$ & $\begin{array}{l}0.154^{* *} \\
(0.069)\end{array}$ & $\begin{array}{l}0.158^{* *} \\
(0.069)\end{array}$ & $\begin{array}{l}0.149^{* *} \\
(0.069)\end{array}$ & $\begin{array}{r}0.059 \\
(0.098)\end{array}$ & $\begin{array}{l}0.249^{* *} \\
(0.116)\end{array}$ & $\begin{array}{l}0.165^{* *} \\
(0.074)\end{array}$ \\
\hline Income & $\begin{array}{l}-0.071^{* * *} \\
(0.021)\end{array}$ & $\begin{array}{l}-0.067^{* * *} \\
(0.021)\end{array}$ & $\begin{array}{l}-0.064^{* * *} \\
(0.021)\end{array}$ & $\begin{array}{l}-0.065^{* * *} \\
(0.020)\end{array}$ & $\begin{array}{r}-0.021 \\
(0.064)\end{array}$ & $\begin{array}{l}-0.126^{* * *} \\
(0.048)\end{array}$ & $\begin{array}{l}-0.133^{* * *} \\
(0.048)\end{array}$ \\
\hline Income $x$ Inequality averse & & & & & & & $\begin{array}{c}0.091^{*} \\
(0.052)\end{array}$ \\
\hline Income $\mathrm{x}$ Altruistic & & & & & & & $\begin{array}{r}0.067 \\
(0.052)\end{array}$ \\
\hline Male & $\begin{array}{r}0.008 \\
(0.048)\end{array}$ & $\begin{array}{r}-0.007 \\
(0.048)\end{array}$ & $\begin{array}{r}-0.005 \\
(0.048)\end{array}$ & $\begin{array}{r}-0.013 \\
(0.048)\end{array}$ & $\begin{array}{r}-0.018 \\
(0.065)\end{array}$ & $\begin{array}{r}-0.001 \\
(0.081)\end{array}$ & $\begin{array}{r}-0.014 \\
(0.048)\end{array}$ \\
\hline Age & $\begin{array}{c}0.019^{*} \\
(0.011)\end{array}$ & $\begin{array}{r}0.010 \\
(0.010)\end{array}$ & $\begin{array}{r}0.008 \\
(0.010)\end{array}$ & $\begin{array}{r}0.008 \\
(0.010)\end{array}$ & $\begin{array}{r}-0.005 \\
(0.015)\end{array}$ & $\begin{array}{r}0.028 \\
(0.022)\end{array}$ & $\begin{array}{r}0.008 \\
(0.010)\end{array}$ \\
\hline Effort matters for success & & $\begin{array}{l}-0.113^{* * *} \\
(0.040)\end{array}$ & $\begin{array}{l}-0.110^{* * *} \\
(0.039)\end{array}$ & $\begin{array}{l}-0.122^{* * *} \\
(0.039)\end{array}$ & $\begin{array}{l}-0.146^{* * *} \\
(0.048)\end{array}$ & $\begin{array}{r}-0.105 \\
(0.070)\end{array}$ & $\begin{array}{l}-0.117^{* * *} \\
(0.039)\end{array}$ \\
\hline Luck and inheritance matter for success & & $\begin{array}{l}0.120^{* * *} \\
(0.028)\end{array}$ & $\begin{array}{l}0.122^{* * *} \\
(0.029)\end{array}$ & $\begin{array}{l}0.111^{* * *} \\
(0.029)\end{array}$ & $\begin{array}{l}0.142^{* * *} \\
(0.043)\end{array}$ & $\begin{array}{r}0.075 \\
(0.048)\end{array}$ & $\begin{array}{l}0.109^{* * *} \\
(0.029)\end{array}$ \\
\hline Have been unemployed in past & & & $\begin{array}{r}0.062 \\
(0.046)\end{array}$ & $\begin{array}{r}0.071 \\
(0.046)\end{array}$ & $\begin{array}{r}0.056 \\
(0.065)\end{array}$ & $\begin{array}{r}0.016 \\
(0.079)\end{array}$ & $\begin{array}{r}0.072 \\
(0.046)\end{array}$ \\
\hline Beliefs about future upwards mobility & & & $\begin{array}{r}0.066 \\
(0.047)\end{array}$ & $\begin{array}{c}0.080^{*} \\
(0.047)\end{array}$ & $\begin{array}{r}-0.022 \\
(0.065)\end{array}$ & $\begin{array}{r}0.095 \\
(0.077)\end{array}$ & $\begin{array}{r}0.075 \\
(0.047)\end{array}$ \\
\hline Perceived past upwards mobility & & & $\begin{array}{r}0.033 \\
(0.042)\end{array}$ & $\begin{array}{r}0.022 \\
(0.042)\end{array}$ & $\begin{array}{r}0.067 \\
(0.062)\end{array}$ & $\begin{array}{r}-0.001 \\
(0.072)\end{array}$ & $\begin{array}{r}0.025 \\
(0.042)\end{array}$ \\
\hline Trust in strangers & & & & $\begin{array}{l}0.069^{* * *} \\
(0.022)\end{array}$ & $\begin{array}{l}0.068^{* *} \\
(0.030)\end{array}$ & $\begin{array}{c}0.069^{*} \\
(0.037)\end{array}$ & $\begin{array}{l}0.068^{* * *} \\
(0.021)\end{array}$ \\
\hline Mistrust in politicians & & & & $\begin{array}{c}0.066^{* *} \\
(0.032)\end{array}$ & $\begin{array}{l}0.087^{* *} \\
(0.043)\end{array}$ & $\begin{array}{r}0.074 \\
(0.060)\end{array}$ & $\begin{array}{l}0.066^{* *} \\
(0.033)\end{array}$ \\
\hline Perceived inequality & & & & $\begin{array}{r}0.014 \\
(0.022)\end{array}$ & $\begin{array}{r}0.001 \\
(0.028)\end{array}$ & $\begin{array}{r}0.029 \\
(0.040)\end{array}$ & $\begin{array}{r}0.013 \\
(0.022)\end{array}$ \\
\hline Constant & $\begin{array}{l}-0.539^{* *} \\
(0.252)\end{array}$ & $\begin{array}{r}-0.349 \\
(0.325)\end{array}$ & $\begin{array}{r}-0.413 \\
(0.328)\end{array}$ & $\begin{array}{r}-0.482 \\
(0.328)\end{array}$ & $\begin{array}{r}0.104 \\
(0.469)\end{array}$ & $\begin{array}{l}-1.362^{* *} \\
(0.576)\end{array}$ & $\begin{array}{r}-0.507 \\
(0.327)\end{array}$ \\
\hline Other socio-demographics & Yes & Yes & Yes & Yes & Yes & Yes & Yes \\
\hline Education & Yes & Yes & Yes & Yes & Yes & Yes & Yes \\
\hline Occupation & Yes & Yes & Yes & Yes & Yes & Yes & Yes \\
\hline Other preference measures & No & Yes & Yes & Yes & Yes & Yes & Yes \\
\hline Canton FE & Yes & Yes & Yes & Yes & Yes & Yes & Yes \\
\hline Overall SD average support for redistribution & 0.58 & 0.58 & 0.58 & 0.58 & 0.58 & 0.58 & 0.58 \\
\hline$R^{2}$ & 0.083 & 0.124 & 0.129 & 0.146 & 0.220 & 0.218 & 0.151 \\
\hline Observations & 815 & 813 & 813 & 813 & 364 & 367 & 813 \\
\hline
\end{tabular}

Notes: OLS regression. The dependent variable is the average support for redistribution. Other sociodemographics include age squared, a dummy variable indicating whether the respondent's native language is french, a dummy indicating whether the respondent is married, and a dummy indicating whether the respondent did not disclose his/her income. Education includes dummies indicating a respondent's highest educational achievement (compulsory school, vocational training, high school, university or other), and occupation includes dummies indicating whether the individual currently has a full-time job, a part-time job, is unemployed or is not in the labor force. Other preference measures include risk aversion, patience, negative and positive reciprocity. Levels of significance: ${ }^{*} p<0.1,{ }^{* *} p<0.05,{ }^{* * *} p<0.01$ 


\subsection{The indirect empirical role of social preferences}

In columns 2 - 4 of Table 3, we controlled for the strength of beliefs that "effort matters" and that "luck and inheritance matters" for an individual's success. Many previous studies (e.g. Fong, 2001; Alesina and La Ferrara, 2005; Alesina and Giuliano, 2011) have shown that these two variables have substantial explanatory power for political support for redistribution. In fact, it is probably fair to say that these two variables are among the most important predictors of support for redistribution. And our study is no exemption (see Table 3). On average, people who more strongly believe that luck and inheritance matter for success are substantially more likely to support redistribution $(p<0.01)$, while individuals who more strongly believe that effort matters for an individual's success are significantly less likely to support redistribution $(p<0.01)$. Thus, the data suggest that a strong belief that effort matters legitimizes inequality while a strong belief in the importance of luck and inheritance legitimizes redistribution.

The influence of beliefs about effort, luck and inheritance on the demand for redistribution basically rests on meritocratic fairness arguments. Meritocratic fairness arguments are based on the notion of individual responsibility and deservingness. Individuals who are themselves responsible for their income and wealth deserve to be wealthy while individuals who are just lucky are less deserving and, therefore, it appears more justified to redistribute some of their wealth. Note however, that those who care about meritocratic fairness automatically also care about other people's payoff, i.e., they are not indifferent to how much others earn and deserve to earn. In other words, they are not entirely selfish but should have some sort of social preference. In contrast, for individuals who are entirely selfish it is not clear why beliefs about effort and luck should matter for their demand for redistribution. After all, a perfectly selfish individual cares only about herself and therefore redistribution is "good" if one benefit from it and "bad" if one has to pay for it - and this holds irrespective of the source of inequality.

These arguments raise the question whether social preferences are a precondition for beliefs about effort and luck to matter for the demand for redistribution? In other words, are these beliefs only relevant for those with social preferences but not for the selfish? It is worthwhile to point out that if this is the case, then social preferences would also provide a basis for motivational forces that are opposed to redistribution because the belief that effort is key for an individual's success is typically a robust predictor of opposition to redistribution.

We address this question in Table 4 below where we show type-specific regressions with a full set of control variables, i.e., regressions analogous to equation 4 in table 3 . Table 4 reveals a striking result. The coefficients for "effort matters" and "luck and inheritance matters" are close to zero and insignificant for selfish individuals. However, for the inequality averse individuals and those with an altruistic concern the coefficients of these variables are large and significant. For example, a one unit increase in the belief that luck and inheritance matter for 
success among individuals who are inequality averse or have an altruistic concern is associated with an increase in support for redistribution by 16 percent or 28 percent of a standard deviation, respectively. Thus, it indeed appears that the existence of social preferences is a precondition for beliefs about effort, luck and inheritance to matter for redistribution while for selfish individuals these beliefs play little role. Therefore, social preferences appear to play not only a direct role but also an indirect role in the support for redistribution by providing the basis for other key factors to become relevant.

\subsection{Is inequality aversion associated with stronger support for initiatives that fo- cus on reducing the income of the rich?}

Our previous results show that both inequality aversion and an altruistic concern for the worse off play a considerable direct and indirect role in the average support for redistribution. Aggregating across various redistributive proposals has the advantage of smoothing the inevitable randomness in respondents' answers, but it has the disadvantage of hiding that the two types of other-regarding preferences may play a heterogeneous role across the different policy proposals. In fact, inequality aversion and altruistic concerns differ from each other with regard to the willingness to incur a cost to reduce the income of the rich for the sake of achieving equality.

Two of the plebiscites have a strong egalitarian flavor - the 1:20 and the fair taxes initiatives. Their initiators framed both of these initiatives in terms of rectifying the unjust distribution of income and the unfairly low taxes that rich people pay in a fair number of Swiss cantons. We asked the participants of our follow up study how they perceived these initiatives in terms of redistributive consequences. With regard to the 1:20 plebiscite, we asked whether the initiative will primarily "increase the income of those who earn little" or "decrease the income of those earning a lot" on a five-point scale. The rationale for this question is that restricting the relationship between the lowest and the highest income in a company could, in principle, lift up the salaries of the low-paid or reduce the salaries of the highly paid employees. With regard to the fair tax plebiscite, we asked whether participants believe that this initiative will primarily "reduce the taxes of those with low incomes" (i.e., benefit the people with low incomes) or "increase the taxes of those with high incomes". The vast majority of the people perceived these initiatives as decreasing the incomes of the rich and only a tiny minority perceived them as increasing the incomes of those who earn little (see also Figure C.1 in the Appendix). These initiatives might therefore be particularly appealing to individuals who are generally inequality averse, while people with an altruistic concern for the worse off may find them less appealing.

Are the above conjectures regarding the differential role of inequality aversion and altruistic concerns borne out by the data? Table 5 shows how these preferences are associated 
Table 4: Aggregate political support for redistribution (Type specific regressions)

\begin{tabular}{|c|c|c|c|}
\hline & Inequality Averse & Altruistic & Selfish \\
\hline & $(1)$ & $(2)$ & (3) \\
\hline Income & $\begin{array}{r}-0.039 \\
(0.028)\end{array}$ & $\begin{array}{r}-0.055 \\
(0.036)\end{array}$ & $\begin{array}{r}-0.121 \\
(0.076)\end{array}$ \\
\hline Male & $\begin{array}{r}0.015 \\
(0.066)\end{array}$ & $\begin{array}{r}-0.034 \\
(0.086)\end{array}$ & $\begin{array}{r}-0.073 \\
(0.192)\end{array}$ \\
\hline Age & $\begin{array}{r}0.011 \\
(0.015)\end{array}$ & $\begin{array}{r}-0.001 \\
(0.021)\end{array}$ & $\begin{array}{r}0.008 \\
(0.033)\end{array}$ \\
\hline Effort matters for success & $\begin{array}{l}-0.101^{* *} \\
(0.051)\end{array}$ & $\begin{array}{l}-0.254^{* * *} \\
(0.080)\end{array}$ & $\begin{array}{r}-0.025 \\
(0.134)\end{array}$ \\
\hline Luck and inheritance matter for success & $\begin{array}{c}0.096^{* *} \\
(0.040)\end{array}$ & $\begin{array}{c}0.165^{* * *} \\
(0.060)\end{array}$ & $\begin{array}{r}0.032 \\
(0.119)\end{array}$ \\
\hline Have been unemployed in past & $\begin{array}{r}0.078 \\
(0.060)\end{array}$ & $\begin{array}{r}0.056 \\
(0.096)\end{array}$ & $\begin{array}{r}0.116 \\
(0.183)\end{array}$ \\
\hline Beliefs about future upwards mobility & $\begin{array}{r}0.075 \\
(0.065)\end{array}$ & $\begin{array}{l}0.236^{* * *} \\
(0.088)\end{array}$ & $\begin{array}{r}0.032 \\
(0.180)\end{array}$ \\
\hline Perceived past upwards mobility & $\begin{array}{r}-0.077 \\
(0.058)\end{array}$ & $\begin{array}{r}-0.043 \\
(0.078)\end{array}$ & $\begin{array}{r}0.197 \\
(0.175)\end{array}$ \\
\hline Trust in strangers & $\begin{array}{c}0.065^{* *} \\
(0.029)\end{array}$ & $\begin{array}{c}0.088^{* *} \\
(0.039)\end{array}$ & $\begin{array}{c}0.118^{*} \\
(0.066)\end{array}$ \\
\hline Mistrust in politicians & $\begin{array}{c}0.084^{* *} \\
(0.042)\end{array}$ & $\begin{array}{r}0.037 \\
(0.066)\end{array}$ & $\begin{array}{r}0.046 \\
(0.091)\end{array}$ \\
\hline Perceived inequality & $\begin{array}{r}0.021 \\
(0.027)\end{array}$ & $\begin{array}{r}-0.025 \\
(0.047)\end{array}$ & $\begin{array}{r}-0.030 \\
(0.070)\end{array}$ \\
\hline Constant & $\begin{array}{r}-0.233 \\
(0.427)\end{array}$ & $\begin{array}{r}0.332 \\
(0.593)\end{array}$ & $\begin{array}{r}-0.588 \\
(1.196)\end{array}$ \\
\hline Other socio-demographics & Yes & Yes & Yes \\
\hline Education & Yes & Yes & Yes \\
\hline Occupation & Yes & Yes & Yes \\
\hline Other preference measures & Yes & Yes & Yes \\
\hline Canton FE & Yes & Yes & Yes \\
\hline$R^{2}$ & 0.192 & 0.265 & 0.378 \\
\hline Observations & 413 & 279 & 121 \\
\hline
\end{tabular}

Notes: OLS regression. The dependent variable is the average support for redistribution. Other socio-demographics include age squared, a dummy variable indicating whether the respondent's native language is french, a dummy indicating whether the respondent is married, and a dummy indicating whether the respondent did not disclose his/her income. Education includes dummies indicating a respondent's highest educational achievement (compulsory school, vocational training, high school, university or other), and occupation includes dummies indicating whether the individual currently has a full-time job, a part-time job, is unemployed or is not in the labor force. Other preference measures include risk aversion, patience, negative and positive reciprocity. Levels of significance: ${ }^{*} p<0.1,{ }^{* *} p<0.05,{ }^{* * *} p<0.01$ 
Table 5: The role of social preferences in "reduce the income of the rich" and "help the worse off" initiatives

\begin{tabular}{|c|c|c|c|c|}
\hline & \multicolumn{2}{|c|}{ Reduce income of the rich } & \multicolumn{2}{|c|}{ Help the poor } \\
\hline & (1) & (2) & (3) & (4) \\
\hline Inequality averse & $\begin{array}{l}0.241^{* * *} \\
(0.078)\end{array}$ & $\begin{array}{l}0.268^{* * *} \\
(0.081)\end{array}$ & $\begin{array}{r}0.130 \\
(0.080)\end{array}$ & $\begin{array}{c}0.153^{*} \\
(0.084)\end{array}$ \\
\hline Altruistic & $\begin{array}{r}0.126 \\
(0.085)\end{array}$ & $\begin{array}{c}0.153^{*} \\
(0.089)\end{array}$ & $\begin{array}{c}0.171^{* *} \\
(0.084)\end{array}$ & $\begin{array}{c}0.177^{* *} \\
(0.089)\end{array}$ \\
\hline Income & $\begin{array}{l}-0.088^{* * *} \\
(0.023)\end{array}$ & $\begin{array}{l}-0.179^{* * *} \\
(0.057)\end{array}$ & $\begin{array}{r}-0.043 \\
(0.026)\end{array}$ & $\begin{array}{r}-0.086 \\
(0.057)\end{array}$ \\
\hline Income $x$ Inequality averse & & $\begin{array}{c}0.108^{*} \\
(0.062)\end{array}$ & & $\begin{array}{r}0.075 \\
(0.062)\end{array}$ \\
\hline Income $\mathrm{x}$ Altruistic & & $\begin{array}{c}0.109^{*} \\
(0.063)\end{array}$ & & $\begin{array}{r}0.025 \\
(0.061)\end{array}$ \\
\hline Male & $\begin{array}{r}0.023 \\
(0.056)\end{array}$ & $\begin{array}{r}0.022 \\
(0.055)\end{array}$ & $\begin{array}{r}-0.050 \\
(0.063)\end{array}$ & $\begin{array}{r}-0.050 \\
(0.063)\end{array}$ \\
\hline Age & $\begin{array}{r}0.004 \\
(0.012)\end{array}$ & $\begin{array}{r}0.004 \\
(0.012)\end{array}$ & $\begin{array}{r}0.012 \\
(0.013)\end{array}$ & $\begin{array}{r}0.012 \\
(0.013)\end{array}$ \\
\hline Effort matters for success & $\begin{array}{c}-0.087^{*} \\
(0.049)\end{array}$ & $\begin{array}{c}-0.082^{*} \\
(0.049)\end{array}$ & $\begin{array}{l}-0.157^{* * *} \\
(0.048)\end{array}$ & $\begin{array}{l}-0.153^{* * *} \\
(0.048)\end{array}$ \\
\hline Luck and inheritance matter for success & $\begin{array}{l}0.121^{* * *} \\
(0.034)\end{array}$ & $\begin{array}{l}0.117^{* * *} \\
(0.034)\end{array}$ & $\begin{array}{l}0.102^{* * *} \\
(0.035)\end{array}$ & $\begin{array}{l}0.101^{* * *} \\
(0.035)\end{array}$ \\
\hline Have been unemployed in past & $\begin{array}{r}0.072 \\
(0.055)\end{array}$ & $\begin{array}{r}0.071 \\
(0.055)\end{array}$ & $\begin{array}{r}0.071 \\
(0.058)\end{array}$ & $\begin{array}{r}0.073 \\
(0.058)\end{array}$ \\
\hline Beliefs about future upwards mobility & $\begin{array}{c}0.112^{* *} \\
(0.056)\end{array}$ & $\begin{array}{c}0.107^{*} \\
(0.056)\end{array}$ & $\begin{array}{r}0.048 \\
(0.060)\end{array}$ & $\begin{array}{r}0.044 \\
(0.060)\end{array}$ \\
\hline Perceived past upwards mobility & $\begin{array}{r}0.062 \\
(0.051)\end{array}$ & $\begin{array}{r}0.065 \\
(0.051)\end{array}$ & $\begin{array}{r}-0.017 \\
(0.054)\end{array}$ & $\begin{array}{r}-0.015 \\
(0.054)\end{array}$ \\
\hline Trust in strangers & $\begin{array}{l}0.081^{* * *} \\
(0.026)\end{array}$ & $\begin{array}{l}0.079^{* * *} \\
(0.026)\end{array}$ & $\begin{array}{c}0.057^{* *} \\
(0.027)\end{array}$ & $\begin{array}{c}0.056^{* *} \\
(0.027)\end{array}$ \\
\hline Mistrust in politicians & $\begin{array}{r}0.049 \\
(0.036)\end{array}$ & $\begin{array}{r}0.048 \\
(0.036)\end{array}$ & $\begin{array}{c}0.083^{*} \\
(0.042)\end{array}$ & $\begin{array}{c}0.085^{* *} \\
(0.042)\end{array}$ \\
\hline Perceived inequality & $\begin{array}{r}0.013 \\
(0.025)\end{array}$ & $\begin{array}{r}0.012 \\
(0.025)\end{array}$ & $\begin{array}{r}0.016 \\
(0.029)\end{array}$ & $\begin{array}{r}0.014 \\
(0.029)\end{array}$ \\
\hline Constant & $\begin{array}{r}-0.585 \\
(0.392)\end{array}$ & $\begin{array}{r}-0.604 \\
(0.389)\end{array}$ & $\begin{array}{r}-0.380 \\
(0.404)\end{array}$ & $\begin{array}{r}-0.409 \\
(0.404)\end{array}$ \\
\hline Other socio-demographics & Yes & Yes & Yes & Yes \\
\hline Education & Yes & Yes & Yes & Yes \\
\hline Occupation & Yes & Yes & Yes & Yes \\
\hline Other preference measures & Yes & Yes & Yes & Yes \\
\hline Canton FE & Yes & Yes & Yes & Yes \\
\hline Overall SD average support for redistribution & 0.58 & 0.58 & 0.58 & 0.58 \\
\hline H0: Inequality Averse = Altruistic & 0.038 & 0.050 & 0.498 & 0.697 \\
\hline$R^{2}$ & 0.141 & 0.146 & 0.112 & 0.114 \\
\hline Observations & 813 & 813 & 813 & 813 \\
\hline
\end{tabular}

Notes: OLS regression. The dependent variable is the average support for redistribution. Other sociodemographics include age squared, a dummy variable indicating whether the respondent's native language is french, a dummy indicating whether the respondent is married, and a dummy indicating whether the respondent did not disclose his/her income. Education includes dummies indicating a respondent's highest educational achievement (compulsory school, vocational training, high school, university or other), and occupation includes dummies indicating whether the individual currently has a full-time job, a part-time job, is unemployed or is not in the labor force. Other preference measures include risk aversion, patience, negative and positive reciprocity. Levels of significance: ${ }^{*} p<0.1,{ }^{* *} p<0.05,{ }^{* * *} p<0.01$ 
with the overall support for the "reduce the income of the rich" initiatives while controlling for the full set of control variables. Column 1 of Table 5 shows that inequality aversion is highly significant $(p<0.01)$ and almost twice as important as altruistic concerns in these referenda while the coefficient for altruistic concerns is not significant. The difference between the coefficient on inequality aversion and altruistic concerns is also significant ( $p=0.038$ ). The coefficients of inequality aversion and altruistic concerns in column 2, which shows the results when income is interacted with social preferences, confirms this picture. "The coefficient on inequality aversion is much larger and significantly different $(p=0.05)$ from the one on altruistic concerns.

Which role do the two different social preference types play in the unconditional basic income and the minimum wage initiative? These two initiatives were strongly motivated by improving the situation of workers and families with low incomes and the public discussions were focused on the situation of low-income people and how to improve their economic situation. We also asked the participants of our follow up study how they perceived these initiatives in terms of redistributive consequences. As Figure C.1 in the Appendix shows, the large majority perceived them as being primarily about improving the incomes of those who are less well off. Therefore, we term them "help the worse off" initiatives. For these initiatives there is no reason for the two different social preference types to display different support for redistribution as both types showed a willingness to sacrifice own income for the sake of those who are worse off in the money allocation task.

Column 3 and 4 present the regression results for these initiatives. The regression coefficients indicate that both inequality aversion and altruistic concerns appear to have a similar role in "help the worse off" referenda - an impression that is confirmed by the fact that the coefficients clearly are not significantly different from each other ( $p=0.498$ in column 3 and $p=0.697$ in column 4). Taken together, the results thus suggest that inequality aversion plays a more prominent role than altruistic concerns whenever income reductions for the rich are the primary focus while in "help the worse off" referenda the two types of social preferences appear to be roughly equally important.

\subsection{Specificity, heterogeneity and robustness checks}

\section{Do social preferences predict support for a placebo initiative?}

Ideally, the preferences for distributional outcomes measured in our money allocation task are specifically relevant for (re)distributive policies. They should, however, not be a general proxy for political activism or other political concerns. Therefore, they should not predict support for a proposal that is unrelated to redistribution. In our follow-up survey, we measured political support for a "placebo" initiative that is unrelated to redistribution. This initiative intends to constrain the influence of political parties on the selection of federal judges by proposing 
that they be selected using a random draw from a pool of skilled applicants. Support for this initiative was elicited in the same way as support for the four redistributive proposals from the main survey. Because this proposal is unrelated to issues of income distribution, it helps us assess the specificity of social preferences, i.e., whether they specifically capture concerns about distributional - but not other - issues. Table C.8 in the Appendix provides compelling evidence that, no matter the specification, social preferences have no predictive power in the support for the placebo initiative. Similarly, income, which played an important role in predicting support for redistribution, does also not explain political support for the placebo initiative.

\section{Does within-type heterogeneity matter?}

Our method of clustering individuals into types has the advantage of parsimony and of directing the attention to the key qualitative differences across preference types. We show in section 3 and in Appendix B.4 that digging deeper into the heterogeneity of preferences does not yield additional insights into the existence of basic preference types. Instead, this merely shows that the roughly $35 \%$ of individuals belonging to the altruistic type can be partitioned into a moderate $(14 \%)$ and a strong altruistic type (21\%). This heterogeneity is also visible in Figure 3 that shows the existence of a small cluster of individuals whose median choice on positively sloped budget lines maximizes their own payoff $(z=1)$ while on negatively sloped budget lines they indicate an altruistic concern $(z<1)$ but this concern is not strong enough to induce them to fully equalize the payoffs $(z>0.5)$ on these budget lines.

Thus, there appears to be some variation among altruistic individuals that might be relevant for the political support for redistribution. We address this issue in two ways. First, we allow for four types that include the moderate and the strong altruistic type when applying the regression models of Table 3. Second, we explicitly measure individual behavioral variation within each of the three basic preference types by measuring individuals' deviations from the average type, and relate these deviations to their support for redistribution.

We show how the existence of moderate and strong altruistic types affects the average support for redistribution in Table C.4 in the Appendix. The table replicates Table 3 of the main text, but allows for four preference types. Table C.4 shows that the role of inequality aversion for redistributive support remains unaffected while the role of altruistic concerns becomes more differentiated: individuals with strong altruistic preferences are significantly more willing to support redistribution relative to the selfish types. The individuals belonging to the moderately altruistic type are showing, however, a smaller and insignificant increase in the support for redistribution relative to the selfish type. All other coefficients in the regressions remain basically unchanged when we allow for four types. Thus, the overall conclusions derived on the basis of three preference types remain valid, except that the minority of mod- 
erately altruistic individuals are not significantly different from the predominantly selfish type.

To acquire further insights into the relevance of within type heterogeneity we also constructed an individual-level measure of behavioral deviations from a type's typical behavior in the money allocation task. These individual deviation measures enable us to control for individual-level heterogeneity by interacting them with the social preference dummies. The regression results are displayed in the Appendix in Table C.5. They show that within-type variation matters neither for the selfish type nor for the inequality averse type but they provide again a slightly more nuanced picture for the altruistic type. Individuals with a stronger altruistic concern tend to be more supportive of redistribution than those with a more moderate altruistic concern. An increase in the within-type individual-level measure of altruistic concerns by one standard deviation increases support for redistribution by seven percent of a standard deviation in average political support.

\section{Other-regarding preferences and political identity}

In principle, other-regarding preferences may be a determinant of the degree to which people feel affiliated with political parties. For example, people with a strong egalitarian preference may feel a stronger affiliation with the Democratic Party in the US, as this party is typically more in favor of reducing inequality. In fact, Fisman et al. (2017) report that individuals who put more weight on equality relative to efficiency were more likely to vote for Obama in 2012 and Dawes et al. (2012) report that individuals who are more generous in a single dictator game tend to be more left leaning.

However, political affiliation or the degree to which individuals perceive themselves on a left-right political scale may also be an independent factor in the support for redistribution. For this reason, we collected individuals' self-reported position on the political spectrum on a scale from 1 to 10 and included this measure as a control variable in the regressions reported in Appendix C.4. We were particularly interested in the question whether the substantial role of other- regarding preferences remains robust to controlling for political attitude.

Table C.6 shows the results of our basic specification with three different preference types and Table C.7 displays the results with four types (i.e., with strongly and moderately altruistic types). In both sets of regressions, political attitude plays a significant role: individuals who are more left leaning are more likely to support redistribution. Inequality aversion still plays a substantial and significant role when we control for political attitude - regardless of whether we allow for three or four preference types. The picture is, however, somewhat more differentiated for the altruistic types. While the dummy for altruistic preferences becomes much smaller and insignificant when we control for political attitude in the specification with three preference types (Table C.6), individuals with a strong altruistic concern (i.e., allowing 
for four types) are still significantly more likely $(p<0.1)$ to vote for redistribution (Table C.7) relative to selfish individuals even when we control for political attitude. Thus, taken together, other-regarding preferences in the form of inequality aversion remains a robust and significant predictor of support for redistribution while the influence of altruistic concerns becomes somewhat weaker when we control for political attitude. ${ }^{29}$

\section{The role of other factors in the support for redistribution}

\subsection{The role of beliefs about mobility}

The theoretical and empirical literature (e.g Fong, 2001; Benabou and Ok, 2001; Alesina and Giuliano, 2011) has pointed out that future income and well-being may affect the demand for redistribution. Individuals who expect to have higher incomes in the future have a selfish reason to vote against redistribution because it affects their future income negatively. In addition, past experiences of increases in income and well-being may also matter. However, the results shown in columns $3-7$ of Table 3 indicate that in our sample beliefs about future increases in income and well-being do not predict average political support for redistribution. Furthermore, the respondents' perception of past upwards mobility also does not significantly predict their demand for redistribution. ${ }^{30}$

\subsection{The role of other economic preferences, general trust and mistrust in politi- cians}

Previous studies have suggested that risk aversion might play a role in individuals' demand for redistribution (e.g. Gärtner et al., 2017). Since redistributive policies also function as an insurance against negative income shocks, more risk averse individuals may be more supportive of these policies. We therefore added individual-specific controls for risk aversion in Columns 2 to 7 of Table 3. We also included measures of (positive and negative) reciprocity and impatience, and in Columns 4 to 7 we also controlled for general trust in strangers as well as mistrust in politicians. While we did not show the coefficients for these measures in Table 3, we present them in Table C.1 in the Appendix. The coefficients of risk aversion, impatience, positive and negative reciprocity are close to zero and not significantly associated with support for redistribution.

General trust and mistrust in politicians significantly predict support for redistribution, however. A one one-unit increase in general trust in other people (on a scale from 1-4) leads to

\footnotetext{
${ }^{29}$ Interestingly, the belief in the role of effort for an individual's success also becomes much smaller and insignificant when we control for political attitude while the belief in the role of luck and inheritance remains a robust predictor of support for redistribution.

${ }^{30}$ Table 3 uses dummies that capture the above-median expectation for upwards mobility and the above median perception of past upwards mobility. If we use a more continuous measure of these covariates, the associated coefficients remain small and insignificant.
} 
an increase in support for redistribution of about 12 percent of a standard deviation $(p<0.01)$. Also, individuals who more strongly believe that Swiss politicians work to enrich themselves display stronger support for redistribution: a one-point increase of mistrust in politicians (on a scale from 1-4) increases support for redistribution by 11 percent of a standard deviation - also a quite substantial effect. In view of previous results (Kuziemko et al., 2015), this finding might seem surprising, but it makes sense in the Swiss institutional context because direct democracy constrains - and is also widely perceived to do so - politicians' space for non-transparent back-office deals. These constraints may well be perceived as limiting "hidden costs" of redistribution and favor support in national plebiscites that force "corrupt politicians" to implement redistributive proposals. Interestingly, this positive role of mistrust in politicians for the demand for redistribution is mainly present in the inequality averse individuals and completely absent in the selfish individuals (see Table 4).

\subsection{The role of other socio-demographic factors}

Several studies have investigated the role of socio-demographic factors in explaining support for redistribution (Alesina and Giuliano, 2011). Particular attention has been paid to gender, race, religion, unemployment, and history of unemployment, amongst others. These variables are, however, insignificant in our sample. Occupational variables (such as part-time work or current unemployment) as well as educational variables are also not significantly associated with support for redistribution except for respondents who are currently not in the labor force: they are weakly more likely to support redistribution $(p<0.1)$. In our sample, these individuals are mainly retired $(50 \%$ of the individuals indicating that they are not in the labor force are aged 60 or more). The remaining socio-demographic variables such as age or marriage status are all insignificant.

\section{Summary and conclusions}

Rising inequality in advanced capitalist countries has again put the issue of redistribution on the political agenda. In this paper, we examined the role of other-regarding preferences for individuals' support for redistribution. To answer this question, we took advantage of Swiss direct democracy where four strongly redistributive proposals were put to vote in national plebiscites during the last 10 years. This enabled us to measure people's support for policy proposals that were actually put to vote instead of using more general hypothetical questions related to demand for redistribution.

Previous research suggests that other-regarding preferences may have multiple facets, i.e., individuals may not simply differ in their degree of "other-regardingness", but they may have qualitatively distinct, i.e., fundamentally different, types of other-regarding preferences. 
People may, in particular, not only differ by their degree of altruism or by their degree of envy towards others but the differences also concern whether they have altruistic or envious components in their preferences. Therefore, the first task is to identify which fundamentally distinct social preference types exist in the broader population and to assess their quantitative importance.

For this purpose, we designed an experiment that enables us to identify the existence and quantitative relevance of distinct clusters of social preferences in a broad sample of the Swiss population. Applying a novel Bayesian nonparametric clustering method to these experimental data, we uncover three fundamentally distinct social preference types with a clear behavioral interpretation: inequality averse individuals (comprising roughly $50 \%$ of our population), individuals with altruistic concerns for the worse off (35\%) and predominantly selfish individuals $(15 \%)$.

We incorporate social preferences into a Meltzer-Richards model of the demand for redistribution and show that their influence is likely to be income dependent as there is more scope for richer individuals' social preferences to play a role. We document a quantitatively large association between social preferences and political support for redistribution with an effect size that is in a similar ballpark as the average association between income and support for redistribution. This relationship between social preferences and support for redistribution is robust to controlling for a large number of additional covariates which include socio-demographic variables and other important determinants of demand for redistribution previously discussed in the literature. The link between social preferences and support for redistribution is strongly dependent on income, with a particularly strong role for social preferences at above-median incomes. As a consequence, while for selfish individuals rising incomes are associated with a steeply declining support for redistribution, a rise in the income of inequality averse individuals is no longer significantly associated with support for redistribution.

Our analysis also shows that social preferences help us to better understand the role of two previously identified key factors in the support for redistribution - the strength of individuals' belief that effort matters for success and their belief that luck and inheritance matters. We document that these beliefs play a quantitively large and highly significant role for individuals with social preferences, but a very small and insignificant role for selfish individuals. Thus, social preferences do not only play a direct role in the demand for redistribution, but they also have an indirect role as they appear to be a precondition for meritocratic fairness arguments to become relevant.

Finally, we show that knowledge about the distribution of individuals to fundamentally distinct social preference types - such as inequality aversion versus altruism - can be useful in better understanding who is likely to support specific redistributive policies. While inequality averse individuals display strong support for policies that primarily aim at reducing the 
incomes of the rich, altruistic individuals are considerably less supportive of such policies.

Altogether, these results highlight the importance of taking other-regarding preferences - and the variety thereof - into account when studying the political economy of demand for redistribution. We therefore believe that future research in this domain would benefit from routinely integrating other-regarding preferences like inequality aversion and altruistic concerns to study such questions. 


\section{References}

Alesina, Alberto and Eliana La Ferrara, "Preferences for redistribution in the land of opportunities," Journal of Public Economics, 2005, 89 (5-6), 897-931.

- and George-Marios Angeletos, "Fairness and redistribution," American Economic Review, 2005, 95 (4), 960-980.

- and Paola Giuliano, "Preferences for redistribution," in "Handbook of social economics," Vol. 1, Elsevier, 2011, pp. 93-131.

_ , Stefanie Stantcheva, and Edoardo Teso, "Intergenerational mobility and preferences for redistribution," American Economic Review, 2018, 108 (2), 521-54.

Alger, Ingela and Jörgen W Weibull, "Homo moralis-preference evolution under incomplete information and assortative matching," Econometrica, 2013, 81 (6), 2269-2302.

Almås, Ingvild, Alexander W Cappelen, and Bertil Tungodden, "Cutthroat capitalism versus cuddly socialism: Are Americans more meritocratic and efficiency-seeking than Scandinavians?," NHH Dept. of Economics Discussion Paper, 2019.

Andreoni, James and John Miller, "Giving according to GARP: An experimental test of the consistency of preferences for altruism," Econometrica, 2002, 70 (2), 737-753.

Ashok, Vivekinan, Ilyana Kuziemko, and Ebonya Washington, "Support for redistribution in an age of rising inequality: New stylized facts and some tentative explanations," Brookings Papers on Economic Activity, 2015, pp. 400-434.

Bellemare, Charles, Sabine Kröger, and Arthur Van Soest, "Measuring inequity aversion in a heterogeneous population using experimental decisions and subjective probabilities," Econometrica, 2008, 76 (4), 815-839.

- , - , and Arthur van Soest, "Preferences, intentions, and expectation violations: A largescale experiment with a representative subject pool," Journal of Economic Behavior E Organization, 2011, 78 (3), 349-365.

Benabou, Roland and Efe A Ok, "Social mobility and the demand for redistribution: the POUM hypothesis," The Quarterly Journal of Economics, 2001, 116 (2), 447-487.

_ and Jean Tirole, "Belief in a just world and redistributive politics," The Quarterly Journal of Economics, 2006, 121 (2), 699-746.

Berinsky, Adam J, Michele F Margolis, and Michael W Sances, "Separating the shirkers from the workers? Making sure respondents pay attention on self-administered surveys," American Journal of Political Science, 2014, 58 (3), 739-753. 
Bolton, Gary E and Axel Ockenfels, “ERC: A theory of equity, reciprocity, and competition," American Economic Review, 2000, 90 (1), 166-193.

Bruhin, Adrian, Ernst Fehr, and Daniel Schunk, "The many faces of human sociality: Uncovering the distribution and stability of social preferences," Journal of the European Economic Association, 2018.

_, Helga Fehr-Duda, and Thomas Epper, "Risk and rationality: Uncovering heterogeneity in probability distortion," Econometrica, 2010, 78 (4), 1375-1412.

Burghart, Daniel R, Thomas Epper, and Ernst Fehr, "The uncertainty triangle-Uncovering heterogeneity in attitudes towards uncertainty," Journal of Risk and Uncertainty, 2020, 60 (2), 125-156.

Buschena, David and David Zilberman, "Generalized expected utility, heteroscedastic error, and path dependence in risky choice," Journal of Risk and Uncertainty, 2000, 20 (1), 67-88.

Cappelen, Alexander W, Astri Drange Hole, Erik Ø Sørensen, and Bertil Tungodden, "The Pluralism of Fairness Ideals: An Experimental Approach," The American Economic Review, 2007, 97 (3), 818-827.

Charness, Gary and Matthew Rabin, "Understanding social preferences with simple tests," Quarterly Journal of Economics, 2002, pp. 817-869.

Comiter, Marcus Zachary, Miriam Cha, HT Kung, and Surat Teerapittayanon, "Lambda means clustering: automatic parameter search and distributed computing implementation," 2016.

Cruces, Guillermo, Ricardo Perez-Truglia, and Martin Tetaz, "Biased perceptions of income distribution and preferences for redistribution: Evidence from a survey experiment," Journal of Public Economics, 2013, 98, 100-112.

Dawes, Christopher, Magnus Johannesson, Erik Lindqvist, Peter John Loewen, Robert Ostling, Marianne Bonde, and Frida Priks, “Generosity and political preferences," 2012.

Dawes, Christopher T, James H Fowler, Tim Johnson, Richard McElreath, and Oleg Smirnov, “Egalitarian motives in humans," Nature, 2007, 446 (7137), 794.

DellaVigna, Stefano, John A List, and Ulrike Malmendier, "Testing for altruism and social pressure in charitable giving," The Quarterly Journal of Economics, 2012, 127 (1), 1-56.

Dhami, Sanjit and Ali al Nowaihi, "Redistributive policies with heterogeneous social preferences of voters," European Economic Review, 2010, 54 (6), 743-759. 
Dimick, Matthew, David Rueda, and Daniel Stegmueller, "The altruistic rich? Inequality and other-regarding preferences for redistribution," Quarterly Journal of Political Science, 2016, 11 (4), 385-439.

Durante, Ruben, Louis Putterman, and Joël Van der Weele, "Preferences for redistribution and perception of fairness: An experimental study," Journal of the European Economic Association, 2014, 12 (4), 1059-1086.

Engelmann, Dirk and Martin Strobel, "Inequality aversion, efficiency, and maximin preferences in simple distribution experiments," American Economic Review, 2004, 94 (4), 857-869.

Epper, Thomas, Ernst Fehr, and Julien Senn, "Other-regarding preferences and redistributive politics," University of Zurich, Department of Economics, Working Paper, 2020, (339).

Falk, Armin, Anke Becker, Thomas J Dohmen, David Huffman, and Uwe Sunde, "The preference survey module: A validated instrument for measuring risk, time, and social preferences," 2016.

Fehr, Ernst and K Schmidt, “A Theory Of Fairness, Competition, and Cooperation," Quarterly Journal of Economics, January 1999, 114 (3), 817-868.

Fisman, Raymond, Pamela Jakiela, and Shachar Kariv, “Distributional preferences and political behavior," Journal of Public Economics, 2017, 155, 1-10.

_ , _ , _, and Daniel Markovits, "The distributional preferences of an elite," Science, 2015, 349 (6254), aab0096.

_ , Shachar Kariv, and Daniel Markovits, "Individual preferences for giving," American Economic Review, 2007, 97 (5), 1858-1876.

Fong, Christina, "Social preferences, self-interest, and the demand for redistribution," Journal of Public Economics, 2001, 82 (2), 225-246.

Fong, Christina M, "Prospective mobility, fairness, and the demand for redistribution," Fairness, and the Demand for Redistribution (February 26, 2006), 2006.

Forgy, Edward W, "Cluster analysis of multivariate data: efficiency versus interpretability of classifications," biometrics, 1965, 21, 768-769.

Funk, Patricia, "Social incentives and voter turnout: evidence from the Swiss mail ballot system," Journal of the European Economic Association, 2010, 8 (5), 1077-1103.

- and Christina Gathmann, "Does direct democracy reduce the size of government? New evidence from historical data, 1890-2000," The Economic Journal, 2011, 121 (557), 1252-1280. 
Gärtner, Manja, Johanna Mollerstrom, and David Seim, "Individual risk preferences and the demand for redistribution," Journal of Public Economics, 2017, 153, 49-55.

Giuliano, Paola and Antonio Spilimbergo, "Growing up in a Recession," Review of Economic Studies, 2013, 81 (2), 787-817.

Karadja, Mounir, Johanna Mollerstrom, and David Seim, "Richer (and holier) than thou? The effect of relative income improvements on demand for redistribution," Review of Economics and Statistics, 2017, 99 (2), 201-212.

Kerschbamer, Rudolf and D Müller, "Social preferences and political attitudes: An online experiment on a large heterogeneous sample," Journal of Public Economics, 2020, 182.

Kulis, Brian and Michael I. Jordan, "Revisiting k-means: New Algorithms via Bayesian Nonparametrics," Proceedings of the 29th International Conference of Machine Learning, 2012.

Kuziemko, Ilyana, Michael I Norton, Emmanuel Saez, and Stefanie Stantcheva, "How elastic are preferences for redistribution? Evidence from randomized survey experiments," American Economic Review, 2015, 105 (4), 1478-1508.

Lloyd, SP, "Least squares quantization in PCM," Bell Telephone Laboratories Papers, 1957.

Lloyd, Stuart, "Least squares quantization in PCM," IEEE transactions on information theory, 1982, 28 (2), 129-137.

Meltzer, Allan H and Scott F Richard, "A rational theory of the size of government," Journal of Political Economy, 1981, 89 (5), 914-927.

Piketty, Thomas, "Social mobility and redistributive politics," The Quarterly Journal of Economics, 1995, 110 (3), 551-584.

Stevenson, Betsey and Justin Wolfers, "Subjective well-being and income: Is there any evidence of satiation?," American Economic Review, 2013, 103 (3), 598-604.

Tyran, Jean-Robert and Rupert Sausgruber, "A little fairness may induce a lot of redistribution in democracy," European Economic Review, 2006, 50 (2), 469-485. 


\section{Appendix}

\section{Table of Contents}

A Background information on experimental tasks, survey measures and population sample $\quad 48$

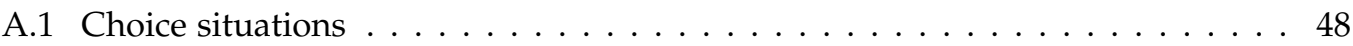

A.2 Demographic characteristics of sample population . . . . . . . . . . 50

A.3 Details on the measurement of political support for redistribution and covari-

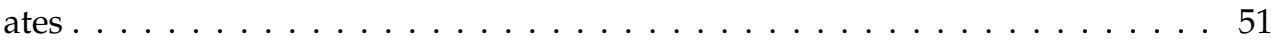

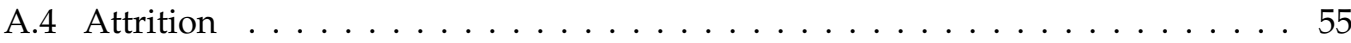

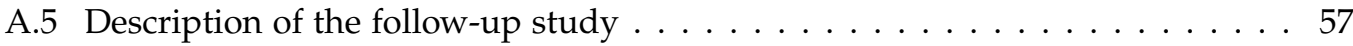

A.6 Distribution of individuals' average political support for redistribution . . . . 60

B Material related to the identification of the type distribution of other-regarding $\begin{array}{ll}\text { preferences } & 61\end{array}$

B.1 Details on the method for identifying the distribution of preference types . . 61

B.2 Validating the behavioral types with the south bundle $\ldots \ldots \ldots \ldots$. . . . 64

B.3 Validating the behavioral types with the north bundle $\ldots \ldots \ldots$. . . 67

B.4 Allowing for four and more types . . . . . . . . . . . . . . . . 69

C Material related to the role of other-regarding preferences in the political support $\begin{array}{ll}\text { for redistribution } & 70\end{array}$

C.1 Derivation of individuals' demand for redistribution in terms of their preferred tax rate . . . . . . . . . . . . . . . . . . . . . . . . 70

C.2 The association between other-regarding preferences and political support for redistribution with all covariates explicitly shown . . . . . . . . . 72

C.3 Assessing the role of other-regarding preferences when restricting the subjects pool to individuals who successfully passed either both or at least one attention check . . . . . . . . . . . . . . . . . . . . . . 73

C.4 The role of other-regarding preferences under within-type heterogeneity . . . . 76

C.5 The role of other-regarding preferences when controlling for political attitudes 80

C.6 The role of other-regarding preferences in the placebo referendum . . . . . 83

C.7 The perceived redistributive consequences of different initiatives . . . . . . . . 84 


\section{A Background information on experimental tasks, survey measures and population sample}

\section{A.1 Choice situations}

Figure A.1: Budget lines

(a) All Budgets

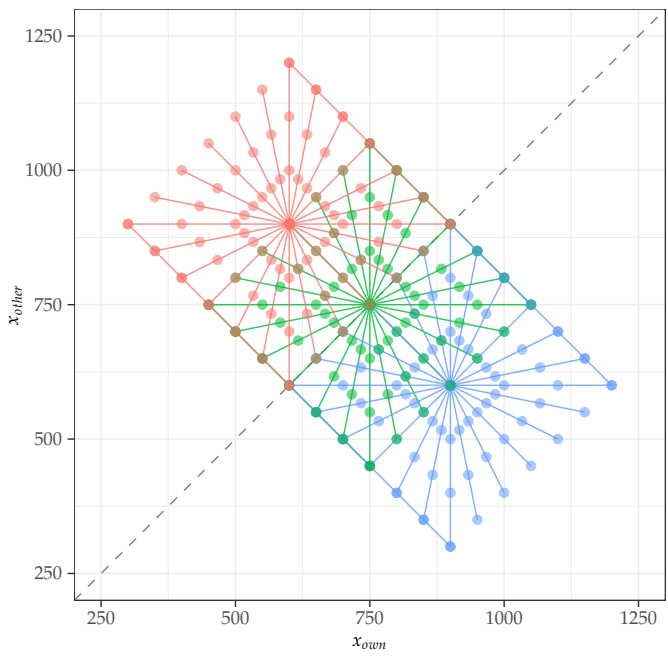

(c) North Budgets

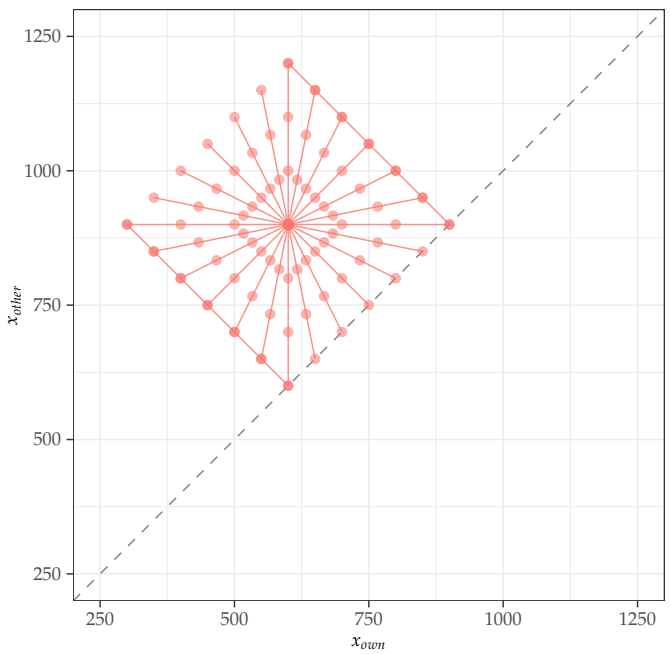

(b) Center Budgets

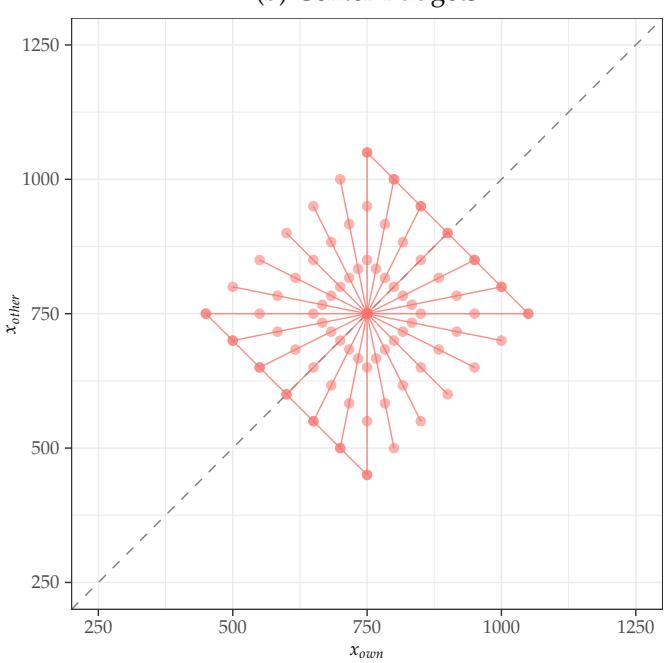

(d) South Budgets

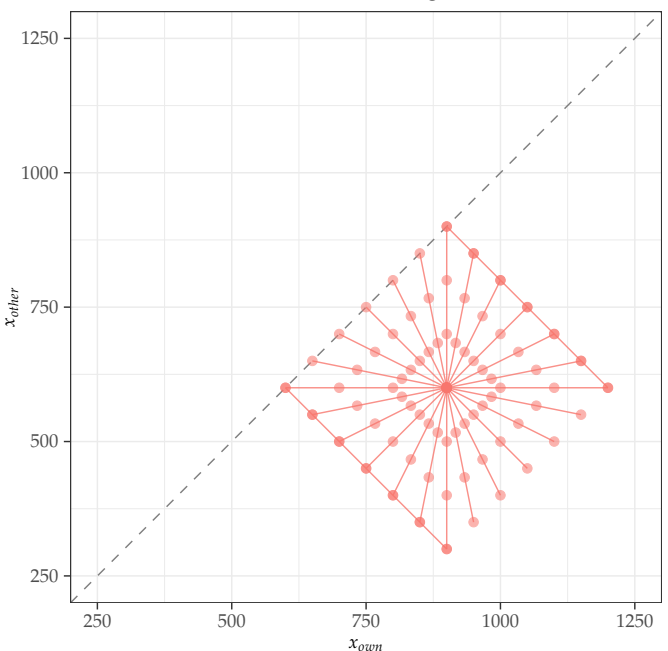

The following Table A.1 shows the choice situations in the money allocation task that were used to identify subjects' other-regarding preferences. We used the 14 choice situations in the center bundle to identify the different types of other-regarding preferences and the distribution of individuals across types while the 14 choices in the north bundle and the 14 choices in the south bundle were used to validate the behavioral interpretation of the type distribution identified in the center bundle.

The meaning of the list of variables in Table A.1 is as follows:

- 'choiceId': the unique identifier for each choice situation. 
- (own 1 , other 1 ): represents the payoff combination at the lower end of the budget line (in points).

- (own2, other2): represents the payoff combination at the upper end of the budget line (in points).

- 'bundle': indicates to which bundle the respective choice situation belongs to.

- 'slope': the slope of the budget line in the "own payoff - other payoff" space.

Table A.1: Choice situations in the money allocation task

\begin{tabular}{|c|c|c|c|c|c|c|}
\hline choiceId & own1 & own2 & other1 & other2 & bundle & slope \\
\hline 1 & 450 & 750 & 750 & 450 & center & -1.0 \\
\hline 2 & 750 & 1050 & 1050 & 750 & center & -1.0 \\
\hline 3 & 450 & 1050 & 750 & 750 & center & 0.0 \\
\hline 4 & 500 & 1000 & 800 & 700 & center & -0.2 \\
\hline 5 & 550 & 950 & 850 & 650 & center & -0.5 \\
\hline 6 & 600 & 900 & 900 & 600 & center & -1.0 \\
\hline 7 & 650 & 850 & 950 & 550 & center & -2.0 \\
\hline 8 & 700 & 800 & 1000 & 500 & center & -5.0 \\
\hline 9 & 750 & 750 & 1050 & 450 & center & -Inf \\
\hline 10 & 700 & 800 & 500 & 1000 & center & 5.0 \\
\hline 11 & 650 & 850 & 550 & 950 & center & 2.0 \\
\hline 12 & 600 & 900 & 600 & 900 & center & 1.0 \\
\hline 13 & 550 & 950 & 650 & 850 & center & 0.5 \\
\hline 14 & 500 & 1000 & 700 & 800 & center & 0.2 \\
\hline 15 & 300 & 600 & 900 & 600 & north & -1.0 \\
\hline 16 & 600 & 900 & 1200 & 900 & north & -1.0 \\
\hline 17 & 300 & 900 & 900 & 900 & north & 0.0 \\
\hline 18 & 350 & 850 & 950 & 850 & north & -0.2 \\
\hline 19 & 400 & 800 & 1000 & 800 & north & -0.5 \\
\hline 20 & 450 & 750 & 1050 & 750 & north & -1.0 \\
\hline 21 & 500 & 700 & 1100 & 700 & north & -2.0 \\
\hline 22 & 550 & 650 & 1150 & 650 & north & -5.0 \\
\hline 23 & 600 & 600 & 1200 & 600 & north & -Inf \\
\hline 24 & 550 & 650 & 650 & 1150 & north & 5.0 \\
\hline 25 & 500 & 700 & 700 & 1100 & north & 2.0 \\
\hline 26 & 450 & 750 & 750 & 1050 & north & 1.0 \\
\hline 27 & 400 & 800 & 800 & 1000 & north & 0.5 \\
\hline 28 & 350 & 850 & 850 & 950 & north & 0.2 \\
\hline 29 & 600 & 900 & 600 & 300 & south & -1.0 \\
\hline 30 & 900 & 1200 & 900 & 600 & south & -1.0 \\
\hline 31 & 600 & 1200 & 600 & 600 & south & 0.0 \\
\hline 32 & 650 & 1150 & 650 & 550 & south & -0.2 \\
\hline 33 & 700 & 1100 & 700 & 500 & south & -0.5 \\
\hline 34 & 750 & 1050 & 750 & 450 & south & -1.0 \\
\hline 35 & 800 & 1000 & 800 & 400 & south & -2.0 \\
\hline 36 & 850 & 950 & 850 & 350 & south & -5.0 \\
\hline 37 & 900 & 900 & 900 & 300 & south & -Inf \\
\hline 38 & 850 & 950 & 350 & 850 & south & 5.0 \\
\hline 39 & 800 & 1000 & 400 & 800 & south & 2.0 \\
\hline 40 & 750 & 1050 & 450 & 750 & south & 1.0 \\
\hline 41 & 700 & 1100 & 500 & 700 & south & 0.5 \\
\hline 42 & 650 & 1150 & 550 & 650 & south & 0.2 \\
\hline
\end{tabular}




\section{A.2 Demographic characteristics of sample population}

In Table A.2 below we describe the main socio-demographic characteristics of the population in our main study and the follow-up study. In Table A.3, we compare our sample population from the main study with the overall population of Swiss voters for key demographic characteristics.

Table A.2: Socio-demographic characteristics of sample population

\begin{tabular}{|c|c|c|c|c|}
\hline & \multicolumn{2}{|c|}{ Main study } & \multicolumn{2}{|c|}{ Follow-up } \\
\hline & Mean & S.D. & Mean & S.D. \\
\hline Male & 0.55 & 0.50 & 0.56 & 0.50 \\
\hline $18-25$ у.о. & 0.11 & 0.31 & 0.10 & 0.29 \\
\hline $26-35$ y.o. & 0.13 & 0.34 & 0.12 & 0.32 \\
\hline $36-45$ у.о. & 0.25 & 0.43 & 0.24 & 0.43 \\
\hline $46-55$ у.о. & 0.22 & 0.42 & 0.23 & 0.42 \\
\hline $56-65$ у.о. & 0.16 & 0.37 & 0.18 & 0.39 \\
\hline$>65$ y.o. & 0.12 & 0.33 & 0.13 & 0.34 \\
\hline Have been unemployed in past & 0.32 & 0.47 & 0.34 & 0.47 \\
\hline Married & 0.53 & 0.50 & 0.53 & 0.50 \\
\hline Occupation: Full-time job & 0.44 & 0.50 & 0.43 & 0.50 \\
\hline Occupation: Part-time job & 0.27 & 0.45 & 0.26 & 0.44 \\
\hline Occupation: Currently unemployed & 0.03 & 0.17 & 0.03 & 0.17 \\
\hline Occupation: Not in labor force & 0.26 & 0.44 & 0.28 & 0.45 \\
\hline Education: Obligatory school (up to 14 y.o.) & 0.04 & 0.20 & 0.04 & 0.19 \\
\hline Education: Vocational training & 0.37 & 0.48 & 0.38 & 0.49 \\
\hline Education: High school & 0.13 & 0.34 & 0.15 & 0.36 \\
\hline Education: University & 0.34 & 0.47 & 0.33 & 0.47 \\
\hline Education: Other & 0.11 & 0.31 & 0.10 & 0.30 \\
\hline Income bracket: $\leq \mathrm{CHF} 4000$ & 0.25 & 0.43 & 0.24 & 0.43 \\
\hline Income bracket: CHF 4001-6000 & 0.20 & 0.40 & 0.21 & 0.41 \\
\hline Income bracket: CHF 6001-8000 & 0.20 & 0.40 & 0.20 & 0.40 \\
\hline Income bracket: CHF 8001-10000 & 0.14 & 0.35 & 0.14 & 0.35 \\
\hline Income bracket: CHF 10001-15000 & 0.09 & 0.29 & 0.09 & 0.29 \\
\hline Income bracket: > CHF 15000 & 0.02 & 0.13 & 0.02 & 0.13 \\
\hline Income bracket: NA & 0.10 & 0.30 & 0.10 & 0.29 \\
\hline French speaking & 0.23 & 0.42 & 0.20 & 0.40 \\
\hline Observations & 815 & & 573 & \\
\hline
\end{tabular}


Table A.3: Comparison of sample population with the population of Swiss voters

\begin{tabular}{lcc}
\hline \hline & Sample & Population \\
\hline Age & 46.48 & 51.08 \\
Male & 0.55 & 0.48 \\
& & \\
Education : Obligatory school & 0.04 & 0.11 \\
Education : Vocational training & 0.37 & 0.42 \\
Education : High school & 0.13 & 0.10 \\
Education : University & 0.34 & 0.35 \\
Education : Other & 0.10 & - \\
& & \\
& 0.25 & 0.28 \\
Income bracket : $\leq$ CHF 4000 & 0.20 & 0.26 \\
Income bracket : CHF 4001-6000 & 0.20 & 0.22 \\
Income bracket : CHF 6001-8000 & 0.14 & 0.12 \\
Income bracket : CHF 8001-10000 & 0.09 & 0.09 \\
Income bracket : CHF 10001-15000 & 0.09 & 0.03 \\
Income bracket : $\geq$ CHF 15000 & 0.02 & - \\
Income bracket : NA & 0.10 & \\
& & \\
Unemployed & 0.03 & 0.03 \\
\hline \hline $\bar{l}$ & & \\
\hline
\end{tabular}

\section{A.3 Details on the measurement of political support for redistribution and co- variates}

\section{Political support for redistribution}

Fair taxes initiative Suppose that a vote takes place next weekend. The goal of this vote is to subject higher incomes to a minimum level of taxation. In particular, the law provides the following two points :

- Municipalities and cantons are required to tax any income exceeding CHF 250,000 per year at a minimum rate of $22 \%$. This means that, above the threshold of CHF 250 '000, each additionally earned franc is taxed at a rate of at least $22 \%$. For example, if a person has an income of CHF 300,000, then that person is taxed on the first CHF 250,000 at a rate that can be freely set by the cantons and the municipalities, but the remaining CHF 50,000 must taxed at a rate of at least $22 \%$.

- Municipalities and cantons are obliged to tax any wealth exceeding CHF 2'000'000 at a rate of at least $0.5 \%$. This means that, above the threshold of CHF 2 million, every 
additional Swiss franc of wealth is taxed at a rate of at least $0.5 \%$ (i.e. at 0.5 centimes per franc). For example, if a person owns a fortune of CHF 4 million, the first CHF 2 million will be taxed at a rate that can be freely set by the cantons and the municipalities, but must be taxed at a rate of at least $0.5 \%$ on the remaining CHF 2 millions

Would you support or reject this initiative? [Answer categories: Support, Rather support, Don't Know, Rather reject, Reject]

Minimum wage initiative Suppose that a vote on the introduction of a minimum wage takes place next weekend. This initiative provides that each worker must be paid at least this minimum wage. A company can pay its employees more than the minimum wage, but no employee should be paid less than the minimum wage. The minimum wage proposed by this initiative is 16.50 Francs per hour, i.e. around 3'000 Francs per month (before taxes) for a full-time employee. Would you support or reject this initiative? [Answer categories: Support, Rather support, Don't Know, Rather reject, Reject]

1:20 initiative Suppose that a vote on an initiative aimed at limiting pay inequality within companies takes place next weekend. This initiative provides that the highest salary paid by a company may not exceed twenty times (20 times) the lowest salary paid by that same company. Would you support or reject this initiative? [Answer categories: Support, Rather support, Don't Know, Rather reject, Reject]

Unconditional basic income (UBI) initiative Suppose that a vote on the introduction of an unconditional basic income takes place next weekend. If this initiative is accepted, the federal government automatically pays the basic income to every citizen in Switzerland. Would you support or reject this initiative? [Answer categories: Support, Rather support, Don't Know, Rather reject, Reject]

\section{Socio-demographics, other preference measures and trust}

We collected information on age, gender, marital status, the highest achieved level of education (compulsory school, vocational training, high school, university, other), occupational status (full time job, part-time job, currently unemployed, not in the labor force), whether the individual has experienced unemployment in the past, municipality of residence and income. In addition, we measured risk preferences, patience, negative reciprocity and positive reciprocity as well as subjects general trust in people with the experimentally validated survey questions of Falk et al. (2016). We also elicited individuals' beliefs that are potentially relevant for their voting behavior such as their beliefs about the chances to improve one's life over the next few years ('mobility'), perceived inequality, trust in politicians and the sources of individuals' success in life. We describe the details of these measures below. 


\section{Effort matters for individual success}

Individuals are asked the following questions (taken from Fong 2001 and Gallup): "Below are several reasons why some people get ahead and succeed in life and others do not. Using a 1-5 scale, where 1 means not at all important and 5 means extremely important, please tell us how important each of the following items is as a reason for a person's success. You can choose any number from one to five. How important is:

- Willingness to take risks (risk)

- Hard work and initiative (hardwork)

- Have the right education and training (education)

We then create an index denoted as "Effort matters for success" which is given by (risk+hardwork+ education)/3.

\section{Luck and inheritance matter for individual success}

Individuals are asked the following questions (taken from Fong 2001 and Gallup): "Below are several reasons why some people get ahead and succeed in life and others do not. Using a 1-5 scale, where 1 means not at all important and 5 means extremely important, please tell us how important ieach of the following items is as a reason for a person's success. You can choose any number from one to five. How important is:

- Inheritance (inheritance)

- Luck, being at the right time at the right place (luck)

We then create an index denoted as "Luck and inheritance matter for success" which is given by (inheritance + luck) $/ 2$.

\section{Mistrust in politicians}

What do you think about the following statement? "Swiss politicians work to enrich themselves and the lobbies that they support instead of working for the benefit of the majority of the citizens. [1. Disagree, 2. Rather disagree, 3. Rather agree, 4. Agree]

\section{Mobility}

Two mobility measures are constructed from the following three questions (based on Fong 2001 and Gallup): 
1. Think of a picture of a ladder. Suppose we say that the top of the ladder represents the best possible life for you, and the bottom represents the worst possible life for you. If the top step is 10 and the bottom step is 0 , on which step of the ladder do you feel you personally stand at the present time? [current step]

2. On which step would you say you stood five years ago? [past step]

3. Just your best guess, on which step do you think you will stand in the future, say about five years from now? [future step]

Based on the answers we create the following measures:

- Beliefs about future mobility = future step - current step. This variable ranges from -10 to +10 .

- Perceived past mobility $=$ current step - past step. This variable ranges from -10 to +10 .

We then construct two dummies for [expected future/perceived past] mobility:

- 'Beliefs about future upwards mobility' $=1$ if beliefs about future mobility $>0$

- 'Perceived past upwards mobility' $=1$ if perceived past mobility $>0$.

\section{Perceived inequality}

Subjects are presented the following text: "For the next questions, we define income as the total salary received by an individual for his work. We refer to gross income as the income received by an individual prior to any tax, pension and social insurance deduction. The total income of a country corresponds to the sum of incomes that all households in the country receive. Consider the two most extreme examples:

- In a country with nearly the maximum level of income inequality, the $10 \%$ of the households with the highest earnings receive $100 \%$ of the total income. The remaining $90 \%$ of the households receive $0 \%$ of the total income.

- In a country with nearly the minimum level of income inequality, the $10 \%$ of the households with the highest earnings receive $10 \%$ of the total income. The $10 \%$ of the households with the lowest earnings receive $10 \%$ of the total income

What do you think is the share of the total income that the $10 \%$ of households with the highest income receives in Switzerland? [perceived top share] The 10\% of households with the highest income earn the following share of the total income: ...

What do you think is the share of the total income that the $10 \%$ of households with the lowest income receives in Switzerland? [perceived bottom share] The 10\% of households 
with the lowest income earn the following share of the total income: ...

We then construct the following index of perceived inequality (and we standardize it): Perceived Inequality $=($ Perceived top share - Perceived bottom share $) / 100$.

\section{A.4 Attrition}

The Table A.4 below shows that participation in wave 2 is orthogonal to social preferences, and to most of the covariates. 
Table A.4: Attrition

\begin{tabular}{|c|c|c|}
\hline & \multicolumn{2}{|c|}{ Participated in follow up } \\
\hline & (1) & (2) \\
\hline Inequality averse & $\begin{array}{r}-0.047 \\
(0.046)\end{array}$ & $\begin{array}{r}-0.017 \\
(0.050)\end{array}$ \\
\hline Altruistic & $\begin{array}{r}-0.025 \\
(0.048)\end{array}$ & $\begin{array}{r}-0.003 \\
(0.052)\end{array}$ \\
\hline Income: above-median & & $\begin{array}{r}-0.028 \\
(0.041)\end{array}$ \\
\hline Male & & $\begin{array}{r}0.043 \\
(0.039)\end{array}$ \\
\hline Age & & $\begin{array}{l}0.028^{* * *} \\
(0.008)\end{array}$ \\
\hline Age squared & & $\begin{array}{l}-0.000^{\text {*** }} \\
(0.000)\end{array}$ \\
\hline French speaking & & $\begin{array}{l}-0.116 \\
(0.176)\end{array}$ \\
\hline Married & & $\begin{array}{r}-0.023 \\
(0.038)\end{array}$ \\
\hline Risk aversion & & $\begin{array}{r}0.015 \\
(0.017)\end{array}$ \\
\hline Positive reciprocity 1 (return favor) & & $\begin{array}{r}-0.008 \\
(0.016)\end{array}$ \\
\hline Positive reciprocity 2 (reciprocate help) & & $\begin{array}{r}0.009 \\
(0.017)\end{array}$ \\
\hline Negative reciprocity 1 (revenge injustice) & & $\begin{array}{r}0.013 \\
(0.021)\end{array}$ \\
\hline Negative reciprocity 2 (put in bad position) & & $\begin{array}{r}0.013 \\
(0.022)\end{array}$ \\
\hline Impatience & & $\begin{array}{r}-0.006 \\
(0.017)\end{array}$ \\
\hline Income: Undisclosed & & $\begin{array}{l}-0.066 \\
(0.060)\end{array}$ \\
\hline Education: Vocational training & & $\begin{array}{c}-0.114 \\
(0.087)\end{array}$ \\
\hline Education: High school & & $\begin{array}{r}0.024 \\
(0.092)\end{array}$ \\
\hline Education: University & & $\begin{array}{l}-0.139 \\
(0.089)\end{array}$ \\
\hline Education: Other & & $\begin{array}{l}-0.209^{* *} \\
(0.101)\end{array}$ \\
\hline Occupation: Part-time job & & $\begin{array}{r}0.002 \\
(0.045)\end{array}$ \\
\hline Occupation: Currently unemployed & & $\begin{array}{r}0.068 \\
(0.101)\end{array}$ \\
\hline Occupation: Not in labor force & & $\begin{array}{r}0.070 \\
(0.049)\end{array}$ \\
\hline Beliefs about future upwards mobility & & $\begin{array}{l}-0.004 \\
(0.039)\end{array}$ \\
\hline Perceived past upwards mobility & & $\begin{array}{l}-0.044 \\
(0.034)\end{array}$ \\
\hline Perceived inequality & & $\begin{array}{r}0.021 \\
(0.018)\end{array}$ \\
\hline Mistrust in politicians & & $\begin{array}{r}0.010 \\
(0.024)\end{array}$ \\
\hline Effort matters for success & & $\begin{array}{r}0.030 \\
(0.031)\end{array}$ \\
\hline Luck and inheritance matter for success & & $\begin{array}{r}0.012 \\
(0.023)\end{array}$ \\
\hline Constant & $\begin{array}{l}0.736^{* * *} \\
(0.040)\end{array}$ & $\begin{array}{r}-0.069 \\
(0.256)\end{array}$ \\
\hline Canton FE & No & Yes \\
\hline $\begin{array}{l}R^{2} \\
\text { Observations }\end{array}$ & $\begin{array}{r}0.001 \\
815\end{array}$ & $\begin{array}{r}0.079 \\
813\end{array}$ \\
\hline
\end{tabular}

Notes: OLS regression. The dependent variable measures participation in wave 2 . It is a dummy which equals 1 if the subject did participate in the follow-up study, and zero otherwise. Levels of significarife: ${ }^{*} p<0.1,{ }^{* *} p<0.05,{ }^{* * *} p<$ 


\section{A.5 Description of the follow-up study}

Two years after the main study, we contacted the same respondents again in order to collect several additional pieces of information: a) their beliefs about the perceived distributional consequences of the different initiatives, $b$ ) their willingness to donate real money to civic organizations that either support or oppose redistribution, and c) their support for a placebo initiative that is unrelated to redistribution. In addition, we also asked a question about past and expected future income mobility (see footnote 19 in the main text). In this section, we describe how these different measures were elicited.

\section{Perceived distributional consequences of the different initiatives}

We measured respondent's beliefs about the primary goals and implications of the four initiatives by asking respondents to indicate whether a particular initiative would primarily affect those with low income, or those with high income. For each initiative, we described the proposal in a similar way as in the main study. For example, we elicited respondents beliefs about the perceived distributional consequences of the 1:20 initiative as follows:

"Suppose that a vote on an initiative aimed at limiting pay inequality within companies takes place next weekend. This initiative demands that the highest salary paid by a company must not exceed twenty times (20 times) the lowest salary paid by that same company. In your opinion, what will be the primary effect of this initiative? Do you think this initiative will primarily increase the income of the employees who earn only little, or do you think that it will primarily reduce the income of the employees at the top of companies who earn a lot? Please indicate your answer on a scale from 1 to 5, where 1 means you think this initiative will "primarily increase the income of those who earn only little" and 5 means you think this initiative will "primarily reduce the income of those earning very much"."

Beliefs about the perceived distributional consequences of the other initiatives were elicited in a similar way.

\section{Donation tasks}

We measured support for and opposition to redistribution using three donation tasks with real monetary stakes using the following questions.

"In recent years, international competition, globalization and technological progress have put the issue of inequality in our societies at the center of the discussion. Some people feel that inequality has increased too much while others do not see this as a big problem. There are, in principle, several ways to reduce inequality in a country. 
- One way to reduce inequality is to improve the economic situation of those who have low incomes. This can be achieved, for example, through raising wages (via a minimum wage initiative that ensures that companies cannot pay wages below the minimum) or by giving those with low incomes financial support (for example by offering them Child allowances, discounted health insurance premiums, discounted kindergarten tariffs or subsidies to cover their housing costs).

- Another way to reduce inequality is by reducing the income or the wealth of the rich. This can be achieved, for example, by ensuring that they pay more taxes or by putting a limit on the maximum salary or bonus they can be paid.

Various political and social groups are currently supporting different measures intended to reduce inequality in Switzerland. Some groups are primarily concerned with helping those with lower incomes, while others primarily support measures that would ensure that the rich contribute more to tax revenues or that very high salaries and bonuses are limited. Examples of such groups include non-profit organizations (e.g. CARITAS), unions and political parties. In contrast, other political and social groups want lower taxes for people with high incomes, and do not want to limit the salaries and the bonuses of top managers.

In the following task, your will have to take three decisions. Each decision will involve splitting CHF 20 (that you receive from us) between yourself and a political or a civic group. In each of the three decisions, the policies supported by the group will be different. At the end of the study, the computer will randomly select one of your decisions and implement it. This means that one of these groups will really receive your donation, and you will keep the remaining money. The money that you decide to keep for yourself will be transferred directly to your bank account by LINK at the end of this survey. The university of Zurich will transfer your donation to the civic group shortly after the end of the survey."

For each decision, we then told subjects that they received CHF 20 from us, and asked them to decide how to spend these 20 francs. For example, we asked:

"For this decision we give you CHF 20. You can use this money to help a group or an organization that supports political measures that increase the contribution of the rich to tax revenue. The money that you do not give to such a civic group can be kept by yourself. How much of the CHF 20 do you want to give to a group or an organization that supports political measures that improve the tax and income situation of those with lower incomes? Please indicate how much you want to donate. You can choose any number between 0 and 20."

The two other donation decisions were formulated in a similar way. 


\section{Support for a placebo initiative}

We elicited support for the placebo initiative using the exact same methodology as for the four redistributive initiatives from the main study. Specifically, we asked:

"Suppose that next weekend a referendum on the designation of federal judges takes place. The initiative wants to constrain the influence of political parties on the selection of federal judges by proposing that they are elected via a random draw. A specialized commission makes sure that the candidates that can be drawn as judges have the appropriate professional and personal skills to be eligible to become a federal judge. The members of the specialized commission are elected by the Federal Council and can serve for a maximum of 12 years. Would you accept this initiative, or would you reject it?"

The answer categories are: Accept, Rather accept, I don't know, Rather reject, Reject. 


\section{A.6 Distribution of individuals' average political support for redistribution}

Figure A.2: Distribution of individuals' average political support for redistribution

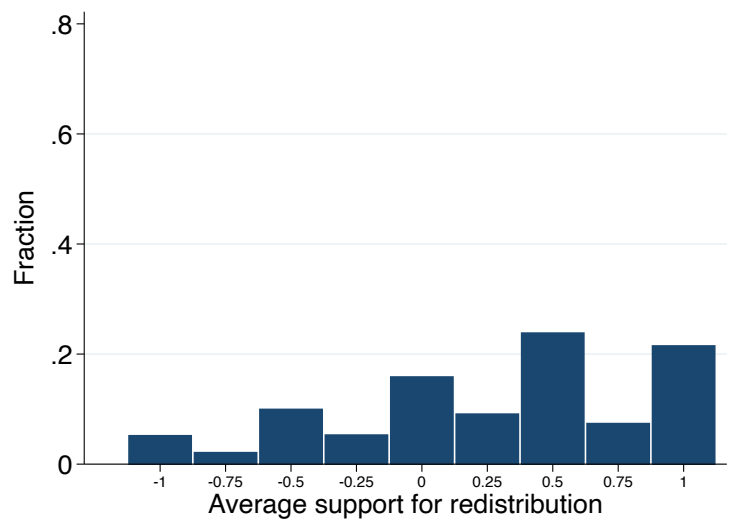




\section{B Material related to the identification of the type distribution of other-regarding preferences}

\section{B.1 Details on the method for identifying the distribution of preference types}

This appendix provides more details about the clustering algorithm used to identify the preference types and their distribution in the population. We first briefly compare the Dirichlet process (DP) means algorithm used in this paper to the widely used $k$-means algorithm. We then outline our implementation of the DP means approach.

The $k$-means algorithm (originally proposed by Lloyd $(1957,1982)$ and Forgy $(1965)$ can be derived as a limiting case of the Expectation-Maximization (EM) algorithm for a Gaussian mixture (see, e.g., Bruhin et al. (2010) and Burghart et al. (2020) for applications of the EM algorithm). More specifically, when letting the posterior probabilities of being assigned to one of $k$ clusters (where the number of clusters is fixed ex-ante) converge towards certainty or impossibility we obtain a hard clustering corresponding to $k$-means clustering. The same can be done in a Bayesian setting: Starting with a Gibbs sampler of the Dirichlet process (DP) mixture one obtains DP-means as an asymptotic result (see Kulis and Jordan, 2012). There are several key differences between the $k$-means and the DP-means algorithm. First, for $k$-means the statistician has to ex-ante define the number of clusters she wants the observations to be assigned to. For DP-means, she has to set only a cluster penalty parameter that we denote by $\lambda$ and that penalizes the addition of new clusters. Once $\lambda$ is fixed, the number of clusters emerge endogenously.

The number of types that emerge depends, in principle, on the chosen penalization parameter $\lambda$. There are methods to endogenize this parameter ${ }^{31}$, but one convention is to choose the number of types for which larger variations of the penalization parameter leaves the number of types unchanged. Instead, we examine what happens if we change $\lambda$ and thus potentially change the number of types. First, we ask whether fundamentally new types emerge or whether existing preference types simply split into subgroups of an already existing type. If no fundamentally new behavioral types emerge, there is little additional insight generated by a lower level of $\lambda$, and thus little reason to reduce $\lambda$. Second, we ask whether clearly important behavioral types of non-negligible size (e.g., the predominantly selfish type) are hidden when we increase the penalization parameter.

In Appendix B.4 below we show that no fundamentally new types emerge if we lower the penalization parameter $\lambda$ in the DP algorithm. Rather, when $\lambda$ is chosen low enough so that a four-type distribution emerges, the altruistic type divides into two subtypes - a moderate and a strong altruistic type that differ in their degree of other-regardingness: the strong type

\footnotetext{
${ }^{31}$ For extensions of the DP-means algorithm that endogenize the penalization parameter, see e.g. Comiter et al. (2016). Such extensions imply, however, much more complexity, and do not provide further insights for our application.
} 
displays a higher willingness to pay to increase the other individual's payoff when bestowing an altruistic benefit to the other individual is expensive (see Appendix B.4). If we further lower the penalization parameter so that 5 or 6 types emerge, the fifth and the sixth types comprise only a few individuals $(1.4 \%$ and $0.1 \%$ of the population, respectively), implying again that no fundamentally new types emerge.

What would happen if we chose a high enough penalization parameter $\lambda$ in the DP algorithm such that the number of types is restricted to two? In that case, the predominantly selfish type vanishes and is merged with the other two types: roughly $60 \%$ of them are submerged to the inequity averse type and $40 \%$ to the altruistic type. However, in view of the fundamentally different behavioral patterns the predominantly selfish type displays across all three budget bundles, a two-type distribution would clearly not do justice to the actually existing fundamental heterogeneity of preferences in our population.

Our implementation of the algorithm is based on an iterative refinement. We first span an $m$-dimensional space, with $\mathrm{m}$ denoting the number of budget lines used for the clustering algorithm. As we use the center bundle for clustering $m=14$. Consequently, each individual's choices are represented by a single point in the 14-dimensional space. We then ask how subjects populate this space. Specifically, we are interested in the number of clusters (i.e. types) that emerge and individuals' assignment to clusters. A cluster is characterized by the set of the individuals assigned to the cluster and the associated mean vector of observations (the "centroid"), which - in our case - represents the mean (cluster- representative) behavior of all individuals in $m$-dimensional space that belong to the cluster.

We initialize the algorithm with a single centroid specified as the global mean vector. At this stage, all data points are assigned to this single centroid. We then refine by iterating over the following two steps: First, we sequentially go through the list of data points in $m$-dimensional space (i.e. subjects), and check for each subject whether any of the squared Euclidean distances to the centroid exceeds the cluster penalty parameter $\lambda$. If this is the case, we open up a new cluster with the actual data point's location vector as the centroid. Otherwise, we assign the data point to its nearest cluster. Second, we collect the subjects assigned to the same clusters and update the centroids by computing the mean vector for each cluster. These two steps are repeated until convergence is reached, i.e. until there is no change in subjects' assignments. ${ }^{32}$

As Kulis and Jordan (2012) demonstrate, this iterative procedure is equivalent to minimizing the objective

$$
\min _{\left\{g_{c}\right\}_{c=1}^{k}} \sum_{c=1}^{k} \sum_{x \in g_{c}}\left\|\boldsymbol{x}-\boldsymbol{\mu}_{c}\right\|^{2}+\lambda k,
$$

\footnotetext{
${ }^{32}$ In principle, the clustering could depend on the ordering of observations in the data. To check whether this poses an issue in our case, we shuffled the observations and re-ran the clustering for each permutation. Our conclusions and, in particular, the types that emerge from our data and the individuals' assignments are not affected by this exercise.
} 
where $x$ denotes the vector of observations, $\mu$ the vector of centroids, and $g$ the cluster partitioning of $x$. It is straightforward to see that this objective is equivalent to the $k$-means objective except for the additional penalty term $\lambda k$. 


\section{B.2 Validating the behavioral types with the south bundle}

In this appendix ${ }^{33}$, we examine whether the preferences identified with the help of the center bundle are consistent with subjects' behavior in the south bundle. In this bundle all budget lines are (weakly) below the 45 degree line where the decision maker is always (weakly) better off than the other participant (see Figure A.1d in Appendix A.1). We do this for each of the three types separately. We start with the predominantly selfish type because for this type the predictions are straightforward. The selfish type should predominantly make selfish choices $(z=1)$. Figures B.1a and B.1b below indicate that this is indeed the case. The vast majority of selfish individuals' median choices is exactly $z=1$ and the average over the medians is 0.84 and 0.86 for negatively and positively sloped budget lines, respectively.

Next, let us turn to the inequality averse type. In the south bundle, equality is maximized by the own-payoff minimizing allocation for all budget lines with slopes smaller than 1 . This means the inequality averse type should make primarily own-payoff minimizing choices (i.e., $z=0$ ) for these budgets, which is exactly what we observe in Figure B.1c. For these budget lines more than 70 percent of the inequality averse subjects choose the own-payoff-minimizing allocation $(z=0)$ and most of the remaining subjects choose allocations that are close to $z=0$. In contrast, equality is maximized for budget lines with slope larger than 1 by choosing the own-payoff maximizing allocation $(z=1)$, which is what happens again in the vast majority of the cases (see Figure B.1d). Moreover, the deviations from these behavioral patterns are rather infrequent, as indicated by the low standard deviation of the median choice in Figures B.1c and B.1d. In both figures the average over the median choices is close to $z=0$ or $z=1$, which indicates that the behavioral patterns of inequality averse individuals in the south bundle are very consistent with a preference for equality across the bundles.

The predictions for the altruistic type are slightly more complicated because the south bundle contains budget lines where a tension between the altruistic component of their preferences and the motive to maximize joint payoffs can arise. This tension is present for the negatively sloped budget lines but is absent in the positively sloped budget lines.

For all budget lines with a positive slope in the south bundle the joint payoff for both individuals is maximized by the own-payoff maximizing allocation $(z=1)$, which simultaneously also maximizes the other individuals' payoff. Thus, there is no tension here between altruism and joint payoff maximization. Therefore, the altruistic type is predicted to choose the joint payoff-maximizing allocation for these budget lines. Figure B.1g indicates that this is indeed the case. Roughly $95 \%$ of all individuals assigned to the altruistic type behave as predicted in the south bundle by displaying exactly a median choice that maximizes the own

\footnotetext{
${ }^{33}$ In Appendix B.2 and B.3 we present evidence in terms of subjects' median (or average) behavior for relevant subsets of budget lines in the south bundle and the north bundle. This considerably simplifies the discussion and presentation. In a previous version of the paper (see Epper et al., 2020) we have shown subjects' behavior for all budget lines in the south and the north bundle.
} 
and joint-payoff $(z=1)$.

For the negatively sloped budget lines with slopes $<-1$ there is also no tension between the altruism motive and the joint payoff maximization motive because altruistic choices cost very little and yield large benefits to the other individual. Therefore, the allocation that maximizes the other's payoff is also the one the maximizes the joint payoff, and simultaneously minimizes the own payoff $(z=0)$. In this situation even very small positive $\beta$-parameters in the utility function suffice to induce other-payoff maximizing behavior. Thus, the altruistic type is predicted to choose the own-payoff minimizing allocation for these budget lines which is indeed the median choice of more than $90 \%$ of individuals of this type for these budget lines (see Figure B.1e).

For the budget lines with slopes between -1 and 0, however, sacrificing CHF 1 increases the other individual's payoff by less than CHF 1, i.e., the altruistic action is quite costly and thus reduces the joint payoff because altruistic acts are very costly. In fact, the joint-payoff maximizing allocation is here the one that maximizes the own-payoff. Therefore, there is a tension between altruism and joint payoff maximization. In this situation only altruistic individuals with a relatively large $\beta$-parameter will make an other-payoff maximizing choice while those with lower $\beta$-parameters will choose allocations that are less altruistic, e.g., the egalitarian allocation or even the own-payoff maximizing allocation. We should thus observe a more scattered behavioral pattern. Figure B.1f shows that this is indeed the case. Some altruistic individuals prefer to act altruistically while others choose the own-payoff maximizing allocation. The wider distribution of choices in Figure B.1f also nicely documents the source of heterogeneity among individuals belonging to the altruistic type (discussed in more detail in Appendix B.4 below). The strongly altruistic type has a larger $\beta$-parameter and puts more weight on the other individual's welfare in this situation than the moderately altruistic type who has a lower $\beta$-parameter. 
Figure B.1: Distribution of individuals' median choices in the south bundle.

Predominantly selfish

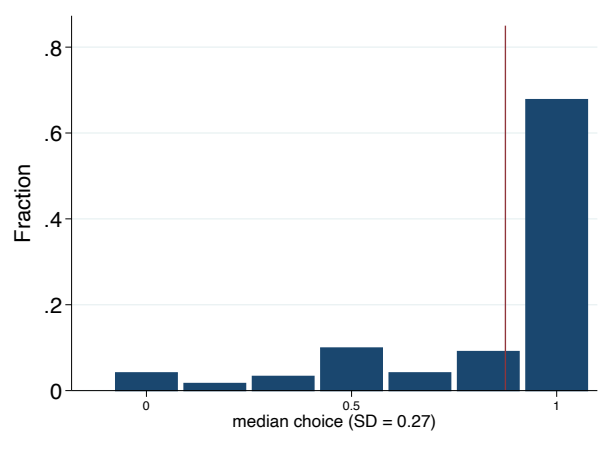

(a) BL with slope $<0$ (excl. -Inf)

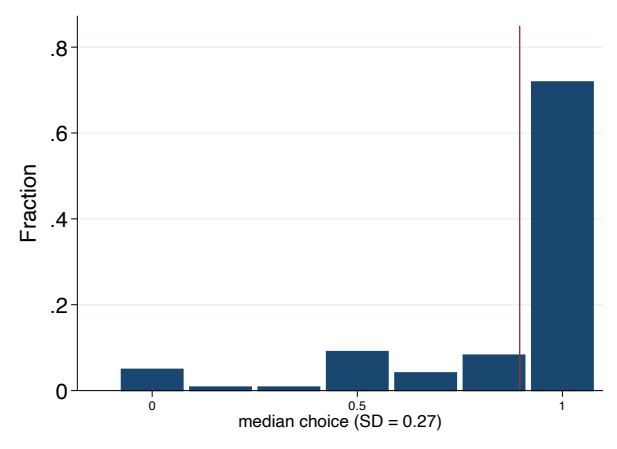

(b) BL with slope $>0$

Inequality averse

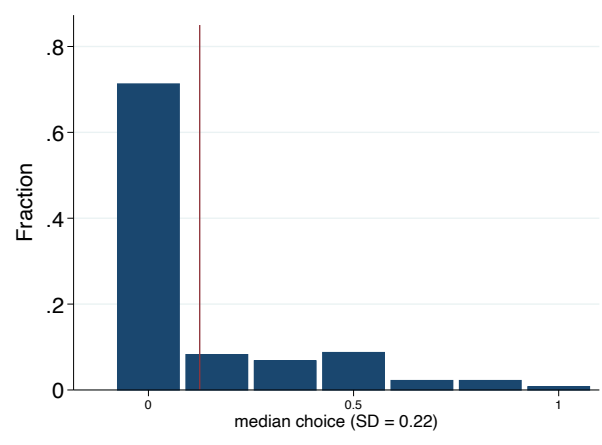

(c) BL with slope $<1$

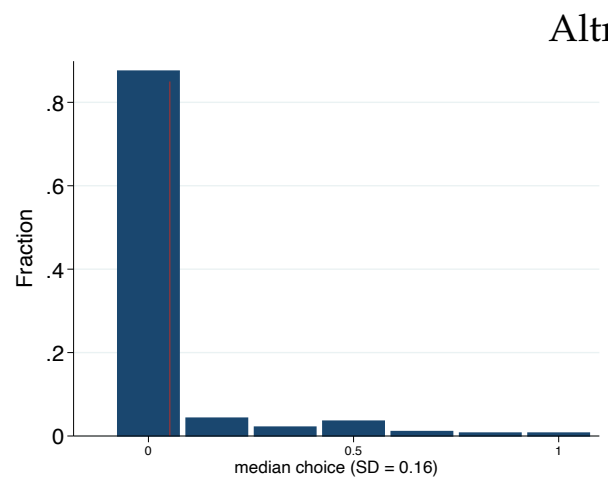

(e) BL with slope $<-1$

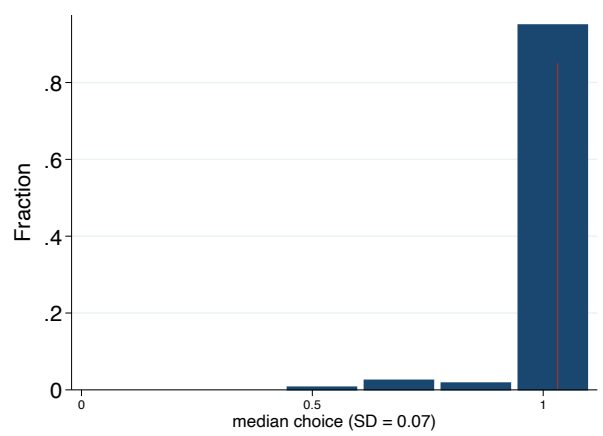

(g) BL with slope $>0$

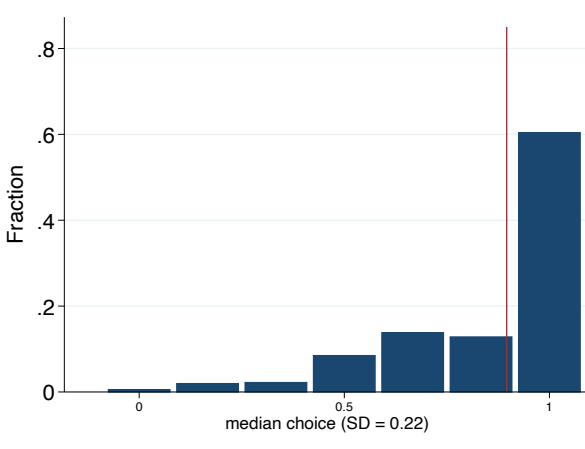

(d) BL with slope $>1$

Altruistic

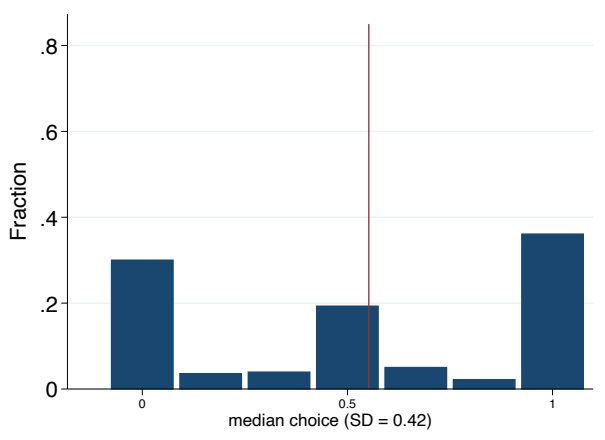

(f) BL with slope strictly between -1 and 0

Note: The figure shows the distribution of individuals' median choices among sets of budget lines with different slopes for each of the three behavioral types identified by the clustering algorithm. For each budget line, $z=1$ indicates an own-payoff maximizing choice and $z=0$ indicates an own-payoff minimizing choice. The different sets of budget lines are constructed to yield (as much as possible) clear predictions for each type. The red vertical line indicates always the average over all median choices. SD indicates the standard deviation of median choices. 66 


\section{B.3 Validating the behavioral types with the north bundle}

In this part of the appendix we examine whether the behavioral types identified in the center bundle behave as predicted in the north bundle. In this bundle all budget lines are (weakly) above the 45 degree line where the decision maker is always (weakly) worse off than the other participant (see Figure Figure A.1c in Appendix A.1). The predictions are again straightforward for the predominantly selfish type - these individuals should predominantly choose the own-payoff maximizing allocation $(z=1)$. Figures B.2a and B.2b shows that this is indeed the case. For the negatively sloped budget lines nearly all selfish individuals display a median choice of $z=1$ and for the positively sloped budget lines the vast majority also shows a median choice of exactly $z=1$ or close to it.

The predictions are a bit more complicated for the inequality averse individuals. For all budget lines with a slope strictly smaller than 1 the equality-maximizing allocation, i.e., the one with the smallest payoff differences between the individuals, is identical with the ownpayoff maximizing allocation $(z=1)$. Thus, inequality averse individuals should choose $\mathrm{z}=$ 1 for these budget lines. Figure B.2c shows that the vast majority of the inequality averse individuals behave accordingly. The prediction is different, however, for the budget lines with slopes strictly larger than 1 . Here, the equality-maximizing allocation is given by the own-payoff minimizing choice, i.e., by $z=0$. Figure B.2d indeed shows that a big majority of inequality averse individuals are willing to substantially reduce inequality by choosing allocations between $z=0$ and $z=0.5$.

Finally, we discuss the predictions for the altruistic type. In the north bundle there is no tension between the altruistic motive and the joint payoff-maximization motive for all budget lines with a slope that is strictly larger than -1 . These motives are maximally satisfied by choosing the own-payoff maximizing allocation $z=1$. Thus, the individuals of this type should choose $z=1$ for these budget lines which basically all of them do (see Figure B.2f).

For the budget lines with slopes $\leq-1$, a tension between the altruistic motive and joint payoff maximization on the one hand and self-interest and equality on the other hand arises: joint payoff maximization and altruism require the choice of $z=0$ but this choice involves a large amount of disadvantageous inequality. In contrast, a choice of $z=0$ maximizes selfinterest and achieves equality. Figure B.2e indicates that roughly 70 percent of altruistic individuals move in the direction of joint and other- payoff maximization. 40 percent of this type even go to the extreme and sacrifice substantial money to maximize the other players payoff thereby also maximizing the joint payoff. 
Figure B.2: Distribution of individuals' median choices in the north bundle.

Predominantly selfish

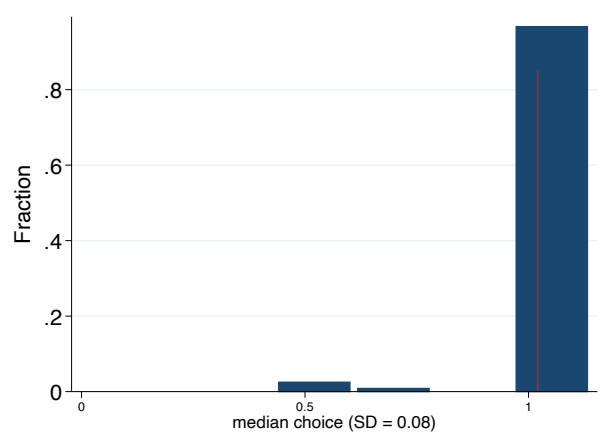

(a) BL with slope $<0$ (excl. -Inf)

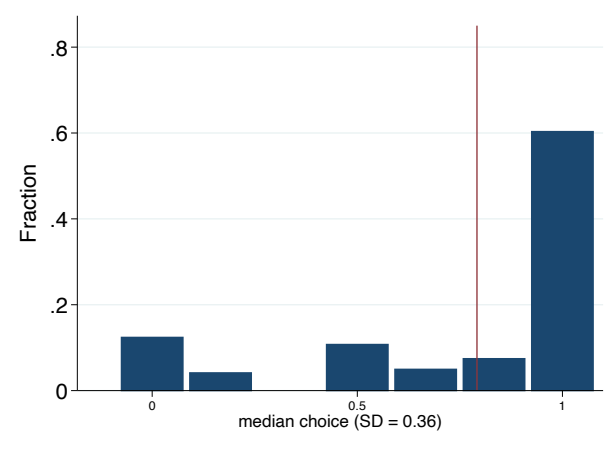

(b) BL with slope $>0$

Inequality averse

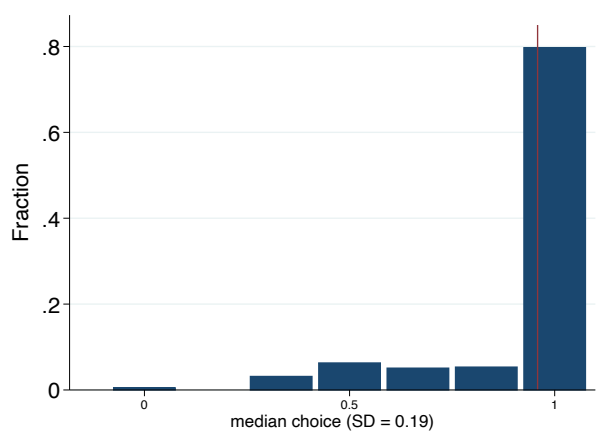

(c) BL with slope $<1$

Altruistic

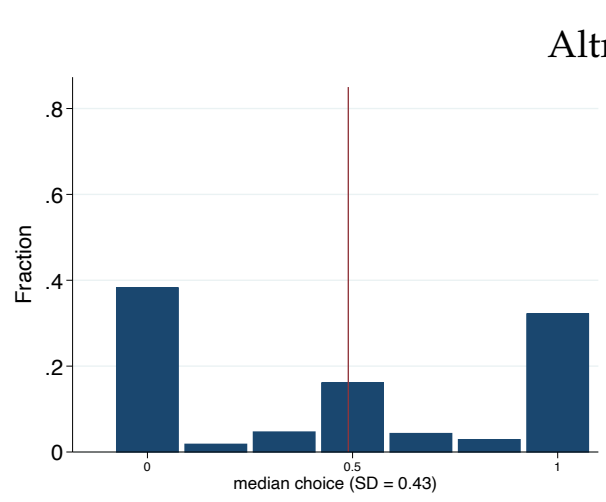

(e) BL with slope $<-1$

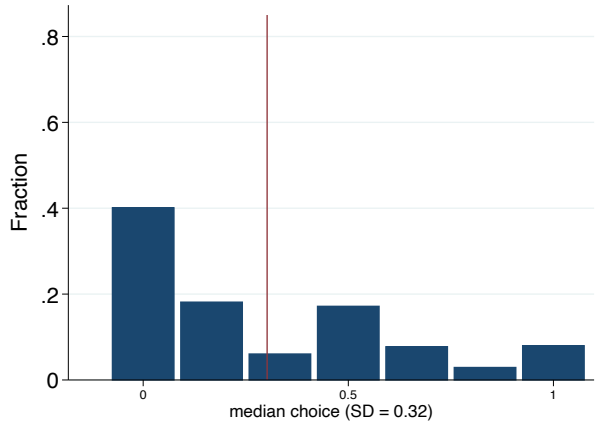

(d) BL with slope $>1$

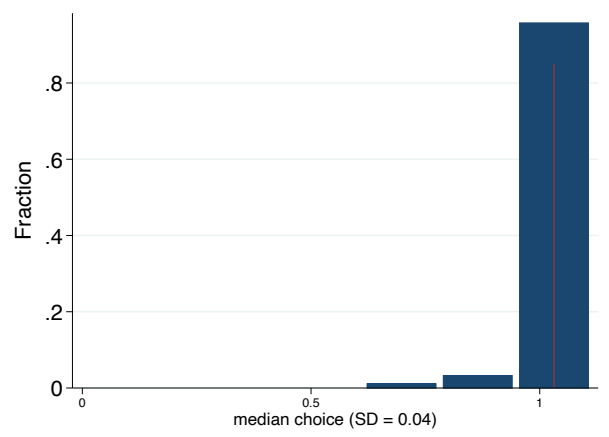

(f) BL with slope $>-1$

Note: The figure shows the distribution of individuals' median choices among sets of budget lines with different slopes for each of the three behavioral types identified by the clustering algorithm. For each budget line, $z=1$ indicates an own-payoff maximizing choice and $z=0$ indicates an own-payoff minimizing choice. The different sets of budget lines are constructed to yield (as much as possible) clear predictions for each type. The red vertical line indicates always the average over all median choices. SD indicates the standard deviation of median choices. 


\section{B.4 Allowing for four and more types}

In Section 3 of the paper we show that there are three fundamentally different social preference types and we validate our interpretation of the observed behavioral patterns by demonstrating that the different types behave rather consistently across different budget line bundles (Appendix B.2 and B.3). Because these three types show qualitatively very different behavioral patterns, key differences in preferences would be hidden with a lower number of types. It is, however, still interesting to see what happens if we reduce the penalty parameter $\lambda$ in the DP-means algorithm such that more than three types emerge.

If we reduce $\lambda$ such that four types emerge, we find again an inequality averse type and a predominantly selfish type but the altruistic type is divided up in a moderate and a strong altruistic type. We document this explicitly in Table B.1 below. The table indicates that almost all individuals assigned to the inequality averse cluster for $k=3$ types remain in that cluster, and almost all predominantly selfish individuals also remain in "their" cluster when $k=4$. Moreover, each of the individuals in the altruistic cluster in case of $k=3$ remains in one of the two altruistic clusters in case of $k=4$.

Table B.1: Transition of individuals between types

\begin{tabular}{|c|c|c|c|c|c|c|}
\hline & & \multirow{2}{*}{\multicolumn{4}{|c|}{$k=4$ types }} & \multirow[b]{3}{*}{$\begin{array}{l}\text { Total } \\
\text { (\%) }\end{array}$} \\
\hline & & & & & \\
\hline & & $\begin{array}{c}\text { Inequality } \\
\text { averse }\end{array}$ & $\begin{array}{l}\text { Strongly } \\
\text { altruistic }\end{array}$ & $\begin{array}{c}\text { Moderately } \\
\text { altruistic }\end{array}$ & $\begin{array}{l}\text { Predominantly } \\
\text { selfish }\end{array}$ & \\
\hline \multirow{4}{*}{$\begin{array}{l}\mathrm{k}=3 \\
\text { types }\end{array}$} & $\begin{array}{c}\text { Inequality } \\
\text { averse }\end{array}$ & 406 & 7 & 1 & 0 & $\begin{array}{c}414 \\
(50.8 \%)\end{array}$ \\
\hline & Altruistic & 0 & 162 & 118 & 0 & $\begin{array}{c}280 \\
(34.4 \%)\end{array}$ \\
\hline & $\begin{array}{l}\text { Predominantly } \\
\text { selfish }\end{array}$ & 1 & 8 & 0 & 112 & $\begin{array}{c}121 \\
(14.8 \%)\end{array}$ \\
\hline & $\begin{array}{l}\text { Total } \\
(\%)\end{array}$ & $\begin{array}{c}407 \\
(49.9 \%)\end{array}$ & $\begin{array}{c}177 \\
(21.7 \%)\end{array}$ & $\begin{array}{c}119 \\
(14.6 \%)\end{array}$ & $\begin{array}{c}112 \\
(13.8 \%)\end{array}$ & $\begin{array}{c}815 \\
(100 \%)\end{array}$ \\
\hline
\end{tabular}

If we decrease the penalty parameter $\lambda$ further such that 5 types emerge we basically get again 4 types that are very similar to those illustrated in Table B.1 above. The four types comprise $98.65 \%$ of the population, i.e., the fifth type only attracts $1.35 \%$ of the population. Similar remarks apply when we allow for $k=6$ types. Together, the fifth and the sixth type only comprise $1.47 \%$ of the population. Thus, taking the whole picture into account, the emerging clusters and their associated behavioral patterns together with our validation exercises suggest that there are 3 qualitatively fundamentally distinct social preference types - and these three types basically comprise the whole population. However, there is some meaningful and interesting heterogeneity within the altruistic type that justifies that we look deeper into the behavior of this type when we study certain aspects of the relation between other-regarding preferences and support for political redistribution. 


\section{Material related to the role of other-regarding preferences in the political support for redistribution}

\section{C.1 Derivation of individuals' demand for redistribution in terms of their pre- ferred tax rate}

To derive an individual's demand for redistribution, we maximize the other-regarding utility function

$$
V_{i}=c_{i}-\alpha \frac{1}{n-1} \sum_{j \neq i} \max \left(c_{j}-c_{i}, 0\right)-\beta \frac{1}{n-1} \sum_{j \neq i} \max \left(c_{i}-c_{j}, 0\right) .
$$

with regard to an individual's preferred tax rate $\tau(0 \leq \tau \leq 1)$ and subject to the individual's and the government's budget constraint

$$
\begin{aligned}
c_{i} & =(1-\tau) y_{i}+T \\
T & =\left(\tau-\frac{1}{2} \tau^{2}\right) \bar{y}
\end{aligned}
$$

where the average income $\bar{y}$ is given by $\bar{y}=\frac{1}{n} \sum_{i=1}^{n} y_{i}$. In the following, we denote individual $i$ 's preferred tax rate by $\tau_{i}$. The first-order condition for this maximization problem is given by

$$
\left(1-\tau_{i}\right) \bar{y}-y_{i}-\alpha \frac{1}{n-1} \sum_{j \neq i} \max \left(y_{j}-y_{i}, 0\right)-\beta \frac{1}{n-1} \sum_{j \neq i} \max \left(y_{i}-y_{j}, 0\right) \stackrel{!}{=} 0
$$

It is noteworthy that the terms involving the inequity aversion parameters $\alpha$ and $\beta$ contain only gross income. Rearranging the first order condition yields an individuals desired tax rate as

$$
\tau_{i}^{*}=1-\frac{1}{\bar{y}}\left(y_{i}-\alpha \frac{1}{n-1} \sum_{j \neq i} \max \left(y_{j}-y_{i}, 0\right)-\beta \frac{1}{n-1} \sum_{j \neq i} \max \left(y_{i}-y_{j}, 0\right)\right)
$$




\section{C.2 The association between other-regarding preferences and political support for redistribution with all covariates explicitly shown}

Table C.1: Social preferences and average political support for redistribution (all coefficients)

\begin{tabular}{|c|c|c|c|c|c|c|c|}
\hline & \multicolumn{4}{|c|}{$\begin{array}{c}\text { Full } \\
\text { sample }\end{array}$} & \multirow{2}{*}{$\begin{array}{l}\begin{array}{c}\text { Below median } \\
\text { income }\end{array} \\
(5)\end{array}$} & \multirow{2}{*}{$\begin{array}{l}\begin{array}{c}\text { Above median } \\
\text { income }\end{array} \\
(6)\end{array}$} & \multirow{2}{*}{$\begin{array}{c}\begin{array}{c}\text { Full sample } \\
\text { (interactions) }\end{array} \\
(7)\end{array}$} \\
\hline & (1) & (2) & (3) & (4) & & & \\
\hline Inequality averse & $\begin{array}{l}0.186^{* * *} \\
(0.063)\end{array}$ & $\begin{array}{l}0.197^{* * *} \\
(0.063)\end{array}$ & $\begin{array}{l}0.199^{* * *} \\
(0.063)\end{array}$ & $\begin{array}{l}0.186^{* * *} \\
(0.063)\end{array}$ & $\begin{array}{r}0.035 \\
(0.091)\end{array}$ & $\begin{array}{l}0.330^{* * *} \\
(0.107)\end{array}$ & $\begin{array}{l}0.210^{* * *} \\
(0.067)\end{array}$ \\
\hline Altruistic & $\begin{array}{l}0.159^{* *} \\
(0.069)\end{array}$ & $\begin{array}{l}0.154^{* *} \\
(0.069)\end{array}$ & $\begin{array}{c}0.158^{* *} \\
(0.069)\end{array}$ & $\begin{array}{l}0.149^{* *} \\
(0.069)\end{array}$ & $\begin{array}{r}0.059 \\
(0.098)\end{array}$ & $\begin{array}{l}0.249^{* *} \\
(0.116)\end{array}$ & $\begin{array}{l}0.165^{* *} \\
(0.074)\end{array}$ \\
\hline Income & $\begin{array}{l}-0.071^{* * *} \\
(0.021)\end{array}$ & $\begin{array}{l}-0.067^{* * *} \\
(0.021)\end{array}$ & $\begin{array}{l}-0.064^{* * *} \\
(0.021)\end{array}$ & $\begin{array}{l}-0.065^{* * *} \\
(0.020)\end{array}$ & $\begin{array}{l}-0.021 \\
(0.064)\end{array}$ & $\begin{array}{l}-0.126^{* * *} \\
(0.048)\end{array}$ & $\begin{array}{l}-0.133^{* * *} \\
(0.048)\end{array}$ \\
\hline Income $\mathrm{x}$ Inequality averse & & & & & & & $\begin{array}{c}0.091^{*} \\
(0.052)\end{array}$ \\
\hline Income $x$ Altruistic & & & & & & & $\begin{array}{r}0.067 \\
(0.052)\end{array}$ \\
\hline Income: Undisclosed & $\begin{array}{r}-0.070 \\
(0.073)\end{array}$ & $\begin{array}{r}-0.068 \\
(0.072)\end{array}$ & $\begin{array}{r}-0.064 \\
(0.070)\end{array}$ & $\begin{array}{r}-0.053 \\
(0.071)\end{array}$ & $\begin{array}{r}0.000 \\
(.)\end{array}$ & $\begin{array}{r}0.000 \\
(.)\end{array}$ & $\begin{array}{r}-0.055 \\
(0.071)\end{array}$ \\
\hline Male & $\begin{array}{r}0.008 \\
(0.048)\end{array}$ & $\begin{array}{r}-0.007 \\
(0.048)\end{array}$ & $\begin{array}{r}-0.005 \\
(0.048)\end{array}$ & $\begin{array}{r}-0.013 \\
(0.048)\end{array}$ & $\begin{array}{r}-0.018 \\
(0.065)\end{array}$ & $\begin{array}{r}-0.001 \\
(0.081)\end{array}$ & $\begin{array}{r}-0.014 \\
(0.048)\end{array}$ \\
\hline Age & $\begin{array}{c}0.019^{*} \\
(0.011)\end{array}$ & $\begin{array}{r}0.010 \\
(0.010)\end{array}$ & $\begin{array}{r}0.008 \\
(0.010)\end{array}$ & $\begin{array}{r}0.008 \\
(0.010)\end{array}$ & $\begin{array}{r}-0.005 \\
(0.015)\end{array}$ & $\begin{array}{r}0.028 \\
(0.022)\end{array}$ & $\begin{array}{r}0.008 \\
(0.010)\end{array}$ \\
\hline Age squared & $\begin{array}{r}-0.000 \\
(0.000)\end{array}$ & $\begin{array}{r}-0.000 \\
(0.000)\end{array}$ & $\begin{array}{r}-0.000 \\
(0.000)\end{array}$ & $\begin{array}{r}-0.000 \\
(0.000)\end{array}$ & $\begin{array}{r}0.000 \\
(0.000)\end{array}$ & $\begin{array}{r}-0.000 \\
(0.000)\end{array}$ & $\begin{array}{r}-0.000 \\
(0.000)\end{array}$ \\
\hline French speaking & $\begin{array}{r}-0.214 \\
(0.150)\end{array}$ & $\begin{array}{l}-0.297^{*} \\
(0.157)\end{array}$ & $\begin{array}{c}-0.276^{*} \\
(0.162)\end{array}$ & $\begin{array}{r}-0.262 \\
(0.168)\end{array}$ & $\begin{array}{r}-0.217 \\
(0.219)\end{array}$ & $\begin{array}{r}-0.370 \\
(0.235)\end{array}$ & $\begin{array}{r}-0.236 \\
(0.165)\end{array}$ \\
\hline Married & $\begin{array}{r}0.013 \\
(0.048)\end{array}$ & $\begin{array}{r}0.020 \\
(0.048)\end{array}$ & $\begin{array}{r}0.034 \\
(0.048)\end{array}$ & $\begin{array}{r}0.029 \\
(0.048)\end{array}$ & $\begin{array}{r}0.012 \\
(0.070)\end{array}$ & $\begin{array}{r}0.083 \\
(0.077)\end{array}$ & $\begin{array}{r}0.029 \\
(0.048)\end{array}$ \\
\hline Education: Vocational training & $\begin{array}{r}-0.044 \\
(0.092)\end{array}$ & $\begin{array}{l}-0.005 \\
(0.100)\end{array}$ & $\begin{array}{l}-0.020 \\
(0.099)\end{array}$ & $\begin{array}{l}-0.028 \\
(0.100)\end{array}$ & $\begin{array}{r}0.026 \\
(0.119)\end{array}$ & $\begin{array}{r}0.186 \\
(0.239)\end{array}$ & $\begin{array}{l}-0.025 \\
(0.100)\end{array}$ \\
\hline Education: High school & $\begin{array}{r}0.066 \\
(0.098)\end{array}$ & $\begin{array}{r}0.091 \\
(0.107)\end{array}$ & $\begin{array}{r}0.069 \\
(0.107)\end{array}$ & $\begin{array}{r}0.051 \\
(0.108)\end{array}$ & $\begin{array}{r}-0.122 \\
(0.135)\end{array}$ & $\begin{array}{l}0.541^{* *} \\
(0.247)\end{array}$ & $\begin{array}{r}0.047 \\
(0.107)\end{array}$ \\
\hline Education: University & $\begin{array}{r}0.018 \\
(0.095)\end{array}$ & $\begin{array}{r}0.057 \\
(0.103)\end{array}$ & $\begin{array}{r}0.042 \\
(0.103)\end{array}$ & $\begin{array}{r}0.017 \\
(0.103)\end{array}$ & $\begin{array}{r}0.076 \\
(0.133)\end{array}$ & $\begin{array}{r}0.297 \\
(0.233)\end{array}$ & $\begin{array}{r}0.017 \\
(0.103)\end{array}$ \\
\hline Education: Other & $\begin{array}{r}-0.120 \\
(0.103)\end{array}$ & $\begin{array}{l}-0.065 \\
(0.112)\end{array}$ & $\begin{array}{r}-0.085 \\
(0.111)\end{array}$ & $\begin{array}{r}-0.101 \\
(0.111)\end{array}$ & $\begin{array}{r}0.173 \\
(0.147)\end{array}$ & $\begin{array}{r}-0.036 \\
(0.250)\end{array}$ & $\begin{array}{r}-0.093 \\
(0.111)\end{array}$ \\
\hline Occupation: Part-time job & $\begin{array}{r}0.035 \\
(0.059)\end{array}$ & $\begin{array}{r}0.026 \\
(0.059)\end{array}$ & $\begin{array}{r}0.030 \\
(0.060)\end{array}$ & $\begin{array}{r}0.026 \\
(0.059)\end{array}$ & $\begin{array}{r}-0.071 \\
(0.082)\end{array}$ & $\begin{array}{r}0.130 \\
(0.103)\end{array}$ & $\begin{array}{r}0.031 \\
(0.059)\end{array}$ \\
\hline Occupation: Currently unemployed & $\begin{array}{r}0.019 \\
(0.132)\end{array}$ & $\begin{array}{r}0.001 \\
(0.132)\end{array}$ & $\begin{array}{r}-0.037 \\
(0.134)\end{array}$ & $\begin{array}{r}-0.046 \\
(0.130)\end{array}$ & $\begin{array}{r}-0.165 \\
(0.167)\end{array}$ & $\begin{array}{r}0.189 \\
(0.288)\end{array}$ & $\begin{array}{r}-0.055 \\
(0.130)\end{array}$ \\
\hline Occupation: Not in labor force & $\begin{array}{c}0.135^{* *} \\
(0.065)\end{array}$ & $\begin{array}{c}0.113^{*} \\
(0.063)\end{array}$ & $\begin{array}{c}0.122^{*} \\
(0.062)\end{array}$ & $\begin{array}{c}0.109^{*} \\
(0.062)\end{array}$ & $\begin{array}{r}0.108 \\
(0.090)\end{array}$ & $\begin{array}{r}0.029 \\
(0.119)\end{array}$ & $\begin{array}{r}0.101 \\
(0.062)\end{array}$ \\
\hline Effort matters for success & & $\begin{array}{l}-0.113^{* * *} \\
(0.040)\end{array}$ & $\begin{array}{l}-0.110^{* * *} \\
(0.039)\end{array}$ & $\begin{array}{l}-0.122^{* * *} \\
(0.039)\end{array}$ & $\begin{array}{l}-0.146^{* * *} \\
(0.048)\end{array}$ & $\begin{array}{r}-0.105 \\
(0.070)\end{array}$ & $\begin{array}{l}-0.117^{* * *} \\
(0.039)\end{array}$ \\
\hline Luck and inheritance matter for success & & $\begin{array}{l}0.120^{* * *} \\
(0.028)\end{array}$ & $\begin{array}{l}0.122^{* * *} \\
(0.029)\end{array}$ & $\begin{array}{l}0.111^{* * *} \\
(0.029)\end{array}$ & $\begin{array}{l}0.142^{* * *} \\
(0.043)\end{array}$ & $\begin{array}{r}0.075 \\
(0.048)\end{array}$ & $\begin{array}{l}0.109^{* * *} \\
(0.029)\end{array}$ \\
\hline Risk aversion & & $\begin{array}{r}0.015 \\
(0.021)\end{array}$ & $\begin{array}{r}0.019 \\
(0.021)\end{array}$ & $\begin{array}{r}0.024 \\
(0.021)\end{array}$ & $\begin{array}{r}0.029 \\
(0.029)\end{array}$ & $\begin{array}{r}0.025 \\
(0.038)\end{array}$ & $\begin{array}{r}0.020 \\
(0.022)\end{array}$ \\
\hline Positive reciprocity 1 (return favor) & & $\begin{array}{r}0.010 \\
(0.024)\end{array}$ & $\begin{array}{r}0.010 \\
(0.024)\end{array}$ & $\begin{array}{r}0.008 \\
(0.024)\end{array}$ & $\begin{array}{r}-0.006 \\
(0.027)\end{array}$ & $\begin{array}{r}0.010 \\
(0.042)\end{array}$ & $\begin{array}{r}0.008 \\
(0.023)\end{array}$ \\
\hline Positive reciprocity 2 (reciprocate help) & & $\begin{array}{c}0.037^{*} \\
(0.021)\end{array}$ & $\begin{array}{c}0.035^{*} \\
(0.021)\end{array}$ & $\begin{array}{c}0.037^{*} \\
(0.021)\end{array}$ & $\begin{array}{r}0.019 \\
(0.030)\end{array}$ & $\begin{array}{l}0.080^{* *} \\
(0.034)\end{array}$ & $\begin{array}{c}0.038^{*} \\
(0.021)\end{array}$ \\
\hline Negative reciprocity 1 (revenge injustice) & & $\begin{array}{r}0.002 \\
(0.027)\end{array}$ & $\begin{array}{r}0.006 \\
(0.026)\end{array}$ & $\begin{array}{r}0.008 \\
(0.027)\end{array}$ & $\begin{array}{r}0.055 \\
(0.038)\end{array}$ & $\begin{array}{r}-0.020 \\
(0.045)\end{array}$ & $\begin{array}{r}0.011 \\
(0.027)\end{array}$ \\
\hline Negative reciprocity 2 (put in bad position) & & $\begin{array}{r}0.008 \\
(0.027)\end{array}$ & $\begin{array}{r}0.003 \\
(0.027)\end{array}$ & $\begin{array}{r}0.009 \\
(0.027)\end{array}$ & $\begin{array}{r}-0.033 \\
(0.040)\end{array}$ & $\begin{array}{r}0.058 \\
(0.044)\end{array}$ & $\begin{array}{r}0.005 \\
(0.028)\end{array}$ \\
\hline Impatience & & $\begin{array}{r}-0.017 \\
(0.021)\end{array}$ & $\begin{array}{r}-0.017 \\
(0.021)\end{array}$ & $\begin{array}{r}-0.014 \\
(0.020)\end{array}$ & $\begin{array}{r}-0.009 \\
(0.028)\end{array}$ & $\begin{array}{r}-0.026 \\
(0.036)\end{array}$ & $\begin{array}{r}-0.014 \\
(0.020)\end{array}$ \\
\hline Have been unemployed in past & & & $\begin{array}{r}0.062 \\
(0.046)\end{array}$ & $\begin{array}{r}0.071 \\
(0.046)\end{array}$ & $\begin{array}{r}0.056 \\
(0.065)\end{array}$ & $\begin{array}{r}0.016 \\
(0.079)\end{array}$ & $\begin{array}{r}0.072 \\
(0.046)\end{array}$ \\
\hline Beliefs about future upwards mobility & & & $\begin{array}{r}0.066 \\
(0.047)\end{array}$ & $\begin{array}{c}0.080^{*} \\
(0.047)\end{array}$ & $\begin{array}{r}-0.022 \\
(0.065)\end{array}$ & $\begin{array}{r}0.095 \\
(0.077)\end{array}$ & $\begin{array}{r}0.075 \\
(0.047)\end{array}$ \\
\hline Perceived past upwards mobility & & & $\begin{array}{r}0.033 \\
(0.042)\end{array}$ & $\begin{array}{r}0.022 \\
(0.042)\end{array}$ & $\begin{array}{r}0.067 \\
(0.062)\end{array}$ & $\begin{array}{r}-0.001 \\
(0.072)\end{array}$ & $\begin{array}{r}0.025 \\
(0.042)\end{array}$ \\
\hline Trust in strangers & & & & $\begin{array}{l}0.069^{* * *} \\
(0.022)\end{array}$ & $\begin{array}{l}0.068^{* *} \\
(0.030)\end{array}$ & $\begin{array}{c}0.069^{*} \\
(0.037)\end{array}$ & $\begin{array}{l}0.068^{* * *} \\
(0.021)\end{array}$ \\
\hline Mistrust in politicians & & & & $\begin{array}{c}0.066^{* *} \\
(0.032)\end{array}$ & $\begin{array}{l}0.087^{* *} \\
(0.043)\end{array}$ & $\begin{array}{r}0.074 \\
(0.060)\end{array}$ & $\begin{array}{l}0.066^{* *} \\
(0.033)\end{array}$ \\
\hline Perceived inequality & & & & $\begin{array}{r}0.014 \\
(0.022)\end{array}$ & $\begin{array}{r}0.001 \\
(0.028)\end{array}$ & $\begin{array}{r}0.029 \\
(0.040)\end{array}$ & $\begin{array}{r}0.013 \\
(0.022)\end{array}$ \\
\hline Constant & $\begin{array}{l}-0.539^{* *} \\
(0.252)\end{array}$ & $\begin{array}{r}-0.349 \\
(0.325)\end{array}$ & $72^{0.413}$ & $\begin{array}{r}-0.482 \\
(0.328)\end{array}$ & $\begin{array}{r}0.104 \\
(0.469)\end{array}$ & $\begin{array}{l}-1.362^{* *} \\
(0.576)\end{array}$ & $\begin{array}{r}-0.507 \\
(0.327)\end{array}$ \\
\hline Canton FE & Yes & Yes & Yes & Yes & Yes & Yes & Yes \\
\hline $\begin{array}{l}\text { Overall SD average support for redistribution } \\
R^{2}\end{array}$ & $\begin{aligned} 0.58 \\
0.083\end{aligned}$ & $\begin{array}{r}0.58 \\
0.124\end{array}$ & $\begin{array}{r}0.58 \\
0.129\end{array}$ & $\begin{array}{r}0.58 \\
0.146\end{array}$ & $\begin{array}{r}0.58 \\
0.220\end{array}$ & $\begin{array}{r}0.58 \\
0.218\end{array}$ & $\begin{array}{r}0.58 \\
0.151\end{array}$ \\
\hline Observations & 815 & 813 & 813 & 813 & 364 & 367 & 813 \\
\hline
\end{tabular}

Notes: Levels of significance: ${ }^{*} p<0.1,{ }^{* *} p<0.05,{ }^{* * *} p<0.01$ 
C.3 Assessing the role of other-regarding preferences when restricting the subjects pool to individuals who successfully passed either both or at least one attention check

In order to examine the subjects' attentiveness in the online survey, we added 2 attention checks to the survey (one in the first half and one at the later part of the survey). In our sample, data quality is remarkably high: $76 \%$ of the subjects correctly answered both attention checks, and only $11 \%$ failed to pass both checks. A comparison of Tables C.2 and C.3 with Table 3 in the paper shows that, if anything, other-regarding preferences play an even stronger role if we exclude individuals who did not pass one or both attention checks. 
Table C.2: Social preferences and average political support for redistribution among individuals that successfully passed both attention checks

\begin{tabular}{|c|c|c|c|c|c|c|c|}
\hline & \multicolumn{4}{|c|}{$\begin{array}{c}\text { Full } \\
\text { sample }\end{array}$} & \multirow{2}{*}{$\frac{\begin{array}{c}\text { Below median } \\
\text { income }\end{array}}{(5)}$} & \multirow{2}{*}{$\begin{array}{l}\begin{array}{c}\text { Above median } \\
\text { income }\end{array} \\
(6)\end{array}$} & \multirow{2}{*}{$\begin{array}{c}\begin{array}{c}\text { Full sample } \\
\text { (interactions) }\end{array} \\
(7)\end{array}$} \\
\hline & (1) & (2) & (3) & (4) & & & \\
\hline Inequality averse & $\begin{array}{l}0.235^{* * *} \\
(0.076)\end{array}$ & $\begin{array}{l}0.242^{* * *} \\
(0.075)\end{array}$ & $\begin{array}{l}0.244^{* * *} \\
(0.075)\end{array}$ & $\begin{array}{l}0.236^{* * *} \\
(0.077)\end{array}$ & $\begin{array}{r}0.037 \\
(0.106)\end{array}$ & $\begin{array}{l}0.409^{* * *} \\
(0.133)\end{array}$ & $\begin{array}{l}0.267^{* * *} \\
(0.080)\end{array}$ \\
\hline Altruistic & $\begin{array}{l}0.214^{* * *} \\
(0.082)\end{array}$ & $\begin{array}{c}0.198^{* *} \\
(0.081)\end{array}$ & $\begin{array}{l}0.198^{* *} \\
(0.082)\end{array}$ & $\begin{array}{l}0.192^{* *} \\
(0.083)\end{array}$ & $\begin{array}{r}0.080 \\
(0.117)\end{array}$ & $\begin{array}{c}0.329^{* *} \\
(0.143)\end{array}$ & $\begin{array}{l}0.209^{* *} \\
(0.087)\end{array}$ \\
\hline Income & $\begin{array}{l}-0.068^{* * *} \\
(0.025)\end{array}$ & $\begin{array}{l}-0.070^{* * *} \\
(0.025)\end{array}$ & $\begin{array}{l}-0.068^{* * *} \\
(0.024)\end{array}$ & $\begin{array}{l}-0.069^{* * *} \\
(0.024)\end{array}$ & $\begin{array}{r}0.027 \\
(0.074)\end{array}$ & $\begin{array}{l}-0.154^{* * *} \\
(0.057)\end{array}$ & $\begin{array}{l}-0.142^{* *} \\
(0.059)\end{array}$ \\
\hline Income $x$ Inequality averse & & & & & & & $\begin{array}{r}0.101 \\
(0.064)\end{array}$ \\
\hline Income $x$ Altruistic & & & & & & & $\begin{array}{r}0.070 \\
(0.063)\end{array}$ \\
\hline Male & $\begin{array}{l}-0.016 \\
(0.054)\end{array}$ & $\begin{array}{r}-0.021 \\
(0.056)\end{array}$ & $\begin{array}{r}-0.020 \\
(0.056)\end{array}$ & $\begin{array}{l}-0.031 \\
(0.056)\end{array}$ & $\begin{array}{r}-0.028 \\
(0.076)\end{array}$ & $\begin{array}{r}-0.032 \\
(0.101)\end{array}$ & $\begin{array}{r}-0.031 \\
(0.056)\end{array}$ \\
\hline Age & $\begin{array}{r}0.017 \\
(0.013)\end{array}$ & $\begin{array}{r}0.006 \\
(0.012)\end{array}$ & $\begin{array}{r}0.004 \\
(0.013)\end{array}$ & $\begin{array}{r}0.005 \\
(0.013)\end{array}$ & $\begin{array}{r}-0.018 \\
(0.017)\end{array}$ & $\begin{array}{r}0.041 \\
(0.030)\end{array}$ & $\begin{array}{r}0.005 \\
(0.013)\end{array}$ \\
\hline Effort matters for success & & $\begin{array}{l}-0.105^{* *} \\
(0.049)\end{array}$ & $\begin{array}{l}-0.103^{* *} \\
(0.049)\end{array}$ & $\begin{array}{l}-0.116^{* *} \\
(0.050)\end{array}$ & $\begin{array}{l}-0.202^{* * *} \\
(0.064)\end{array}$ & $\begin{array}{r}-0.051 \\
(0.087)\end{array}$ & $\begin{array}{l}-0.110^{* *} \\
(0.049)\end{array}$ \\
\hline Luck and inheritance matter for success & & $\begin{array}{l}0.137^{* * *} \\
(0.033)\end{array}$ & $\begin{array}{l}0.139^{* * *} \\
(0.034)\end{array}$ & $\begin{array}{l}0.132^{* * *} \\
(0.034)\end{array}$ & $\begin{array}{l}0.194^{* * *} \\
(0.051)\end{array}$ & $\begin{array}{r}0.090 \\
(0.056)\end{array}$ & $\begin{array}{l}0.129^{* * *} \\
(0.034)\end{array}$ \\
\hline Have been unemployed in past & & & $\begin{array}{r}0.043 \\
(0.055)\end{array}$ & $\begin{array}{r}0.045 \\
(0.056)\end{array}$ & $\begin{array}{r}0.043 \\
(0.077)\end{array}$ & $\begin{array}{r}0.007 \\
(0.098)\end{array}$ & $\begin{array}{r}0.044 \\
(0.056)\end{array}$ \\
\hline Beliefs about future upwards mobility & & & $\begin{array}{r}0.055 \\
(0.053)\end{array}$ & $\begin{array}{r}0.072 \\
(0.053)\end{array}$ & $\begin{array}{r}0.001 \\
(0.077)\end{array}$ & $\begin{array}{r}0.087 \\
(0.089)\end{array}$ & $\begin{array}{r}0.068 \\
(0.053)\end{array}$ \\
\hline Perceived past upwards mobility & & & $\begin{array}{r}0.006 \\
(0.050)\end{array}$ & $\begin{array}{r}0.001 \\
(0.050)\end{array}$ & $\begin{array}{r}0.075 \\
(0.073)\end{array}$ & $\begin{array}{r}-0.058 \\
(0.086)\end{array}$ & $\begin{array}{r}0.005 \\
(0.050)\end{array}$ \\
\hline Trust in strangers & & & & $\begin{array}{l}0.059^{* *} \\
(0.027)\end{array}$ & $\begin{array}{l}0.091^{* *} \\
(0.040)\end{array}$ & $\begin{array}{r}0.033 \\
(0.043)\end{array}$ & $\begin{array}{c}0.058^{* *} \\
(0.026)\end{array}$ \\
\hline Mistrust in politicians & & & & $\begin{array}{c}0.076^{*} \\
(0.039)\end{array}$ & $\begin{array}{c}0.089^{*} \\
(0.053)\end{array}$ & $\begin{array}{r}0.090 \\
(0.069)\end{array}$ & $\begin{array}{l}0.077^{* *} \\
(0.039)\end{array}$ \\
\hline Perceived inequality & & & & $\begin{array}{r}0.025 \\
(0.027)\end{array}$ & $\begin{array}{r}0.000 \\
(0.036)\end{array}$ & $\begin{array}{r}0.042 \\
(0.048)\end{array}$ & $\begin{array}{r}0.023 \\
(0.027)\end{array}$ \\
\hline Constant & $\begin{array}{l}-0.555^{*} \\
(0.295)\end{array}$ & $\begin{array}{r}-0.448 \\
(0.384)\end{array}$ & $\begin{array}{r}-0.473 \\
(0.389)\end{array}$ & $\begin{array}{r}-0.582 \\
(0.393)\end{array}$ & $\begin{array}{r}0.492 \\
(0.563)\end{array}$ & $\begin{array}{l}-2.294^{* * *} \\
(0.721)\end{array}$ & $\begin{array}{r}-0.625 \\
(0.388)\end{array}$ \\
\hline Other socio-demographics & Yes & Yes & Yes & Yes & Yes & Yes & Yes \\
\hline Education & Yes & Yes & Yes & Yes & Yes & Yes & Yes \\
\hline Occupation & Yes & Yes & Yes & Yes & Yes & Yes & Yes \\
\hline Other preference measures & No & Yes & Yes & Yes & Yes & Yes & Yes \\
\hline Canton FE & Yes & Yes & Yes & Yes & Yes & Yes & Yes \\
\hline Overall SD average support for redistribution & 0.59 & 0.59 & 0.59 & 0.59 & 0.59 & 0.59 & 0.59 \\
\hline$R^{2}$ & 0.115 & 0.162 & 0.165 & 0.180 & 0.274 & 0.273 & 0.185 \\
\hline Observations & 620 & 618 & 618 & 618 & 285 & 273 & 618 \\
\hline
\end{tabular}

Notes: OLS regression. The dependent variable is the average support for redistribution. Other socio-demographics include age squared, a dummy variable indicating whether the respondent's native language is french, a dummy indicating whether the respondent is married, and a dummy indicating whether the respondent did not disclose his/her income. Education includes dummies indicating a respondent's highest educational achievement (compulsory school, vocational training, high school, university or other), and occupation includes dummies indicating whether the individual currently has a full-time job, a part-time job, is unemployed or is not in the labor force. Other preference measures include risk aversion, patience, negative and positive reciprocity. Levels of significance: ${ }^{*} p<0.1,{ }^{* *} p<$ $0.05,{ }^{* * *} p<0.01$ 
Table C.3: Social preferences and average political support for redistribution among individuals that successfully passed a least one attention check

\begin{tabular}{|c|c|c|c|c|c|c|c|}
\hline & \multicolumn{4}{|c|}{$\begin{array}{c}\text { Full } \\
\text { sample }\end{array}$} & \multirow{2}{*}{$\begin{array}{l}\begin{array}{c}\text { Below median } \\
\text { income }\end{array} \\
(5)\end{array}$} & \multirow{2}{*}{$\begin{array}{l}\begin{array}{c}\text { Above median } \\
\text { income }\end{array} \\
(6)\end{array}$} & \multirow{2}{*}{$\begin{array}{c}\begin{array}{c}\text { Full sample } \\
\text { (interactions) }\end{array} \\
(7)\end{array}$} \\
\hline & (1) & (2) & (3) & (4) & & & \\
\hline Inequality averse & $\begin{array}{l}0.183^{* * *} \\
(0.068)\end{array}$ & $\begin{array}{l}0.197^{* * *} \\
(0.068)\end{array}$ & $\begin{array}{l}0.199^{* * *} \\
(0.068)\end{array}$ & $\begin{array}{l}0.188^{* * *} \\
(0.069)\end{array}$ & $\begin{array}{r}-0.000 \\
(0.098)\end{array}$ & $\begin{array}{l}0.379^{* * *} \\
(0.120)\end{array}$ & $\begin{array}{l}0.216^{* * *} \\
(0.071)\end{array}$ \\
\hline Altruistic & $\begin{array}{l}0.188^{* *} \\
(0.074)\end{array}$ & $\begin{array}{c}0.185^{* *} \\
(0.073)\end{array}$ & $\begin{array}{c}0.187^{* * *} \\
(0.073)\end{array}$ & $\begin{array}{l}0.179^{* *} \\
(0.074)\end{array}$ & $\begin{array}{r}0.042 \\
(0.108)\end{array}$ & $\begin{array}{l}0.321^{* *} \\
(0.126)\end{array}$ & $\begin{array}{l}0.199^{* *} \\
(0.077)\end{array}$ \\
\hline Income & $\begin{array}{l}-0.064^{* * *} \\
(0.023)\end{array}$ & $\begin{array}{l}-0.061^{* * *} \\
(0.022)\end{array}$ & $\begin{array}{l}-0.058^{* * *} \\
(0.022)\end{array}$ & $\begin{array}{l}-0.059^{* * *} \\
(0.022)\end{array}$ & $\begin{array}{r}0.035 \\
(0.070)\end{array}$ & $\begin{array}{c}-0.099^{*} \\
(0.052)\end{array}$ & $\begin{array}{l}-0.136^{* *} \\
(0.053)\end{array}$ \\
\hline Income $x$ Inequality averse & & & & & & & $\begin{array}{c}0.101^{*} \\
(0.058)\end{array}$ \\
\hline Income $\mathrm{x}$ Altruistic & & & & & & & $\begin{array}{r}0.080 \\
(0.056)\end{array}$ \\
\hline Male & $\begin{array}{r}0.002 \\
(0.051)\end{array}$ & $\begin{array}{r}-0.007 \\
(0.052)\end{array}$ & $\begin{array}{r}-0.005 \\
(0.052)\end{array}$ & $\begin{array}{r}-0.015 \\
(0.051)\end{array}$ & $\begin{array}{r}0.021 \\
(0.069)\end{array}$ & $\begin{array}{r}-0.016 \\
(0.089)\end{array}$ & $\begin{array}{r}-0.014 \\
(0.051)\end{array}$ \\
\hline Age & $\begin{array}{r}0.018 \\
(0.011)\end{array}$ & $\begin{array}{r}0.008 \\
(0.011)\end{array}$ & $\begin{array}{r}0.005 \\
(0.011)\end{array}$ & $\begin{array}{r}0.006 \\
(0.011)\end{array}$ & $\begin{array}{r}-0.012 \\
(0.016)\end{array}$ & $\begin{array}{r}0.021 \\
(0.026)\end{array}$ & $\begin{array}{r}0.006 \\
(0.011)\end{array}$ \\
\hline Effort matters for success & & $\begin{array}{l}-0.116^{* * *} \\
(0.043)\end{array}$ & $\begin{array}{l}-0.112^{* * *} \\
(0.043)\end{array}$ & $\begin{array}{l}-0.123^{* * *} \\
(0.043)\end{array}$ & $\begin{array}{l}-0.166^{* * *} \\
(0.054)\end{array}$ & $\begin{array}{r}-0.123 \\
(0.076)\end{array}$ & $\begin{array}{l}-0.118^{* * *} \\
(0.043)\end{array}$ \\
\hline Luck and inheritance matter for success & & $\begin{array}{l}0.137^{* * *} \\
(0.031)\end{array}$ & $\begin{array}{l}0.138^{* * *} \\
(0.031)\end{array}$ & $\begin{array}{l}0.129^{* * *} \\
(0.031)\end{array}$ & $\begin{array}{l}0.178^{* * *} \\
(0.047)\end{array}$ & $\begin{array}{c}0.088^{*} \\
(0.052)\end{array}$ & $\begin{array}{l}0.126^{* * *} \\
(0.031)\end{array}$ \\
\hline Have been unemployed in past & & & $\begin{array}{r}0.064 \\
(0.050)\end{array}$ & $\begin{array}{r}0.072 \\
(0.050)\end{array}$ & $\begin{array}{r}0.078 \\
(0.070)\end{array}$ & $\begin{array}{r}0.019 \\
(0.083)\end{array}$ & $\begin{array}{r}0.072 \\
(0.050)\end{array}$ \\
\hline Beliefs about future upwards mobility & & & $\begin{array}{r}0.058 \\
(0.050)\end{array}$ & $\begin{array}{r}0.072 \\
(0.049)\end{array}$ & $\begin{array}{l}-0.017 \\
(0.070)\end{array}$ & $\begin{array}{r}0.088 \\
(0.082)\end{array}$ & $\begin{array}{r}0.068 \\
(0.049)\end{array}$ \\
\hline Perceived past upwards mobility & & & $\begin{array}{r}0.011 \\
(0.046)\end{array}$ & $\begin{array}{r}0.003 \\
(0.046)\end{array}$ & $\begin{array}{r}0.051 \\
(0.068)\end{array}$ & $\begin{array}{r}-0.026 \\
(0.076)\end{array}$ & $\begin{array}{r}0.006 \\
(0.046)\end{array}$ \\
\hline Trust in strangers & & & & $\begin{array}{l}0.067^{* * *} \\
(0.024)\end{array}$ & $\begin{array}{l}0.080^{* *} \\
(0.035)\end{array}$ & $\begin{array}{c}0.072^{*} \\
(0.039)\end{array}$ & $\begin{array}{l}0.066^{* * *} \\
(0.023)\end{array}$ \\
\hline Mistrust in politicians & & & & $\begin{array}{r}0.058 \\
(0.036)\end{array}$ & $\begin{array}{r}0.067 \\
(0.049)\end{array}$ & $\begin{array}{r}0.081 \\
(0.067)\end{array}$ & $\begin{array}{r}0.058 \\
(0.036)\end{array}$ \\
\hline Perceived inequality & & & & $\begin{array}{r}0.023 \\
(0.024)\end{array}$ & $\begin{array}{l}-0.014 \\
(0.032)\end{array}$ & $\begin{array}{r}0.054 \\
(0.045)\end{array}$ & $\begin{array}{r}0.022 \\
(0.024)\end{array}$ \\
\hline Constant & $\begin{array}{c}-0.523^{*} \\
(0.274)\end{array}$ & $\begin{array}{r}-0.383 \\
(0.350)\end{array}$ & $\begin{array}{r}-0.413 \\
(0.355)\end{array}$ & $\begin{array}{r}-0.484 \\
(0.356)\end{array}$ & $\begin{array}{r}0.411 \\
(0.515)\end{array}$ & $\begin{array}{l}-1.530^{* *} \\
(0.620)\end{array}$ & $\begin{array}{l}-0.507 \\
(0.350)\end{array}$ \\
\hline Other socio-demographics & Yes & Yes & Yes & Yes & Yes & Yes & Yes \\
\hline Education & Yes & Yes & Yes & Yes & Yes & Yes & Yes \\
\hline Occupation & Yes & Yes & Yes & Yes & Yes & Yes & Yes \\
\hline Other preference measures & No & Yes & Yes & Yes & Yes & Yes & Yes \\
\hline Canton FE & Yes & Yes & Yes & Yes & Yes & Yes & Yes \\
\hline Overall SD average support for redistribution & 0.58 & 0.58 & 0.58 & 0.58 & 0.58 & 0.58 & 0.58 \\
\hline$R^{2}$ & 0.092 & 0.139 & 0.144 & 0.159 & 0.262 & 0.233 & 0.164 \\
\hline Observations & 720 & 718 & 718 & 718 & 320 & 328 & 718 \\
\hline
\end{tabular}

Notes: OLS regression. The dependent variable is the average support for redistribution. Other socio-demographics include age squared, a dummy variable indicating whether the respondent's native language is french, a dummy indicating whether the respondent is married, and a dummy indicating whether the respondent did not disclose his/her income. Education includes dummies indicating a respondent's highest educational achievement (compulsory school, vocational training, high school, university or other), and occupation includes dummies indicating whether the individual currently has a full-time job, a part-time job, is unemployed or is not in the labor force. Other preference measures include risk aversion, patience, negative and positive reciprocity. Levels of significance: ${ }^{*} p<0.1,{ }^{* *} p<$ $0.05,{ }^{* * *} p<0.01$ 


\section{C.4 The role of other-regarding preferences under within-type heterogeneity}

Table C.4 below shows how other-regarding preferences are related to the average political support for redistribution when there are 4 preference types (as discussed in Appendix B.4), i.e., when the altruistic type, which comprises roughly $36 \%$ of our population is split up into a strongly altruistic type with a relatively large positive $\beta$-parameter $(21 \%)$ and a moderately altruistic type with a smaller $\beta$-parameter (15\%). The table shows that in all specifications (except column 5 that restricts attention to below-median income earners) the strong type is significantly more likely to support redistribution while the moderate type is not significantly different from the predominantly selfish type.

Table C.5 below examines the role of within-type preference variations at the individual level. For this purpose, we construct - for each preference type - a variable that measures the behavioral deviation of individuals from the type's typical behavior in the money allocation task. More specifically, we compute the deviation $\Delta_{i}$ of each individual's median choice in the center bundle, denoted by $\operatorname{med}(z)_{i}$, from the average over all med $(z)_{i}$ 's of the type (denoted by $Z$ ) to which the individual belongs. Recall that $\operatorname{med}(z)_{i}=0$ means that the individual's median choice minimizes the own payoff, while $\operatorname{med}(z)_{i}=1$ maximizes the own payoff and $\operatorname{med}(z)_{i}=0.5$ equalizes payoffs. The deviation measure for the altruistic type is thus defined as $\Delta_{i, A} \equiv-\left(\operatorname{med}(z)_{i, A}-Z_{A}\right)$, where the subscript $A$ denotes the type. We only compute this measure for the negatively sloped budget lines for the altruistic type because there is basically no individual variation for the positively sloped budget lines (as documented Figure 4d). On negatively slope budget lines, $\Delta_{i, A}$ becomes positive if the individual deviates in the altruistic direction from this type's typical behavior and negative if the individual deviates in the selfish direction. The distribution of individual $\operatorname{med}(z){ }_{i}{ }^{\prime} \mathrm{s}\left(\right.$ together with $\left.Z_{A}\right)$ is shown in Figure $4 \mathrm{c}$ and $4 \mathrm{~d}$.

We compute an analogous deviation measure for the predominantly selfish type $\left(\Delta_{i, S}\right)$ across all budget lines because selfish individuals' median choice $z_{i}$ equals 1 in most cases (see Figure $4 \mathrm{e}$ and $4 \mathrm{f})$. We compute analogous deviation measures $\left(\Delta_{i, I A}\right)$ for both the negatively and the positively sloped budget lines for the inequality averse individuals.

These individual deviation measures enable us to control for individual-level heterogeneity by interacting them with the social preference dummies. Thus, the 'pure' dummies still measure the main effect of type and the interactions tell us whether deviations from a type's typical behavior matter for the political support for redistribution. The regression results are displayed in Table C. 5 below. They show that within-type variation matters neither for the selfish type nor for the inequality averse type because the interaction terms are clearly insignificant.

The situation is, however, different with regard to the altruistic individuals. An increase in $\Delta_{i, A}$ by one standard deviation increases support for redistribution by 7 percent of a stan- 
Table C.4: Main regressions when allowing for 4 preferences types

\begin{tabular}{|c|c|c|c|c|c|c|c|}
\hline & \multicolumn{4}{|c|}{$\begin{array}{c}\text { Full } \\
\text { sample }\end{array}$} & \multirow{2}{*}{$\begin{array}{l}\begin{array}{c}\text { Below median } \\
\text { income }\end{array} \\
(5)\end{array}$} & \multirow{2}{*}{$\begin{array}{l}\begin{array}{c}\text { Above median } \\
\text { income }\end{array} \\
(6)\end{array}$} & \multirow{2}{*}{$\begin{array}{l}\begin{array}{c}\text { Full sample } \\
\text { (interactions) }\end{array} \\
(7)\end{array}$} \\
\hline & (1) & (2) & (3) & (4) & & & \\
\hline Inequality averse & $\begin{array}{l}0.177^{* * *} \\
(0.066)\end{array}$ & $\begin{array}{l}0.188^{* * *} \\
(0.065)\end{array}$ & $\begin{array}{l}0.190^{* * *} \\
(0.065)\end{array}$ & $\begin{array}{l}0.177^{* * *} \\
(0.065)\end{array}$ & $\begin{array}{r}0.024 \\
(0.100)\end{array}$ & $\begin{array}{l}0.325^{* * *} \\
(0.105)\end{array}$ & $\begin{array}{l}0.192^{* * *} \\
(0.067)\end{array}$ \\
\hline Strongly altruistic & $\begin{array}{l}0.179^{* *} \\
(0.074)\end{array}$ & $\begin{array}{c}0.169^{* *} \\
(0.074)\end{array}$ & $\begin{array}{c}0.173^{* *} \\
(0.074)\end{array}$ & $\begin{array}{c}0.164^{* *} \\
(0.073)\end{array}$ & $\begin{array}{r}0.067 \\
(0.106)\end{array}$ & $\begin{array}{l}0.246^{* *} \\
(0.118)\end{array}$ & $\begin{array}{c}0.171^{* *} \\
(0.076)\end{array}$ \\
\hline Moderately altruistic & $\begin{array}{r}0.107 \\
(0.086)\end{array}$ & $\begin{array}{r}0.111 \\
(0.086)\end{array}$ & $\begin{array}{r}0.117 \\
(0.086)\end{array}$ & $\begin{array}{r}0.101 \\
(0.086)\end{array}$ & $\begin{array}{r}-0.009 \\
(0.126)\end{array}$ & $\begin{array}{r}0.195 \\
(0.141)\end{array}$ & $\begin{array}{r}0.104 \\
(0.086)\end{array}$ \\
\hline Income & $\begin{array}{l}-0.072^{* * *} \\
(0.021)\end{array}$ & $\begin{array}{l}-0.068^{* * *} \\
(0.021)\end{array}$ & $\begin{array}{l}-0.066^{* * *} \\
(0.021)\end{array}$ & $\begin{array}{l}-0.066^{* * *} \\
(0.020)\end{array}$ & $\begin{array}{r}-0.023 \\
(0.065)\end{array}$ & $\begin{array}{l}-0.128^{* * *} \\
(0.048)\end{array}$ & $\begin{array}{l}-0.094^{* * *} \\
(0.034)\end{array}$ \\
\hline Income $x$ Inequality averse & & & & & & & $\begin{array}{r}0.050 \\
(0.040)\end{array}$ \\
\hline Income $x$ Altruistic & & & & & & & $\begin{array}{r}0.026 \\
(0.044)\end{array}$ \\
\hline Male & $\begin{array}{r}0.008 \\
(0.048)\end{array}$ & $\begin{array}{r}-0.007 \\
(0.048)\end{array}$ & $\begin{array}{r}-0.005 \\
(0.049)\end{array}$ & $\begin{array}{r}-0.013 \\
(0.048)\end{array}$ & $\begin{array}{l}-0.016 \\
(0.065)\end{array}$ & $\begin{array}{r}-0.002 \\
(0.082)\end{array}$ & $\begin{array}{r}-0.014 \\
(0.048)\end{array}$ \\
\hline Age & $\begin{array}{c}0.020^{*} \\
(0.010)\end{array}$ & $\begin{array}{r}0.010 \\
(0.010)\end{array}$ & $\begin{array}{r}0.008 \\
(0.010)\end{array}$ & $\begin{array}{r}0.009 \\
(0.010)\end{array}$ & $\begin{array}{r}-0.005 \\
(0.015)\end{array}$ & $\begin{array}{r}0.030 \\
(0.022)\end{array}$ & $\begin{array}{r}0.009 \\
(0.010)\end{array}$ \\
\hline Effort matters for success & & $\begin{array}{l}-0.111^{* * *} \\
(0.040)\end{array}$ & $\begin{array}{l}-0.107^{* * *} \\
(0.040)\end{array}$ & $\begin{array}{l}-0.120^{* * *} \\
(0.039)\end{array}$ & $\begin{array}{l}-0.146^{* * *} \\
(0.049)\end{array}$ & $\begin{array}{r}-0.099 \\
(0.071)\end{array}$ & $\begin{array}{l}-0.117^{* * *} \\
(0.039)\end{array}$ \\
\hline Luck and inheritance matter for success & & $\begin{array}{l}0.120^{* * *} \\
(0.028)\end{array}$ & $\begin{array}{l}0.122^{* * *} \\
(0.029)\end{array}$ & $\begin{array}{l}0.112^{* * *} \\
(0.029)\end{array}$ & $\begin{array}{l}0.141^{* * *} \\
(0.044)\end{array}$ & $\begin{array}{c}0.080^{*} \\
(0.047)\end{array}$ & $\begin{array}{l}0.112^{* * *} \\
(0.029)\end{array}$ \\
\hline Have been unemployed in past & & & $\begin{array}{r}0.062 \\
(0.046)\end{array}$ & $\begin{array}{r}0.071 \\
(0.046)\end{array}$ & $\begin{array}{r}0.055 \\
(0.065)\end{array}$ & $\begin{array}{r}0.015 \\
(0.079)\end{array}$ & $\begin{array}{r}0.072 \\
(0.046)\end{array}$ \\
\hline Beliefs about future upwards mobility & & & $\begin{array}{r}0.066 \\
(0.047)\end{array}$ & $\begin{array}{c}0.080^{*} \\
(0.047)\end{array}$ & $\begin{array}{l}-0.022 \\
(0.066)\end{array}$ & $\begin{array}{r}0.094 \\
(0.077)\end{array}$ & $\begin{array}{r}0.077 \\
(0.047)\end{array}$ \\
\hline Perceived past upwards mobility & & & $\begin{array}{r}0.034 \\
(0.042)\end{array}$ & $\begin{array}{r}0.023 \\
(0.042)\end{array}$ & $\begin{array}{r}0.071 \\
(0.062)\end{array}$ & $\begin{array}{r}0.004 \\
(0.071)\end{array}$ & $\begin{array}{r}0.024 \\
(0.042)\end{array}$ \\
\hline Trust in strangers & & & & $\begin{array}{l}0.071^{* * *} \\
(0.022)\end{array}$ & $\begin{array}{l}0.068^{* *} \\
(0.030)\end{array}$ & $\begin{array}{c}0.071^{*} \\
(0.037)\end{array}$ & $\begin{array}{l}0.070^{* * *} \\
(0.022)\end{array}$ \\
\hline Mistrust in politicians & & & & $\begin{array}{c}0.065^{* *} \\
(0.032)\end{array}$ & $\begin{array}{c}0.086^{* *} \\
(0.043)\end{array}$ & $\begin{array}{r}0.075 \\
(0.060)\end{array}$ & $\begin{array}{c}0.066^{* *} \\
(0.032)\end{array}$ \\
\hline Perceived inequality & & & & $\begin{array}{r}0.015 \\
(0.022)\end{array}$ & $\begin{array}{r}0.002 \\
(0.028)\end{array}$ & $\begin{array}{r}0.033 \\
(0.040)\end{array}$ & $\begin{array}{r}0.014 \\
(0.022)\end{array}$ \\
\hline Constant & $\begin{array}{l}-0.532^{* *} \\
(0.251)\end{array}$ & $\begin{array}{l}-0.353 \\
(0.325)\end{array}$ & $\begin{array}{l}-0.419 \\
(0.328)\end{array}$ & $\begin{array}{l}-0.484 \\
(0.328)\end{array}$ & $\begin{array}{r}0.130 \\
(0.472)\end{array}$ & $\begin{array}{l}-1.429^{* *} \\
(0.563)\end{array}$ & $\begin{array}{l}-0.499 \\
(0.327)\end{array}$ \\
\hline Other socio-demographics & Yes & Yes & Yes & Yes & Yes & Yes & Yes \\
\hline Education & Yes & Yes & Yes & Yes & Yes & Yes & Yes \\
\hline Occupation & Yes & Yes & Yes & Yes & Yes & Yes & Yes \\
\hline Other preference measures & No & Yes & Yes & Yes & Yes & Yes & Yes \\
\hline Canton FE & Yes & Yes & Yes & Yes & Yes & Yes & Yes \\
\hline Overall SD average support for redistribution & 0.58 & 0.58 & 0.58 & 0.58 & 0.58 & 0.58 & 0.58 \\
\hline$R^{2}$ & 0.082 & 0.123 & 0.128 & 0.146 & 0.221 & 0.216 & 0.148 \\
\hline Observations & 815 & 813 & 813 & 813 & 364 & 367 & 813 \\
\hline
\end{tabular}

Notes: OLS regression. The dependent variable is the average support for redistribution. Other socio-demographics include age squared, a dummy variable indicating whether the respondent's native language is french, a dummy indicating whether the respondent is married, and a dummy indicating whether the respondent did not disclose his/her income. Education includes dummies indicating a respondent's highest educational achievement (compulsory school, vocational training, high school, university or other), and occupation includes dummies indicating whether the individual currently has a full-time job, a part-time job, is unemployed or is not in the labor force. Other preference measures include risk aversion, patience, negative and positive reciprocity. Levels of significance: ${ }^{*} p<0.1,{ }^{* *} p<$ $0.05,{ }^{* * *} p<0.01$ 
dard deviation of overall support for redistribution - an effect that is significant at $p=0.07 .^{34}$ However, the weak significance in of $\Delta_{i, A}$ in column 4 appears to be driven by the fact that for above-median income earner $\Delta_{i, A}$ has little predictive power (see column 6) while for individuals below the median income (see column 5) the coefficient of $\Delta_{i, A}$ is large and significant. For them a one standard deviation increase in $\Delta_{i, A}$ increases redistributive support by 14 percent of a standard deviation.

It is also noteworthy that the strong relationship between a type's typical other-regarding preference (captured by the 'pure' preference dummies) and their support for redistribution remains unchanged and robust. The estimates in column 4 imply that, on average, the typical inequality averse individual is 33 percent and the typical altruistic type is 27 percent of a standard deviation more likely to support redistribution than the typical selfish type. Moreover, for above-median income earners the typical inequality averse (altruistic) type is $60 \%$ ( $47 \%$ ) of a standard deviation more in favor of redistribution than the selfish type.

\footnotetext{
${ }^{34}$ The standard deviation of $\Delta_{i, A}$ equals 0.11 . The coefficient of $\Delta_{i, A}$ in Table C.5 measures the effect of moving the variable from 0 to 1 . Thus, an increase of $\Delta_{i, A}$ by 0.11 increases support for political redistribution by $(0.11)(0.382)=0.042$ which is roughly 7 percent of a standard deviation of political support $(0.042 / 0.58=0.07)$.
} 


\section{Table C.5: Main regression when controlling for individual-level within-type heterogeneity}

\begin{tabular}{|c|c|c|c|c|c|c|c|}
\hline & \multicolumn{4}{|c|}{$\begin{array}{c}\text { Full } \\
\text { sample }\end{array}$} & \multirow{2}{*}{$\begin{array}{l}\begin{array}{c}\text { Below median } \\
\text { income }\end{array} \\
(5)\end{array}$} & \multirow{2}{*}{$\begin{array}{l}\begin{array}{c}\text { Above median } \\
\text { income }\end{array} \\
(6)\end{array}$} & \multirow{2}{*}{$\begin{array}{c}\begin{array}{c}\text { Full sample } \\
\text { (interactions) }\end{array} \\
(7)\end{array}$} \\
\hline & (1) & (2) & (3) & (4) & & & \\
\hline Inequality averse (IA) & $\begin{array}{l}0.188^{* * *} \\
(0.063)\end{array}$ & $\begin{array}{l}0.201^{* * *} \\
(0.063)\end{array}$ & $\begin{array}{l}0.203^{* * *} \\
(0.063)\end{array}$ & $\begin{array}{l}0.189^{* * *} \\
(0.063)\end{array}$ & $\begin{array}{r}0.031 \\
(0.092)\end{array}$ & $\begin{array}{l}0.346^{* * *} \\
(0.106)\end{array}$ & $\begin{array}{l}0.214^{* * *} \\
(0.067)\end{array}$ \\
\hline Altruistic (A) & $\begin{array}{l}0.164^{* *} \\
(0.068)\end{array}$ & $\begin{array}{l}0.160^{* *} \\
(0.069)\end{array}$ & $\begin{array}{l}0.165^{* *} \\
(0.069)\end{array}$ & $\begin{array}{l}0.155^{* *} \\
(0.069)\end{array}$ & $\begin{array}{r}0.049 \\
(0.097)\end{array}$ & $\begin{array}{l}0.272^{* *} \\
(0.115)\end{array}$ & $\begin{array}{l}0.174^{* *} \\
(0.073)\end{array}$ \\
\hline Income & $\begin{array}{l}-0.069^{* * *} \\
(0.021)\end{array}$ & $\begin{array}{l}-0.066^{* * *} \\
(0.021)\end{array}$ & $\begin{array}{l}-0.063^{* * *} \\
(0.021)\end{array}$ & $\begin{array}{l}-0.064^{* * *} \\
(0.020)\end{array}$ & $\begin{array}{r}-0.031 \\
(0.064)\end{array}$ & $\begin{array}{l}-0.117^{* *} \\
(0.048)\end{array}$ & $\begin{array}{l}-0.134^{* * *} \\
(0.048)\end{array}$ \\
\hline Income $x$ Inequality averse & & & & & & & $\begin{array}{c}0.092^{*} \\
(0.052)\end{array}$ \\
\hline Income $x$ Altruistic & & & & & & & $\begin{array}{r}0.073 \\
(0.052)\end{array}$ \\
\hline$\Delta_{i, I A}$ (negative budget lines) & $\begin{array}{r}-0.017 \\
(0.333)\end{array}$ & $\begin{array}{r}0.042 \\
(0.319)\end{array}$ & $\begin{array}{r}0.040 \\
(0.325)\end{array}$ & $\begin{array}{r}0.096 \\
(0.325)\end{array}$ & $\begin{array}{r}-0.386 \\
(0.435)\end{array}$ & $\begin{array}{r}0.749 \\
(0.580)\end{array}$ & $\begin{array}{r}0.075 \\
(0.323)\end{array}$ \\
\hline$\Delta_{i, I A}$ (positive budget lines) & $\begin{array}{r}-0.057 \\
(0.133)\end{array}$ & $\begin{array}{r}-0.063 \\
(0.133)\end{array}$ & $\begin{array}{r}-0.076 \\
(0.134)\end{array}$ & $\begin{array}{r}-0.085 \\
(0.134)\end{array}$ & $\begin{array}{r}0.046 \\
(0.190)\end{array}$ & $\begin{array}{r}-0.055 \\
(0.227)\end{array}$ & $\begin{array}{r}-0.093 \\
(0.133)\end{array}$ \\
\hline$\Delta_{i, A}$ & $\begin{array}{l}0.483^{* *} \\
(0.216)\end{array}$ & $\begin{array}{c}0.401^{*} \\
(0.209)\end{array}$ & $\begin{array}{c}0.386^{*} \\
(0.207)\end{array}$ & $\begin{array}{c}0.382^{*} \\
(0.210)\end{array}$ & $\begin{array}{l}0.744^{* * *} \\
(0.255)\end{array}$ & $\begin{array}{r}0.195 \\
(0.306)\end{array}$ & $\begin{array}{c}0.389^{*} \\
(0.211)\end{array}$ \\
\hline$\Delta_{i, S}$ & $\begin{array}{r}0.642 \\
(0.490)\end{array}$ & $\begin{array}{r}0.689 \\
(0.466)\end{array}$ & $\begin{array}{r}0.691 \\
(0.472)\end{array}$ & $\begin{array}{r}0.572 \\
(0.443)\end{array}$ & $\begin{array}{r}0.301 \\
(0.574)\end{array}$ & $\begin{array}{r}1.662 \\
(1.022)\end{array}$ & $\begin{array}{r}0.552 \\
(0.403)\end{array}$ \\
\hline Male & $\begin{array}{r}0.008 \\
(0.047)\end{array}$ & $\begin{array}{r}-0.007 \\
(0.048)\end{array}$ & $\begin{array}{r}-0.005 \\
(0.048)\end{array}$ & $\begin{array}{r}-0.013 \\
(0.048)\end{array}$ & $\begin{array}{r}-0.013 \\
(0.064)\end{array}$ & $\begin{array}{r}-0.009 \\
(0.082)\end{array}$ & $\begin{array}{r}-0.013 \\
(0.048)\end{array}$ \\
\hline Age & $\begin{array}{c}0.018^{*} \\
(0.010)\end{array}$ & $\begin{array}{r}0.009 \\
(0.010)\end{array}$ & $\begin{array}{r}0.006 \\
(0.010)\end{array}$ & $\begin{array}{r}0.007 \\
(0.010)\end{array}$ & $\begin{array}{r}-0.006 \\
(0.015)\end{array}$ & $\begin{array}{r}0.021 \\
(0.024)\end{array}$ & $\begin{array}{r}0.007 \\
(0.010)\end{array}$ \\
\hline Effort matters for success & & $\begin{array}{l}-0.111^{* * *} \\
(0.040)\end{array}$ & $\begin{array}{l}-0.107^{* * *} \\
(0.039)\end{array}$ & $\begin{array}{l}-0.119^{* * * *} \\
(0.039)\end{array}$ & $\begin{array}{l}-0.131^{* * *} \\
(0.050)\end{array}$ & $\begin{array}{r}-0.107 \\
(0.072)\end{array}$ & $\begin{array}{l}-0.114^{* * *} \\
(0.039)\end{array}$ \\
\hline Luck and inheritance matter for success & & $\begin{array}{l}0.119^{* * *} \\
(0.028)\end{array}$ & $\begin{array}{l}0.121^{* * *} \\
(0.029)\end{array}$ & $\begin{array}{l}0.111^{* * *} \\
(0.029)\end{array}$ & $\begin{array}{l}0.144^{* * *} \\
(0.044)\end{array}$ & $\begin{array}{c}0.078^{*} \\
(0.048)\end{array}$ & $\begin{array}{l}0.108^{* * *} \\
(0.029)\end{array}$ \\
\hline Have been unemployed in past & & & $\begin{array}{r}0.062 \\
(0.047)\end{array}$ & $\begin{array}{r}0.071 \\
(0.047)\end{array}$ & $\begin{array}{r}0.063 \\
(0.067)\end{array}$ & $\begin{array}{r}0.023 \\
(0.078)\end{array}$ & $\begin{array}{r}0.072 \\
(0.047)\end{array}$ \\
\hline Beliefs about future upwards mobility & & & $\begin{array}{r}0.066 \\
(0.048)\end{array}$ & $\begin{array}{c}0.080^{*} \\
(0.047)\end{array}$ & $\begin{array}{r}-0.034 \\
(0.067)\end{array}$ & $\begin{array}{r}0.096 \\
(0.077)\end{array}$ & $\begin{array}{r}0.076 \\
(0.047)\end{array}$ \\
\hline Perceived past upwards mobility & & & $\begin{array}{r}0.027 \\
(0.042)\end{array}$ & $\begin{array}{r}0.017 \\
(0.042)\end{array}$ & $\begin{array}{r}0.061 \\
(0.061)\end{array}$ & $\begin{array}{r}-0.013 \\
(0.072)\end{array}$ & $\begin{array}{r}0.019 \\
(0.042)\end{array}$ \\
\hline Trust in strangers & & & & $\begin{array}{l}0.069^{* * *} \\
(0.022)\end{array}$ & $\begin{array}{c}0.065^{* *} \\
(0.031)\end{array}$ & $\begin{array}{c}0.070^{*} \\
(0.036)\end{array}$ & $\begin{array}{l}0.067^{* * *} \\
(0.021)\end{array}$ \\
\hline Mistrust in politicians & & & & $\begin{array}{l}0.065^{* *} \\
(0.032)\end{array}$ & $\begin{array}{l}0.086^{* *} \\
(0.042)\end{array}$ & $\begin{array}{r}0.071 \\
(0.059)\end{array}$ & $\begin{array}{l}0.066^{* *} \\
(0.032)\end{array}$ \\
\hline Perceived inequality & & & & $\begin{array}{r}0.010 \\
(0.022)\end{array}$ & $\begin{array}{r}-0.003 \\
(0.028)\end{array}$ & $\begin{array}{r}0.019 \\
(0.040)\end{array}$ & $\begin{array}{r}0.009 \\
(0.022)\end{array}$ \\
\hline Constant & $\begin{array}{l}-0.511^{* *} \\
(0.250)\end{array}$ & $\begin{array}{r}-0.335 \\
(0.321)\end{array}$ & $\begin{array}{r}-0.394 \\
(0.325)\end{array}$ & $\begin{array}{r}-0.468 \\
(0.326)\end{array}$ & $\begin{array}{r}0.079 \\
(0.467)\end{array}$ & $\begin{array}{l}-1.335^{* *} \\
(0.575)\end{array}$ & $\begin{array}{r}-0.490 \\
(0.325)\end{array}$ \\
\hline Other socio-demographics & Yes & Yes & Yes & Yes & Yes & Yes & Yes \\
\hline Education & Yes & Yes & Yes & Yes & Yes & Yes & Yes \\
\hline Occupation & Yes & Yes & Yes & Yes & Yes & Yes & Yes \\
\hline Other preference measures & No & Yes & Yes & Yes & Yes & Yes & Yes \\
\hline Canton FE & Yes & Yes & Yes & Yes & Yes & Yes & Yes \\
\hline Overall SD average support for redistribution & 0.58 & 0.58 & 0.58 & 0.58 & 0.58 & 0.58 & 0.58 \\
\hline$R^{2}$ & 0.093 & 0.131 & 0.137 & 0.153 & 0.239 & 0.230 & 0.157 \\
\hline Observations & 815 & 813 & 813 & 813 & 364 & 367 & 813 \\
\hline
\end{tabular}

Notes: OLS regression. The dependent variable is the average support for redistribution. $\Delta_{i, t}$ measures the behavioral deviation of individuals $i$ from its assigned type $t^{\prime}$ s typical behavior (see formal definition in Appendix C.4). Other socio-demographics include age squared, a dummy variable indicating whether the respondent's native language is french, a dummy indicating whether the respondent is married, and a dummy indicating whether the respondent did not disclose his/her income. Education includes dummies indicating a respondent's highest educational achievement (compulsory school, vocational training, high school, university or other), and occupation includes dummies indicating whether the individual currently has a full-time job, a part-time job, is unemployed or is not in the labor force. Other preference measures include risk aversion, patience, negative and positive reciprocity. Levels of significance: ${ }^{*} p<0.1,{ }^{* *} p<0.05,{ }^{* * *} p<0.01$ 


\section{C.5 The role of other-regarding preferences when controlling for political atti- tudes}

In this appendix we regress average political support on the same list of variables as in Table 3 of the main text but we control, in addition, for individuals' political attitude which is measured on a scale from 1 to 10 where 1 means far left and 10 means far right. The standard deviation of this measure is 2.02. Table C.6 shows the regressions based on 3 different preference types. Table C.7 has still 3 fundamentally different preference types but the altruistic type is divided up in a moderate and a strong version of that type. The coefficient of -0.12 for political attitude in clumns 1-4 of Tables C.6 and C.7 means that individuals who are one standard deviation further to the left are roughly 41 percent of a standard deviation more likely to support redistribution - regardless of whether we allow for 3 or four social preference types.

Inequality aversion remains a robust predictor of redistributive support when we control for political attitudes - regardless of whether we allow for three or four preference types. The picture is, however, somewhat more differentiated for the altruistic types. While the dummy for altruistic preferences becomes much smaller and insignificant when we control for political attitude in the specification with three preference types (Table C.6), strongly altruistic individuals (i.e., allowing for four types) are still significantly more likely ( $p=0.07)$ to vote for redistribution (Table C.7) relative to selfish individuals even when we control for political attitude. Thus, taken together, other-regarding preferences in the form of inequality aversion remains a robust and significant predictor of support for redistribution while the influence of altruistic concerns becomes somewhat weaker when we control for political attitudes. 
Table C.6: Main regressions with 3 types when controlling for political attitude

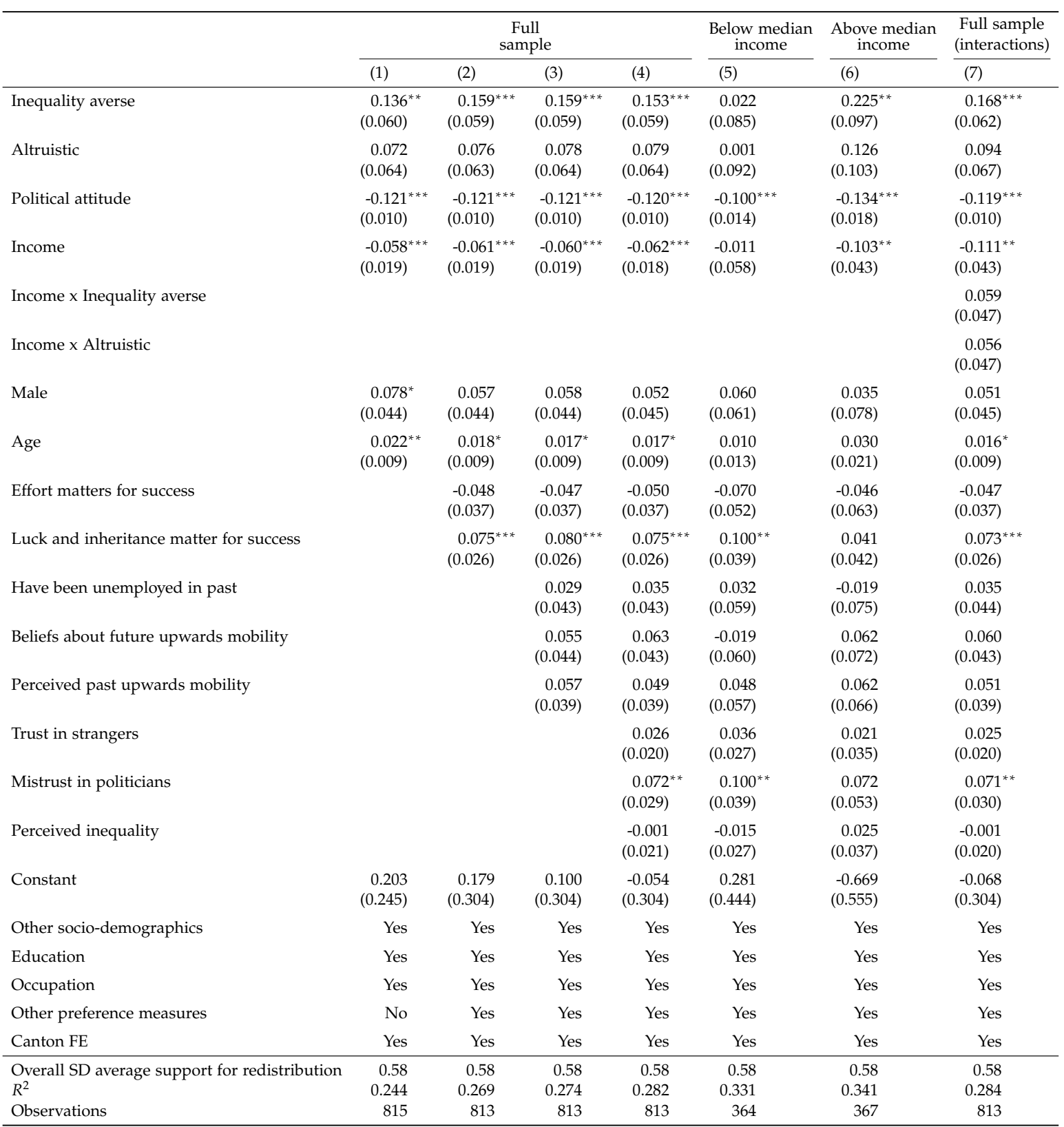

Notes: OLS regression. The dependent variable is the average support for redistribution. Other socio-demographics include age squared, a dummy variable indicating whether the respondent's native language is french, a dummy indicating whether the respondent is married, and a dummy indicating whether the respondent did not disclose his/her income. Education includes dummies indicating a respondent's highest educational achievement (compulsory school, vocational training, high school, university or other), and occupation includes dummies indicating whether the individual currently has a full-time job, a part-time job, is unemployed or is not in the labor force. Other preference measures include risk aversion, patience, negative and positive reciprocity. Levels of significance: ${ }^{*} p<0.1,{ }^{* *} p<$ $0.05,{ }^{* * *} p<0.01$ 
Table C.7: Main regressions with 4 types when controlling for political attitude

\begin{tabular}{|c|c|c|c|c|c|c|c|}
\hline & \multicolumn{4}{|c|}{$\begin{array}{c}\text { Full } \\
\text { sample }\end{array}$} & \multirow{2}{*}{$\frac{\begin{array}{c}\text { Below median } \\
\text { income }\end{array}}{(5)}$} & \multirow{2}{*}{$\begin{array}{l}\begin{array}{c}\text { Above median } \\
\text { income }\end{array} \\
(6)\end{array}$} & \multirow{2}{*}{$\begin{array}{c}\begin{array}{c}\text { Full sample } \\
\text { (interactions) }\end{array} \\
(7)\end{array}$} \\
\hline & (1) & (2) & $(3)$ & (4) & & & \\
\hline Strongly altruistic & $\begin{array}{c}0.117^{*} \\
(0.068)\end{array}$ & $\begin{array}{c}0.117^{*} \\
(0.067)\end{array}$ & $\begin{array}{c}0.120^{*} \\
(0.067)\end{array}$ & $\begin{array}{c}0.119^{*} \\
(0.067)\end{array}$ & $\begin{array}{r}0.027 \\
(0.099)\end{array}$ & $\begin{array}{r}0.144 \\
(0.107)\end{array}$ & $\begin{array}{c}0.124^{*} \\
(0.070)\end{array}$ \\
\hline Political attitude & $\begin{array}{l}-0.122^{* * *} \\
(0.010)\end{array}$ & $\begin{array}{l}-0.122^{* * *} \\
(0.010)\end{array}$ & $\begin{array}{l}-0.122^{* * *} \\
(0.010)\end{array}$ & $\begin{array}{l}-0.121^{* * *} \\
(0.010)\end{array}$ & $\begin{array}{l}-0.100^{* * *} \\
(0.014)\end{array}$ & $\begin{array}{l}-0.136^{* * *} \\
(0.018)\end{array}$ & $\begin{array}{l}-0.120^{* * *} \\
(0.010)\end{array}$ \\
\hline Income & $\begin{array}{l}-0.060^{* * *} \\
(0.019)\end{array}$ & $\begin{array}{l}-0.063^{* * *} \\
(0.019)\end{array}$ & $\begin{array}{l}-0.062^{* * *} \\
(0.019)\end{array}$ & $\begin{array}{l}-0.063^{* * *} \\
(0.018)\end{array}$ & $\begin{array}{r}-0.012 \\
(0.058)\end{array}$ & $\begin{array}{l}-0.101^{* *} \\
(0.043)\end{array}$ & $\begin{array}{l}-0.079^{* *} \\
(0.031)\end{array}$ \\
\hline Income $x$ Inequality averse & & & & & & & $\begin{array}{r}0.025 \\
(0.037)\end{array}$ \\
\hline Male & $\begin{array}{c}0.080^{*} \\
(0.044)\end{array}$ & $\begin{array}{r}0.058 \\
(0.044)\end{array}$ & $\begin{array}{r}0.059 \\
(0.045)\end{array}$ & $\begin{array}{r}0.054 \\
(0.045)\end{array}$ & $\begin{array}{r}0.062 \\
(0.061)\end{array}$ & $\begin{array}{r}0.039 \\
(0.078)\end{array}$ & $\begin{array}{r}0.053 \\
(0.045)\end{array}$ \\
\hline Age & $\begin{array}{l}0.022^{* *} \\
(0.009)\end{array}$ & $\begin{array}{c}0.018^{*} \\
(0.009)\end{array}$ & $\begin{array}{c}0.017^{*} \\
(0.009)\end{array}$ & $\begin{array}{c}0.017^{*} \\
(0.009)\end{array}$ & $\begin{array}{r}0.010 \\
(0.014)\end{array}$ & $\begin{array}{r}0.030 \\
(0.020)\end{array}$ & $\begin{array}{c}0.017^{*} \\
(0.009)\end{array}$ \\
\hline Effort matters for success & & $\begin{array}{r}-0.045 \\
(0.038)\end{array}$ & $\begin{array}{r}-0.044 \\
(0.037)\end{array}$ & $\begin{array}{r}-0.047 \\
(0.037)\end{array}$ & $\begin{array}{r}-0.070 \\
(0.052)\end{array}$ & $\begin{array}{r}-0.040 \\
(0.063)\end{array}$ & $\begin{array}{r}-0.046 \\
(0.037)\end{array}$ \\
\hline Luck and inheritance matter for success & & $\begin{array}{l}0.075^{* * *} \\
(0.025)\end{array}$ & $\begin{array}{l}0.080^{* * *} \\
(0.026)\end{array}$ & $\begin{array}{l}0.074^{* * *} \\
(0.026)\end{array}$ & $\begin{array}{l}0.099^{* *} \\
(0.039)\end{array}$ & $\begin{array}{r}0.045 \\
(0.042)\end{array}$ & $\begin{array}{l}0.075^{* * *} \\
(0.026)\end{array}$ \\
\hline Have been unemployed in past & & & $\begin{array}{r}0.028 \\
(0.044)\end{array}$ & $\begin{array}{r}0.034 \\
(0.044)\end{array}$ & $\begin{array}{r}0.032 \\
(0.059)\end{array}$ & $\begin{array}{r}-0.022 \\
(0.075)\end{array}$ & $\begin{array}{r}0.035 \\
(0.044)\end{array}$ \\
\hline Perceived inequality & & & & $\begin{array}{r}-0.000 \\
(0.020)\end{array}$ & $\begin{array}{r}-0.013 \\
(0.027)\end{array}$ & $\begin{array}{r}0.028 \\
(0.037)\end{array}$ & $\begin{array}{r}-0.000 \\
(0.020)\end{array}$ \\
\hline Constant & $\begin{array}{r}0.216 \\
(0.244)\end{array}$ & $\begin{array}{r}0.179 \\
(0.304)\end{array}$ & $\begin{array}{r}0.098 \\
(0.303)\end{array}$ & $\begin{array}{r}-0.053 \\
(0.304)\end{array}$ & $\begin{array}{r}0.304 \\
(0.449)\end{array}$ & $\begin{array}{r}-0.695 \\
(0.547)\end{array}$ & $\begin{array}{r}-0.060 \\
(0.304)\end{array}$ \\
\hline Other socio-demographics & Yes & Yes & Yes & Yes & Yes & Yes & Yes \\
\hline Education & Yes & Yes & Yes & Yes & Yes & Yes & Yes \\
\hline Occupation & Yes & Yes & Yes & Yes & Yes & Yes & Yes \\
\hline Other preference measures & No & Yes & Yes & Yes & Yes & Yes & Yes \\
\hline Canton FE & Yes & Yes & Yes & Yes & Yes & Yes & Yes \\
\hline Overall SD average support for redistribution & 0.58 & 0.58 & 0.58 & 0.58 & 0.58 & 0.58 & 0.58 \\
\hline$R^{2}$ & 0.246 & 0.271 & 0.276 & 0.283 & 0.333 & 0.344 & 0.284 \\
\hline Observations & 815 & 813 & 813 & 813 & 364 & 367 & 813 \\
\hline
\end{tabular}

Notes: OLS regression. The dependent variable is the average support for redistribution. Other socio-demographics include age squared, a dummy variable indicating whether the respondent's native language is french, a dummy indicating whether the respondent is married, and a dummy indicating whether the respondent did not disclose his/her income. Education includes dummies indicating a respondent's highest educational achievement (compulsory school, vocational training, high school, university or other), and occupation includes dummies indicating whether the individual currently has a full-time job, a part-time job, is unemployed or is not in the labor force. Other preference measures include risk aversion, patience, negative and positive reciprocity. Levels of significance: ${ }^{*} p<0.1,{ }^{* *} p<$ $0.05, * * * p<0.01$ 


\section{C.6 The role of other-regarding preferences in the placebo referendum}

Table C.8: Social preferences and political support for the placebo initiative

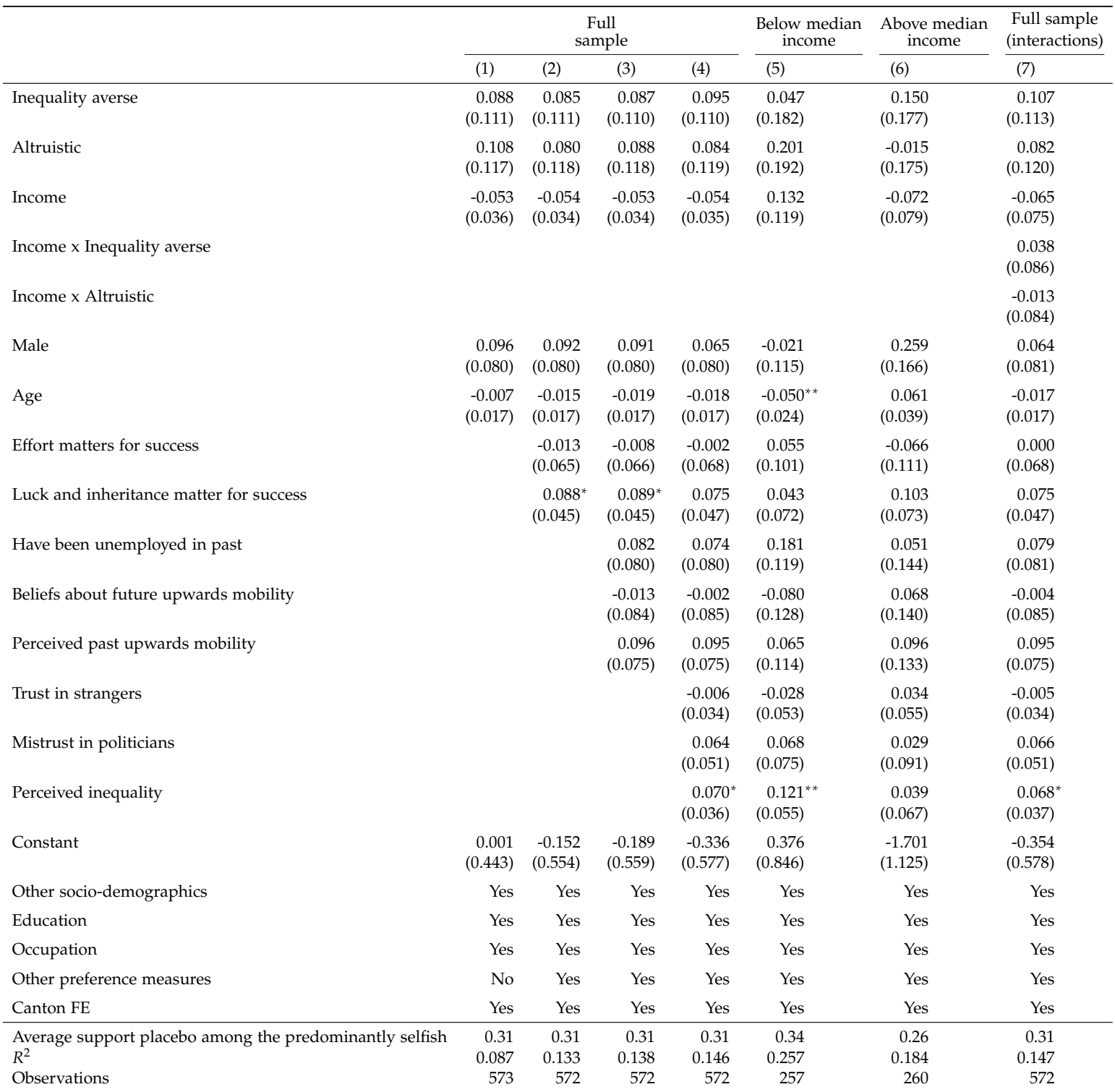

Notes: OLS regression. The dependent variable is the support for placebo initiative. Other socio-demographics include age squared, a dummy variable indicating whether the respondent's native language is french, a dummy indicating whether the respondent is married, and a dummy indicating whether the respondent did not disclose his/her income. Education includes dummies indicating a respondent's highest educational achievement (compulsory school, vocational training, high school, university or other), and occupation includes dummies indicating whether the individual currently has a full-time job, a part-time job, is unemployed or is not in the labor force. Other preference measures include risk aversion, patience, negative and positive reciprocity. Levels of significance: ${ }^{*} p<0.1{ }^{* *} p<$ $0.05, * * * p 0.01$ 


\section{C.7 The perceived redistributive consequences of different initiatives}

In the follow-up survey we measured how subjects perceived the consequences of the four referenda. Figure C.1 below shows that subjects believed that the 1:20 initiative and the fair taxes initiative will predominantly reduce the income of individuals with high incomes while the unconditional income initiative and the minimum wage initiative will predominantly raise the income of those who earn little. This is in line with the intended goals of these initiatives and with how they were discussed in the media and the general public at the time.

Figure C.1: Perceived redistributive consequences of different initiatives

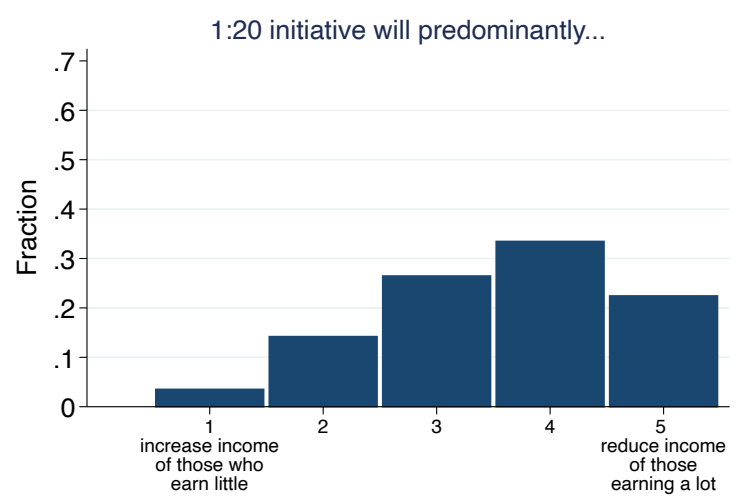

(a) 1 to 20

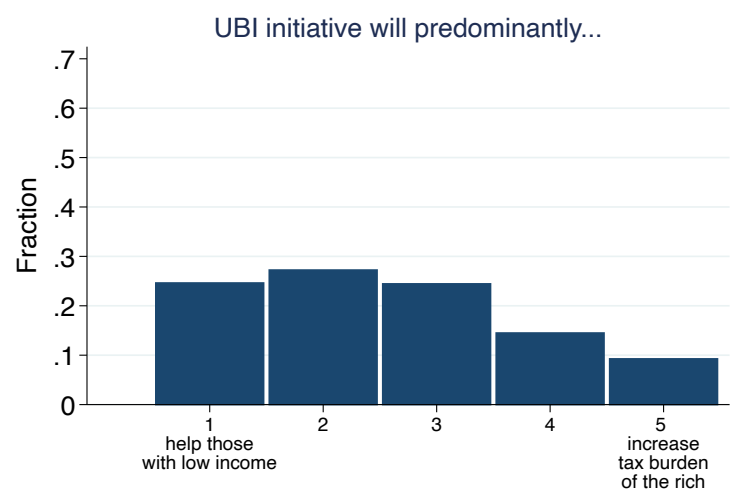

(c) Unconditional basic income

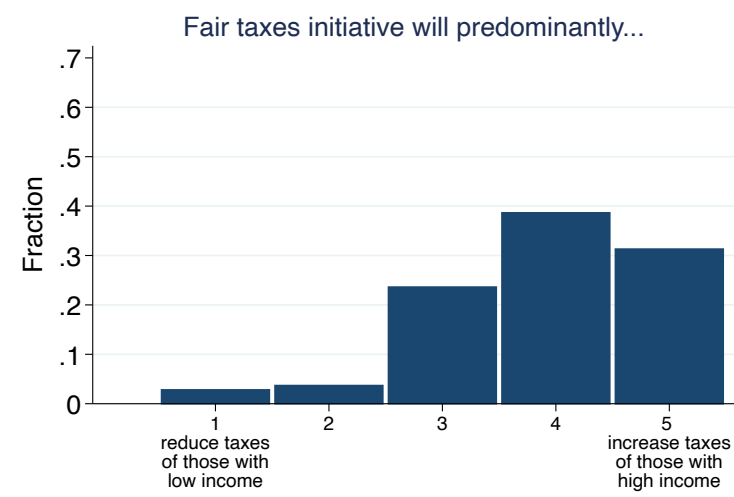

(b) Fair taxes

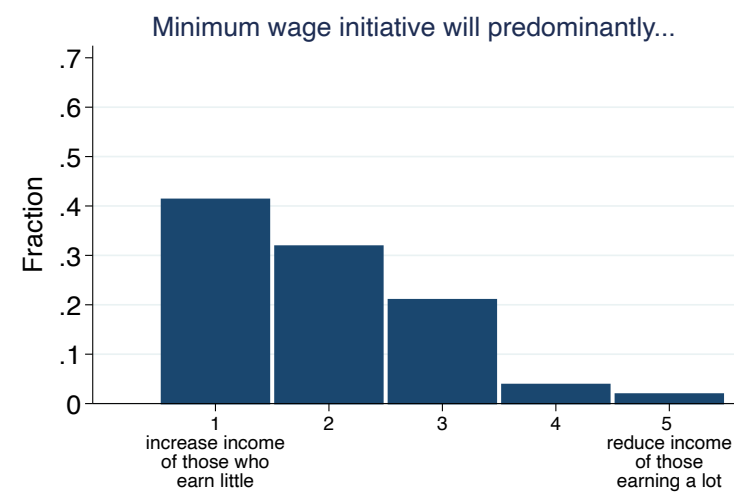

(d) Minimum wage 